INSTITUTO DE PESQUISAS ENERGÉTICAS E NUCLEARES AUTARQUiA ASSOCIADA À UNIVERSIDADE DE SÃo PAULO

\author{
ESPECTROMETRIA E RECONSTRUÇÃO DE IMAGENS \\ TOMOGRÁFICAS DE EMISSÃO ESTIMULADA POR NÊUTRONS \\ VIA ALGORITMO EM E MÉTODO DE MONTE CARLO
}

Rodrigo Sartorelo Salemi Viana

Tese apresentada como parte dos requisitos para a obtenção do Grau de Doutor em Ciências na Área de Tecnologia Nuclear - Reatores. 
INSTITUTO DE PESQUISAS ENERGÉTICAS E NUCLEARES AUTARQUIA ASSOCIADA À UNIVERSIDADE DE SÃo PAULO

\author{
ESPECTROMETRIA E RECONSTRUÇÃO DE IMAGENS \\ TOMOGRÁFICAS DE EMISSÃO ESTIMULADA POR NÊUTRONS \\ VIA ALGORITMO EM E MÉTODO DE MONTE CARLO
}

Rodrigo Sartorelo Salemi Viana

Orientador: Prof. Dr. Adimir dos Santos Coorientador: Prof. Dr. Hélio Yoriyaz

\footnotetext{
Tese apresentada como parte dos requisitos para a obtenção do Grau de Doutor em Ciências na Área de Tecnologia Nuclear - Reatores.

Versão Corrigida

Versão Original se encontra no IPEN
}

São Paulo

2014 


\section{Dedicatória}

Dedico esta tese aos meus pais Sebastião e Valéria que muito contribuíram para a minha formação. 


\section{Agradecimentos}

Agradeço primeiramente à agência de fomento FAPESP pelo apoio financeiro concedido para o desenvolvimento deste projeto.

Agradeço ao apoio e incentivo da minha família não só nesta etapa que se encerra, mas desde o começo da minha vida acadêmica.

Agradeço aos amigos e colegas de trabalho no Departamento de Engenharia Nuclear do Instituto de Pesquisas Energéticas e Nucleares. Dividimos momentos de descontração e colaboração mútua que foram e são importantes para minha formação.

Agradeço ao Dr. Hamilto Akihissa Yamamoto da Faculdade de Medicina da UNESP, câmpus de Botucatu, pela colaboração essencial ao desenvolvimento da pesquisa apresentada.

Agradeço aos meus orientadores Adimir dos Santos e Hélio Yoriyaz. Vocês colaboraram ativamente com o meu progresso e merecem minha sincera gratidão e compromisso profissional.

Agradeço especialmente à Gisela de Assis Martini que, por meio de seu companheirismo e carinho, esteve presente ao meu lado em momentos cruciais.

And finally, I am thankful for the advising from Anuj Kapadia who was my mentor during my one year internship abroad. Several things were accomplished trough a lot of work, research and simulations. I am also thankful for the friendship and collaboration from Greeshma Agasthya, Manu Lakshmanan, and Gretchen Raterman.

Agradeço à Deus... 
"Tenha em mente que tudo que você aprende na escola é trabalho de muitas gerações.

Receba essa herança, honre-a, acrescente a ela e, um dia, fielmente, deposite-a nas mãos de seus filhos."

Albert Einstein 


\section{Sumário}

Página

LISTA DE FIGURAS viii

LISTA DE TABELAS xiii

RESUMO Xv

SUMMARY Xvi

1 INTRODUÇÃO 1

2 REVISÃO DE LITERATURA 3

2.1 Conceitos teóricos da NSECT . . . . . . . . . . . . . . . . . . 3

2.1.1 Tomografia de emissão estimulada associada com a informação do tempo de voo do nêutron . . . . . . . . . . . . . . . . 4

2.1.2 Seleção de elementos de interesse como biomarcadores . . . . . . . . . 5

2.1.3 Aplicações e desenvolvimento da NSECT . . . . . . . . . . . . . . . . 6

2.2 Objetivo e originalidade . . . . . . . . . . . . . 6

2.2.1 Microcalcificações associadas ao câncer de mama . . . . . . . . . . 7

2.2.2 Carcinoma de célula renal . . . . . . . . . . . . . . . . . . . . . . . 8

2.2.3 Otimização da reconstrução tomográfica na NSECT . . . . . . . . . . . 8

3 MATERIAL E MÉTODOS 10

3.1 O método Monte Carlo e o código MCNP5 . . . . . . . . . . . . . . . . 10

3.1 .1 Interações do nêutron com a matéria . . . . . . . . . . . . . . . . 12 
3.1.2 Grandezas quantificadas pelo código MCNP5 . . . . . . . . . . . 13

3.1.2.1 Estimativa do fluxo de partículas . . . . . . . . . . . 13

3.1.2.2 Estimativa da energia depositada . . . . . . . . . . . . . 14

3.1.2.3 Estimativa da altura de pulso . . . . . . . . . . . . . 16

3.2 Sistema tomográfico para a NSECT . . . . . . . . . . . . . 16

3.3 Reconstrução tomográfica de emissão . . . . . . . . . . . . . . . . . . . . 19

3.3 .1 Operador projeção . . . . . . . . . . . . . . . 22

3.4 Cálculo da dose efetiva . . . . . . . . . . . . . . . . . . . . . . 26

3.5 Novas aplicações e aperfeiçoamento da técnica NSECT . . . . . . . . . . 28

3.5.1 Espectroscopia . . . . . . . . . . . . . . . . . 28

3.5.1.1 Detecção de microcalcificações mamárias . . . . . . . . . . . . . . 28

3.5.1.2 Avaliação experimental da composição de tecidos renais . . . . . . . 31

3.5.1.3 Simulação da avaliação experimental para o cálculo de dose na espec-

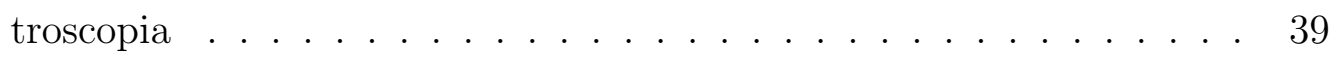

3.5.2 Imageamento . . . . . . . . . . . . . . . . . . . . . . . 41

3.5.2.1 Imageamento 3D de tumor renal . . . . . . . . . . . . . . . . . . 41

3.5.2.1.1 Tomografia de emissão estimulada associada com a informação do tempo de voo do nêutron . . . . . . . . . . . . . . 50

3.5.2.2 Otimização da amostragem do sinograma para NSECT . . . . . . . . 53

4 RESUltados E DisCUSSÃO

4.1 Espectroscopia . . . . . . . . . . . . . . . . 61

4.1.1 Espectroscopia de emissão estimulada empregada na avaliação de microcalcificações associadas ao câncer de mama . . . . . . . . . . . . 61

4.1.1.1 Dosimetria . . . . . . . . . . . . . . . 65

4.1.2 Avaliação experimental da composição de CCR utilizando a espectroscopia de emissão estimulada . . . . . . . . . . . . . . . . . 66

4.1.3 Simulação da distribuição de dose absorvida em órgão adjacente ao órgão irradiado na espectroscopia de emissão estimulada . . . . . . . . 72 
4.2 Imageamento . . . . . . . . . . . . . . . . . . 74

4.2.1 Detecção de CCR através de imagens tomográficas 3D adquiridas pela técnica NSECT . . . . . . . . . . . . . . . . . . . . 74

4.2.1.1 Tomografia de emissão associada ao tempo de voo do nêutron $\quad$. . . 80

4.2.1.2 Dosimetria . . . . . . . . . . . . . . . . . . . . . 86

4.2.1.3 Reconstrução de órgãos irradiados: imagens funcionais e anatômicas 87

4.2 .2 Otimização da reconstrução tomográfica na NSECT . . . . . . . . . . . 89

4.2.2.1 Otimização da amostragem do sinograma em função do limiar de dose efetiva . . . . . . . . . . . . . . . . . . . . . 99

4.2.2.2 Implementação do método: avaliação dosimétrica e as imagens de referência . . . . . . . . . . . . . . . . . . . . . . 102

5 CONCLUSÕES 104

5.1 Perspectivas de novas pesquisas . . . . . . . . . . . . . . 106

$\begin{array}{ll}\text { ANEXO A } & 108\end{array}$

$\begin{array}{ll}\text { REFERÊNCIAS BIBLIOGRÁFICAS } & 109\end{array}$

$\begin{array}{ll}\text { APÊNDICES } & 118\end{array}$

6 PUBLICAÇÕES 128

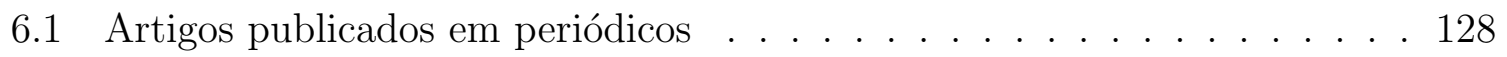

6.2 Resumos publicados em anais de congressos . . . . . . . . . . 128 


\section{Lista de Figuras}

Página

1 Transporte acoplado de nêutrons, fótons e elétrons. Todos os eventos gerados a partir da interação entre a partícula incidente e o meio de transporte são simulados. Figura adaptada de MCNP5 (2003). . . . . . . 11

2 Configuração de simulação para a avaliação da localização dos detectores no sistema tomográfico. Os perfis axial e radial com relação a posição de incidência do feixe de nêutrons são apresentados para o cálculo do fluxo de nêutrons e fótons. . . . . . . . . . . . . . . . . . . . . . 17

3 Perfis axiais do fluxo de fótons (a) e nêutrons (b) calculados paralelamente a superfície circular do objeto simulador. Fluxo radial de fótons e nêutrons (c) calculados ao redor do objeto simulador com relação a posição de incidência do feixe de nêutrons. . . . . . . . . . . . . . . . . . 18

4 Orientações de projeções e eventos gama detectados: contribuição da emissão na i-ésima localização para as contagens detectadas na projeção $j$ (a) e contribuição para as contagens detectadas nas $d$ projeções dada a localização de emissão $i(\mathrm{~b}) . \ldots$. . . . . . . . . . . . . . . . 24

5 Metodologia para construção do operador projeção $p_{i j}$ : matriz binária $S$ representando a emissão de fótons na localização $i$ (a), Transformada de Radon avaliada em $S$ (b), $p_{i j}$ calculado a partir da vetorização da Transformada de Radon avaliada em $S$ alterando a localização do valor unitário (c) e distribuição de probabilidade para as emissões ocorridas ao longo de uma dada projeção do feixe de nêutrons (d) . . . . . . . . . . . . 26 
6 Relação entre o fator de peso da radiação $\mathrm{w}_{R}$ e a energia $(\mathrm{MeV})$ do nêutron. Figura adaptada de (ICRP103, 2007). . . . . . . . . . . . . . 27

7 Sistema para espectroscopia simulado com o código MCNP5: mama (1), HPGe (2), feixe de nêutrons (3) e localização das microcalcificações (4). . 31

8 Energia do nêutron produzido (a) e seção de choque diferencial angular (b) para íons deutério incidentes de 2,5 MeV. Dependência entre a energia do projétil incidente na célula de gás e a energia do nêutron produzido

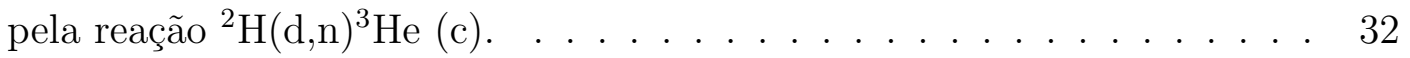

$9 \quad$ Estrutura cúbica de polietileno de alta densidade. O feixe é colimado por um recorte feito no interior da estrutura que se estende desde a célula de gás até a posição de irradiação das amostras. . . . . . . . . . . . . .

10 Amostras (a) utilizadas no experimento: CCR (PA2 T) e tecido renal saudável (PA2 H). Posição de irradiação das amostras (b) com relação ao detector e colimador. Célula de gás deutério (c) onde ocorre a reação ${ }^{2} \mathrm{H}(\mathrm{d}, \mathrm{n})^{3} \mathrm{He} \ldots \ldots \ldots \ldots \ldots \ldots \ldots \ldots$

11 Técnica de supressão de ruído utilizando o tempo de voo do nêutron (Floyd et al., 2007). Eventos gama detectados fora da região de aceitação definida por $\Delta t$ são considerados como ruído. . . . . . . . . . . . . . . 36

12 Dosímetros PRESAGE ${ }^{\mathrm{TM}}$ utilizados no experimento (a). Posicionamento dos dosímetros no interior do objeto simulador de resina (b). A seta indica a posição de incidência do feixe de nêutrons. Arranjo experimental de irradiação com o feixe de nêutrons (c) (Kapadia et al., 2012). . . . . . .

13 Modelo 3D do objeto simulador e sistema tomográfico (a). A superfície do tronco foi removida para evidenciar a presença dos órgãos modelados. A linha pontilhada entre os detectores corresponde ao caminho de translação do feixe de nêutrons (FN). Modelo 2D do sistema tomográfico quando o mesmo é rotacionado $40^{\circ}$ com relação ao eixo x (b) . . . . . . . . . . . .

14 Lesão de CCR contida no rim. A área sombreada compreende as projeções do feixe de nêutrons empregadas na simulação. . . . . . . . . . . . . . . . 53 
15 Geometria do tronco humano (a) utilizadas para criar as imagens de referência respectivamente para C (b) e Fe (c). A variação dos valores de pixel refletem a distribuição da concentração dos elementos apresentada na Tabela 8. . . . . . . . . . . . . . . . . 56

16 Imagem de referência (a) utilizada para reconstrução tomográfica com super amostragem (b) e subamostragem (c). O valor obtido pela IMN quando os pares de imagem a/b é 1,42 enquanto que a/c resulta em 1,35.

17 Contagens normalizadas em função do diâmetro de microcalcificações para a composição de hidroxiapatita (a) e oxalato de cálcio (b). As energias dos fótons selecionados são emitidas pelo isótopo ${ }^{40} \mathrm{Ca}$ (Viana \& Yoriyaz, 2011) . . . . . . . . . . . . . . . .

18 Espectros de emissão de fótons da mama saudável e da mama com agrupamento de microcalcificações. A região do espectro entre $3600 \mathrm{keV}$ e $4000 \mathrm{keV}$ é ampliada para a visualização dos picos de ${ }^{40} \mathrm{Ca}$ (Viana \& Yoriyaz, 2011). Alguns picos são identificados no espectro a partir da energia de emissão: produção de pares, captura radioativa no hidrogênio e espalhamento inelástico nos detectores HPGe. . . . . . . . . . . . . . . 64

19 Supressão de ruído no espectro de emissão: espectro corrigido (a) a partir da subtração dos espectros de fundo e da amostra (b) e ajuste gaussiano no espectro corrigido (c) para supressão de ruído devido ao efeito Compton nos detectores. Espectro de emissão processado com a visualização de picos relacionados com a composição da amostra (d). . . . . . . . . . 67

20 Reconstrução dos picos no espectro de emissão através do MMG. . . . . 68

21 Picos identificados no espectro de emissão das amostras PA2 T e PA2 H. Os picos identificados para os elementos Ca e P estão em concordância com a composição das amostras irradiadas de acordo com a Tabela 4. . . 70

22 Imagens tomográficas reconstruídas para os isótopos ${ }^{12} \mathrm{C},{ }^{32} \mathrm{~S}$ e ${ }^{14} \mathrm{~N}$ (ac) e suas respectivas inversões de valores de pixel (d-f) empregadas na segmentação do volume renal (Viana et al., 2013). . . . . . . . . . . . . . 75 
23 Segmentação do volume renal: (a) imagem normalizada obtida a partir da combinação das imagens de ${ }^{12} \mathrm{C},{ }^{14} \mathrm{~N}$ e ${ }^{32} \mathrm{~S}$, (b) binarização da imagem obtida e (c) renderização das imagens processadas reconstruindo o volume renal. Os três pontos em vermelho representam as localizações onde as ROIs foram avaliadas no teste estatístico: rim direito (RD), rim esquerdo (RE) e tecido mole (BG) (Viana et al., 2013). . . . . . . . . . . . . . . 76

24 Composição 2D (esquerda), valor médio dos pixels (meio) e imagens renderizadas (direita) a partir da combinação das imagens dos isótopos ${ }^{32} \mathrm{~S}$, ${ }^{31} \mathrm{P},{ }^{39} \mathrm{~K}$ e ${ }^{23} \mathrm{Na}$ (Viana et al., 2013). . . . . . . . . . . . . . . . . 78

25 Conversão entre o tempo de detecção de fótons e a localização de emissão em profundidade. As contagens e suas incertezas são apresentadas em escala logarítmica. . . . . . . . . . . . . . . . . .

26 Imagens renderizadas dos elementos ${ }^{23} \mathrm{Na}$ (a) e ${ }^{31} \mathrm{P}$ (b) para diferentes planos de visão. As imagens tomográficas foram adquiridas com uma resolução temporal de 0,1 ns. Os planos de visão interceptam o centro da lesão de CCR . . . . . . . . . . . . . . . . . . . . . .

27 Imagens renderizadas dos elementos ${ }^{23} \mathrm{Na}$ (a) e ${ }^{31} \mathrm{P}$ (b) para diferentes planos de visão. As imagens tomográficas foram adquiridas com uma resolução temporal de 0,3 ns. Os planos de visão interceptam o centro da lesão de CCR.

28 Geometria dos órgãos modelados (a). Reconstrução anatômica a partir de imagens da NSECT (b): rim esquerdo (RE), rim direito (RD), coluna (COL), baço (BA), vesícula biliar (VE) e fígado $(\mathrm{F})$.

29 Valores da IMN calculados entre as imagens reconstruídas para carbono de acordo com os sinogramas amostrados com TR (a) e MCNP5 (b). . . 90

30 Imagem tomográfica reconstruída para carbono de acordo com os sinogramas adquiridos com a TR (a) e simulações com o código MCNP5 (b)

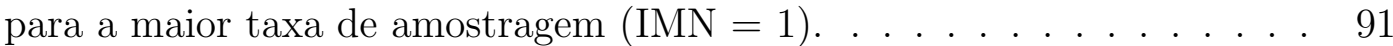


31 Valores da IMN calculados entre as imagens reconstruídas para sódio de acordo com os sinogramas amostrados com TR (a) e MCNP5 (b). . . . . 92

32 Imagem tomográfica reconstruída para sódio de acordo com os sinogramas adquiridos com a TR (a) e simulações com o código MCNP5 (b) para a maior taxa de amostragem $(\mathrm{IMN}=1) \ldots \ldots . \ldots . \ldots . \ldots 93$

33 Valores da IMN calculados entre as imagens reconstruídas para magnésio de acordo com os sinogramas amostrados com TR (a) e MCNP5 (b). . . 94

34 Imagem tomográfica reconstruída para magnésio de acordo com os sinogramas adquiridos com a TR (a) e simulações com o código MCNP5 (b)

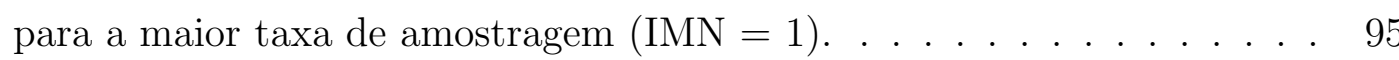

35 Valores da IMN calculados entre as imagens reconstruídas para ferro de acordo com os sinogramas amostrados com TR (a) e MCNP5 (b). . . . . 97

36 Imagem tomográfica reconstruídas para ferro de acordo com os sinogramas amostrados com TR (a) e MCNP5 (b). As setas indicam as lesões modeladas de hemocromatose inseridas no fígado. . . . . . . . . . . . . . 98

37 Dose efetiva calculada para os protocolos de irradiação adotados (a). Imagens reconstruídas a partir dos sinogramas amostrados com a TR (b) e com o código MCNP5 (c) em função do limiar de dose para 5 mSv. . . . 101

38 Entropia $H$ em função da variabilidade da informação. . . . . . . . . . . . 124

39 Imagem do histograma conjunto $q_{a, b}$ (a) calculado a partir das imagens $A$ (b) e $B(\mathrm{c})$. O histograma conjunto é obtido a partir da frequência de ocorrência dos pares de valores de pixel entre as imagens, tal que $a \in A$ e $b \in B$ (Pluim et al., 2003) . . . . . . . . . . . . . 126 


\section{Lista de Tabelas}

Página

1 Fatores de peso $\mathrm{w}_{T}$ de tecidos recomendados pela ICRP103 (2007). . . . 28

2 Composição isotópica do HPGe com densidade $5,32 \mathrm{~g} / \mathrm{cm}^{3}$. . . . . . . . . 29

3 Composição do tecido mamário com densidade $0,93 \mathrm{~g} / \mathrm{cm}^{3}$. . . . . . . . . 30

4 Composição das amostras de tecido renal. A incerteza máxima associada às medidas é $5 \%$. . . . . . . . . . . . . . . . . . . . . 38

5 Composição dos dosímetros modelados com densidade 1,07 g/ $\mathrm{cm}^{3}$ (Guo et al., 2006). . . . . . . . . . . . . . . . . . . . 4 41

6 Composição (fração em massa \%) dos tecidos renais modelados. As densidades do tecido renal saudável e do CCR foram adotadas como a densidade do rim de um indivíduo adulto $\left(1,05 \mathrm{~g} / \mathrm{cm}^{3}\right)$ (ICRU, 1992). . . . .

7 Energias de estado excitado dos isótopos utilizados na identificação dos tecidos renais e reconstrução da anatomia dos tecidos irradiados. . . . . . 47

8 Composição (fração em massa \%) dos elementos avaliados utilizados para criar as imagens de referência. As localizações dos tecidos estão devidamente identificadas na Figura 15. . . . . . . . . . . . . . . . . . 55

9 Configuração de translação dos sinogramas adquiridos pela TR utilizando as imagens de referência. O símbolo '-' corresponde à configuração onde não há sobreposição entre projeções.

10 Energias de estado excitado dos isótopos selecionados para a validação do método proposto. . . . . . . . . . . . . . . . 60 
11 Elementos identificados nas amostras de tecido renal (PA2 H e PA2 T) irradiadas e comparação das alturas de pulso dos picos reconstruídos entre os espectros. O valor médio $\bar{x}$ das contagens e o desvio padrão da média $s$ calculado como a raiz quadrada das contagens são apresentados. . . . . 71

12 Análise quantitativa para diferença de médias entre os valores de pixel

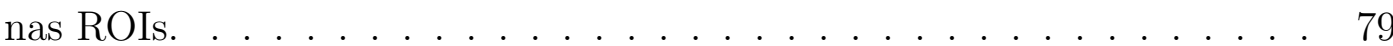




\title{
ESPECTROMETRIA E RECONSTRUÇÃO DE IMAGENS TOMOGRÁFICAS DE EMISSÃO ESTIMULADA POR NÊUTRONS VIA ALGORITMO EM E MÉTODO DE MONTE CARLO
}

\author{
Rodrigo Sartorelo Salemi Viana
}

\section{RESUMO}

A NSECT figura como uma nova técnica espectrográfica capaz de avaliar in vivo a concentração de elementos utilizando a reação de espalhamento inelástico (n,n’). Desde sua introdução, várias melhorias vem sendo propostas com o objetivo de investigar aplicações para o diagnóstico clínico e redução da dose absorvida associada à aquisição tomográfica. Neste contexto, são apresentadas duas novas aplicações de diagnóstico utilizando as abordagens espectroscópica e tomográfica da NSECT. Uma nova metodologia também foi proposta para otimizar a amostragem do sinograma que está diretamente relacionado com a qualidade de reconstrução através do protocolo de irradiação. Os estudos realizados foram desenvolvidos com base em simulações com o código MCNP5. O diagnóstico de Carcinoma de Célula Renal (CCR) e a detecção de microcalcificações mamárias foram avaliadas nos estudos conduzidos utilizando um objeto simulador humano. Os resultados obtidos demonstram a habilidade da técnica NSECT em detectar a alteração da composição dos tecidos modelados em função do desenvolvimento das patologias avaliadas. O método proposto para a otimização dos sinogramas foi capaz de simular analiticamente a composição do meio irradiado permitindo que a qualidade de reconstrução e a dose efetiva fossem avaliados em função da taxa de amostragem. Entretanto, futuras pesquisas devem ser conduzidas para quantificar o limiar de detecção de acordo com os elementos selecionados. 


\title{
SPECTROMETRY AND EMISSION TOMOGRAPHIC IMAGE RECONSTRUCTION STIMULATED BY NEUTRONS VIA EM ALGORITHM AND MONTE CARLO METHOD
}

\author{
Rodrigo Sartorelo Salemi Viana
}

\begin{abstract}
The NSECT figures as a new spectrographic technique able to evaluate in vivo the concentration of elements using the inelastic scattering reaction $\left(\mathrm{n}, \mathrm{n}^{\prime}\right)$. Since its introduction, several improvements have been proposed with the aim of investigating applications for clinical diagnosis and reduction of absorbed dose associated with $\mathrm{CT}$ acquisition. In this context, two new diagnostic applications are presented using spectroscopic and tomographic approaches from NSECT. A new methodology has also been proposed to optimize the sinogram sampling that is directly related to the quality of the reconstruction by the irradiation protocol. The studies were developed based on simulations with MCNP5 code. Diagnosis of Renal Cell Carcinoma (RCC) and the detection of breast microcalcifications were evaluated in studies conducted using a human phantom. The obtained results demonstrate the ability of the NSECT technique to detect changes in the composition of the modeled tissues as a function of the development of evaluated pathologies. The proposed method for optimizing sinograms was able to analytically simulate the composition of the irradiated medium allowing the assessment of quality of reconstruction and effective dose in terms of the sampling rate. However, future research must be conducted to quantify the sensitivity of detection according to the selected elements.
\end{abstract}




\section{INTRODUÇÃO}

A técnica tomográfica NSECT (Neutron Stimulated Emission Computed Tomography) foi apresentada à comunidade acadêmica como uma nova modalidade de aquisição tomográfica que explora a própria composição do meio irradiado para compor as imagens reconstruídas. Diferentemente de outras técnicas tomográficas comercialmente conhecidas, a NSECT vem sendo aplicada com sucesso como uma abordagem in vivo não-invasiva em estudos sobre a identificação e diferenciação entre tecidos sem a administração de contraste ou traçador radioativo (Floyd et al., 2006).

Devido às suas características, o desenvolvimento e aplicações desta técnica vem se tornando foco de estudos apresentados no meio acadêmico e na mídia virtual. Em 2013, o portal de notícias medicalphysicsweb publicou uma matéria online intitulada Neutrons identify kidney cancer apresentando uma das pesquisas originalmente desenvolvidas e descrita nesta tese (Dineley, 2013).

A presente tese apresenta os resultados obtidos a partir de estudos realizados com o objetivo de otimizar e investigar novas aplicações clínicas da técnica NSECT. Foi avaliado o emprego da NSECT na detecção in vivo de microcalcificações associadas ao desenvolvimento do câncer de mama e na detecção de tumores renais, sendo estas abordagens inéditas. Além de investigações computacionais, a detecção de tumores renais também motivou a realização de um experimento utilizando amostras de tecido humano. No âmbito de otimização da técnica NSECT, desenvolveu-se uma nova metodologia aplicada na aquisição dos sinogramas utilizados para a reconstrução tomográfica. A descrição das etapas realizadas nesta pesquisa será organizada nos capítulos como segue. 
Capítulo 2 Revisão de literatura

São abordados os principais conceitos teóricos empregados no desenvolvimento da pesquisa conduzida na presente tese. A descrição dos objetivos e da originalidade da pesquisa realizada são apresentadas neste capítulo.

Capítulo 3 Material e métodos

Este capítulo é dedicado à descrição detalhada das metodologias empregadas e originalmente desenvolvidas no decorrer desta pesquisa. Dado o objetivo desta tese, diferentes aspectos da técnica NSECT foram avaliados através de simulações e experimentos, tais como: espectrometria, otimização e reconstrução de imagens tomográficas e seu emprego no diagnóstico clínico. Uma atenção especial deve ser atribuída à Seção 3.5 onde são descritas as metodologias originais propostas.

Capítulo 4 Resultados e discussão

Este capítulo apresenta os resultados obtidos através das metodologias empregadas. Além da aquisição de espectros de emissão e reconstruções tomográficas, a avaliação dosimétrica das abordagens desenvolvidas é apresentada neste capítulo.

Capítulo 5 Conclusões

Este capítulo apresenta as considerações finais e discute novas perspectivas para a continuidade desta pesquisa.

Anexo A Apresenta uma cópia do Termo de Consentimento Livre e Esclarecido permitindo com que amostras de tecido renal humano fossem utilizadas para pesquisa.

Apêndices Descreve sucintamente a teoria de tópicos adicionais relacionados com a metodologia empregada nesta tese. 


\section{REVISÃO DE LITERATURA}

\subsection{Conceitos teóricos da NSECT}

A NSECT é uma técnica espectrográfica capaz de obter informações quantitativas acerca da distribuição dos elementos químicos presentes no meio irradiado através da reação nuclear de espalhamento inelástico (n,n').

Um feixe de nêutrons rápidos se propaga livremente ao longo do caminho de projeção até colidir com um núcleo de um isótopo estável. Se o nêutron espalha inelasticamente através da reação (n,n’), o núcleo estimulado pela energia cinética altera seu estado energético (excitação). Os núcleos excitados permanecem neste estado durante o estímulo criado pela reação (n,n’), decaindo rapidamente para seu estado energético estável através da emissão de fótons gama com energia igual à diferença entre os estados energéticos. Como estes níveis de energia são intrínsecos ao núcleo emissor, a energia do fóton gama se torna uma assinatura energética do núcleo emissor presente no meio irradiado, o que permite sua identificação e quantificação (Floyd et al., 2006).

O desenvolvimento de patologias se caracteriza pela mudanças na concentração dos elementos que compõem o meio irradiado. Assumindo que a alteração da composição é precedente à alteração morfológica nos tecidos afetados, a quantificação desses elementos pode fornecer um diagnóstico precoce in vivo sobre o desenvolvimento da patologia. Como exemplos, pode-se citar casos como a diferença de composição entre os tecidos tumorais benigno e maligno (Bender et al., 2007), hemocromatose hepática (Agasthya et al., 2012), o transporte de nutrientes para o funcionamento cerebral (Stedman \& Spyrou, 1995), composição de doenças renais 
(Chmielnicka \& Nasiadek, 2003) e doenças cardíacas (Altekin et al., 2005). Dessa forma, a NSECT oferece uma alternativa não-invasiva para a detecção e diagnóstico de patologias como as descritas.

Deve-se ressaltar que, diferentemente de outras técnicas tomográficas cuja radiação é emitida ou transmitida pelo meio irradiado, a NSECT é caracterizada como uma modalidade exclusivamente de emissãa, sendo que o estímulo requerido para a produção de fótons pelo meio irradiado é devido à interação do feixe de nêutrons, primariamente por meio da reação (n,n'). Ainda que outras reações secundárias envolvendo fótons, nêutrons e elétrons ocorram, oriundos da reação (n,n') no meio irradiado; o sinal detectado na NSECT é atribuído ao espectro de emissão originado pela reação $\left(n, n^{\prime}\right)$, onde a presença e concentração dos isótopos emissores são avaliadas através da identificação das energias dos estados excitados.

A técnica NSECT pode ser empregada em duas abordagens distintas e complementares. A primeira consiste na espectroscopia do meio irradiado através da identificação e quantificação dos elementos de interesse de acordo com a amplitude dos canais energéticos do espectro de emissão. A segunda abordagem é nada mais do que uma extensão da primeira, onde múltiplas projeções do feixe de nêutrons são amostradas ao redor do meio irradiado para adquirir o conjunto de dados de entrada para a reconstrução tomográfica. Analogamente à análise da amplitude dos canais energéticos na espectroscopia, os valores de pixel das imagens obtidas são proporcionais à concentração dos elementos selecionados, cuja identificação é realizada através da energia de excitação no espectro de emissão.

\subsubsection{Tomografia de emissão estimulada associada com a informação do tempo de voo do nêutron}

Um dos desafios encontrados para a implementação clínica da técnica NSECT é o tempo de irradiação envolvido na aquisição tomográfica, estimado em 48 horas segundo Kapadia (2007), o que torna impraticável a aquisição tomográfica numa rotina clínica. O tempo de exposição estimado é por sua vez dependente de 
dois fatores: intensidade da fonte de nêutrons $\left(\sim 10^{7} \mathrm{n}\right)$ e eficiência da geometria para detecção. Outro fator de extrema importância na implementação clínica é a dose efetiva durante a aquisição tomográfica que por sua vez é dependente do tempo de exposição, quantidade de projeções e intensidade do feixe de nêutrons empregado. Logo, a aquisição dos espectros de emissão com estatística suficiente pode ser comprometida dependendo dos fatores mencionados.

Com o objetivo de superar tais limitações, Agasthya (2013) propôs em sua pesquisa um novo método de aquisição para a NSECT que consiste em localizar o sítio de emissão de fótons produzidos pela reação $\left(n, n^{\prime}\right)$ com base no tempo de voo do nêutron. Neste método, o tempo de detecção está associado primariamente com o tempo decorrido entre a emissão de fótons e a incidência de nêutrons no meio irradiado. O sítio de emissão onde ocorreu a reação (n,n’) pode ser localizado em profundidade utilizando a relação linear entre a velocidade média de propagação do nêutron e o tempo de detecção dos fótons produzidos. O método de aquisição citado foi empregado nesta tese como uma abordagem auxiliar para a aquisição de imagens tomográficas empregando um menor número de projeções e consequentemente menor energia depositada.

\subsubsection{Seleção de elementos de interesse como biomarcadores}

O espectro de emissão obtido pela NSECT reflete a composição do meio irradiado através das energias que identificam os isótopos emissores. Entretanto, considerando o emprego da NSECT no diagnóstico clínico, a seleção dos elementos como biomarcadores deve satisfazer duas condições básicas: favorecer uma combinação única entre os elementos selecionados nos tecidos avaliados por meio da diferença de concentrações (i) e possuir elevada seção de choque para a reação (n,n’) (ii).

A condição (ii) está relacionada com o limiar de detecção, uma vez que quanto maior a seção de choque maior a taxa de emissão de fótons, enquanto que a condição (i) é empregada como indicador da presença do estado patológico. 
Quando o mesmo elemento se apresenta em diferentes concentrações entre os tecidos afetados, a tendência observada indica a alteração da fisiologia. Se outros elementos são identificados no mesmo espectro de emissão com uma tendência de concentrações complementares (invertidas) entre os tecidos, a diferenciação dos mesmos é conduzida diminuindo a possibilidade de ocorrência de falha no diagnóstico (falso positivo ou falso negativo). Como exemplo deste conceito, os elementos $\mathrm{Ca}, \mathrm{V}, \mathrm{Cu}, \mathrm{Zn}$, Se e Rb são encontrados em diferentes concentrações nas composições de tumores de mama benigno e maligno (Rizk \& Sky-Peck, 1984).

\subsubsection{Aplicações e desenvolvimento da NSECT}

Desde sua introdução em 2006, aplicações como a detecção de câncer de mama (Kapadia et al., 2006a; Bender et al., 2007; Kapadia et al., 2010) e da hemacromatose hepática (Kapadia, 2007; Agasthya et al., 2012) foram avaliadas pela técnica NSECT através de simulações computacionais cujos resultados foram validados por experimentos (Kapadia et al., 2005, 2006b, 2008) e motivaram novas pesquisas, como a apresentada nesta tese. Ainda em 2013, Agasthya (2013) demonstrou que a NSECT também pode ser empregada no diagnóstico de outras doenças hepáticas como cirrose, esteatose e câncer.

Contribuindo para o desenvolvimento da técnica NSECT, esta tese apresenta os resultados obtidos com a pequisa de duas novas aplicações para o diagnóstico clínico com a NSECT e uma abordagem inédita para a otimização da reconstrução tomográfica, como descrito na próxima seção.

\subsection{Objetivo e originalidade}

Utilizando simulações computacionais com o código MCNP5, esta tese tem por objetivo: apresentar a metodologia originalmente desenvolvida com base no emprego da técnica NSECT para a (i) detecção de microcalcificações associadas ao câncer de mama e o (ii) diagnóstico de lesões de Carcinoma de Célula Renal (CCR), além de apresentar uma metodologia inédita para a (iii) otimização da reconstrução 
tomográfica. As motivações dos objetivos propostos são apresentadas a seguir de acordo com a empregabilidade da técnica NSECT.

\subsubsection{Microcalcificações associadas ao câncer de mama}

Segundo estimativas fornecidas pelo Instituto Nacional do Câncer INCA, é esperado que cerca de 57 a cada 100 mil mulheres serão diagnosticadas com câncer de mama em 2014, o que totaliza 21\% de todos os novos casos para este ano (INCA, 2014). Um dos principais efeitos do desenvolvimento do câncer de mama é a formação de depósitos de cálcio conhecidos na literatura como microcalcificações.

A primeira descrição de uma microcalcificação em uma mamografia foi apresentada por Salomom \& Beitrage (1913). Desde então, muitos estudos foram conduzidos para caracterizar e classificar diferentes tipos de microcalcificações. De acordo com Tabar et al. (2000), a taxa de sobrevivência de pacientes que desenvolvem tumor de mama é inversamente proporcional ao tamanho das microcalcificações. Entretanto, a detecção precoce pode ser impraticável devido ao próprio tamanho das microcalcificações, não permitindo a distinção clara entre estruturas no tecido irradiado em mamografias.

O tumor e a mama saudável apresentam características distintas tais como, a densidade e, principalmente a composição química. Considerando que as alterações fisiológicas precedem as alterações morfológicas, qualquer parâmetro extraído a nível molecular, e relacionado ao desenvolvimento tumoral pode ser usado como uma medida preditiva. Este parâmetro pode ser usado como uma potencial ferramenta para o diagnóstico clínico uma vez que expressa a fisiologia do tumor. Sendo uma técnica não-invasiva, a NSECT foi proposta originalmente no presente trabalho para avaliar in vivo a mudança na concentração de cálcio na mama devido a presença de microcalcificações com diferentes tamanhos e composições. 


\subsubsection{Carcinoma de célula renal}

Segundo a Sociedade Brasileira de Urologia - SBU, cerca de 40\% dos casos diagnosticados de tumor renal estão em estágio avançado, diminuindo as chances de cura o que eleva a taxa de mortalidade (SBU, 2014). Além do mais, o diagnóstico desta doença apresenta algumas dificuldades, pois o paciente pode ser assintomático ou apresentar sintomas comuns a outras doenças como hematúria, dores abdominais, fadiga, perda de peso e anemia. Devido a estas características, a detecção do câncer renal é muitas vezes acidental devido a aquisição de imagens abdominais para o diagnóstico de outras enfermidades.

A realização de exames clínicos que envolvem a aquisição de imagens médicas vêm se tornando cada vez mais frequente nos últimos 30 anos devido aos avanços tecnológicos de técnicas não-invasivas de imageamento, e muitas destas foram propostas para o diagnóstico in vivo de tumores (Kim et al., 2008, 2009; Verma et al., 2010). Entretanto, segundo Millet et al. (2011), nenhum critério conclusivo foi estabelecido para a distinção entre tecido saudável e tumor utilizando apenas imagens médicas.

Atualmente, a biópsia ainda é o método padrão empregado para o diagnóstico do Carcinoma de Célula Renal (CCR) apesar de ser invasivo e acarretar riscos ao paciente, uma vez que o mesmo deve estar sedado. Ainda, a acurácia de detecção pela biópsia é diretamente proporcional ao tamanho do tumor, logo, o diagnóstico precoce de tumores renais pode ser comprometido devido a dificuldade associada a punção de pequenas lesões. De acordo com os estes argumentos, é apresentado o primeiro estudo conduzido para avaliar a aplicação da NSECT no diagnóstico in vivo do CCR através da aquisição de imagens tomográficas tridimensionais.

\subsubsection{Otimização da reconstrução tomográfica na NSECT}

A teoria sobre protocolos para aquisição de imagens tomográficas é amplamente explorada na literatura. Técnicas como a tomografia de emissão de 
pósitrons (Positron Emission Tomography - PET) e ressonância magnética nuclear (Magnetic Resonance Imaging - MRI) fazem parte da rotina empregada no diagnóstico clínico e contam com um extenso histórico de avanços tecnológicos. Em especial, as modalidades que empregam radiação ionizante, como a tomografia computadorizada de raios-x (Computed Tomography - CT), são capazes de obter imagens tomográficas de alta resolução sem superar os limites de dose efetiva definidos para os órgãos humanos (McNitt-Gray, 2002).

Segundo Kak \& Slaney (2001), a qualidade das imagens tomográficas reconstruídas é dependente da frequência de amostragem (aquisição) do sinal, tal que o ruído presente nas reconstruções pode ser atribuído, dentre outros fatores, às posições de projeção do feixe ou discretização dos elementos de detecção. Entretanto, os protocolos de aquisição com base na teoria de amostragem não podem ser diretamente empregados na técnica NSECT devido ao fator de qualidade da radiação para nêutrons. Dessa forma, devido ao número de projeções do feixe de nêutrons requerido, a qualidade da imagem tomográfica reconstruída pode ser comprometida em função da elevada dose efetiva.

Para suprir a deficiência de uma metodologia para a criação de protocolos de aquisição especificamente designados para NSECT, foi conduzido um estudo pioneiro com o objetivo de otimizar a qualidade das imagens reconstruídas em função da configuração de irradiação e da dose efetiva. 


\section{MATERIAL E MÉTODOS}

\subsection{O método Monte Carlo e o código MCNP5}

O método Monte Carlo aplicado ao transporte de radiação foi desenvolvido com os primeiros códigos computacionais durante o projeto Manhattan para a produção da bomba atômica na década de 40. O método proposto consiste em subdividir o problema de transporte em vários estágios onde são simulados todos os eventos possíveis de acordo com as distribuições de probabilidade associadas à natureza da partícula transportada, meio de transporte e interações com a matéria. Considerando que os estágios simulados compõem um experimento em que o comportamento da partícula transportada é observado através de suas interações com o meio, a simulação de vários experimentos $\left(\sim 10^{6}-10^{8}\right)$ fornece valores médios dos parâmetros de interesse, por exemplo o fluxo de partículas, considerando o comportamento estocástico da partícula transportada.

Uma série de códigos computacionais baseados no método Monte Carlo foi desenvolvido pelo Los Alamos National Laboratory na década de 50. Estes códigos foram combinados em um único e em 1977 a primeira versão do código MCNP (Monte Carlo $N$-Particle) foi lançada para o transporte acoplado de nêutrons e fótons. Além de aplicações em projeto de reatores nucleares, o código MCNP pode ser empregado na estimativa de doses radiológicas, projetos de blindagem hospitalar, radioterapia, medicina nuclear, tomografia computadorizada e várias outras aplicações em física médica.

A versão 5 do código $\mathrm{MCNP}^{1}$ foi utilizada na pesquisa desenvolvida

\footnotetext{
${ }^{1}$ A biblioteca ENDF/B-VII foi utilizada nas simulações com o código MCNP5.
} 
para o transporte acoplado de nêutrons, fótons e elétrons. De acordo com o princípio do método Monte Carlo aplicado ao transporte de radiação, os eventos associados à interação da partícula incidente de origem (fonte) são simulados no meio de transporte, assegurando que o comportamento observado da partícula se aproxime do real através da natureza dos processos estocásticos simulados. O transporte acoplado realizado pelo código MCNP5 (MCNP5, 2003) simula a cascata de eventos originada pela interação entre as partículas da fonte e o meio, ou seja, independente da partícula incidente, qualquer evento originado pela fonte também será transportado desde sua origem até sua absorção ou fuga. A Figura 1 mostra o conceito do transporte acoplado simulado pelo MCNP5.
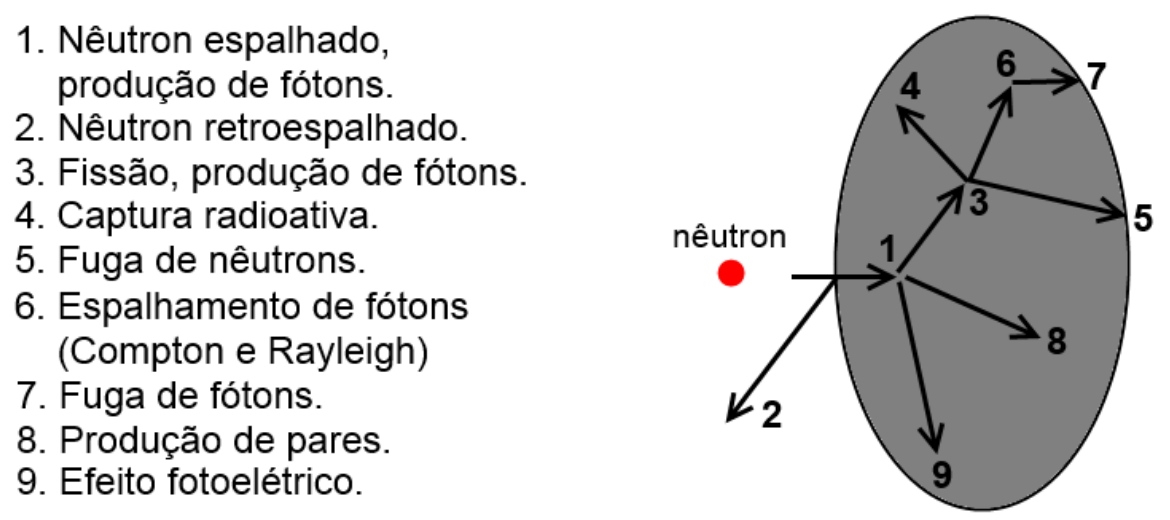

Figura 1 - Transporte acoplado de nêutrons, fótons e elétrons. Todos os eventos gerados a partir da interação entre a partícula incidente e o meio de transporte são simulados. Figura adaptada de MCNP5 (2003).

De acordo com a natureza estocástica do transporte de radiação, a cascata de eventos originada pela interação do nêutron é dependente das distribuições de probabilidade associadas ao comportamento da partícula e do meio de transporte. Logo, um nêutron incidente pode ser retroespalhado (2) ou ser espalhado no meio (1) produzindo um fóton ou induzindo a fissão (3) em materiais físseis o que também produz um fóton e mais dois nêutrons, podendo um deles ser capturado (4) e o outro ejetado para fora do meio de transporte (5). O fóton em (3) pode ser espalhado 
pelo meio (Compton e Rayleigh) (6) e ejetado para fora do meio de transporte (7) enquanto que o fóton produzido em (1) pode interagir com o meio de transporte por produção de pares (8) ou efeito fotoelétrico (9). Quando a interação da partícula incidente é simulada suficientemente para reduzir a incerteza do método, grandezas como a energia depositada em decorrência do fluxo de partículas podem ser estimadas em função das distribuições de probabilidades associadas aos eventos descritos.

\subsubsection{Interações do nêutron com a matéria}

Devido a ausência de carga, o nêutron interage diretamente com o núcleo sem interagir com a eletrosfera do átomo. A seguir serão discutidos os principais mecanismos de interação do nêutron com a matéria.

1. Captura radioativa: Nesta reação o nêutron é capturado e absorvido pelo núcleo seguido pela emissão de radiação $\gamma$ característica ao núcleo emissor. Esta reação é simbolizada na literatura por $(\mathrm{n}, \gamma)$.

2. Reações com partículas carregadas: Nêutrons são absorvidos pelo núcleo seguido pela emissão de partículas carregadas, tais como $\alpha$ e p. Estas reações são descritas na literatura como $(\mathrm{n}, \alpha)$ e $(\mathrm{n}, \mathrm{p})$ respectivamente.

3. Reações com produção de nêutrons: Nêutrons incidentes podem interagir com os nêutrons no núcleo do átomo, ejetando-os do núcleo alvo como nêutrons secundários. Tais reações são encontradas na literatura como (n,2n) e (n,3n).

4. Fissão: Nesta reação o núcleo de átomo que interage com o nêutron pode ser fissionado, liberando na reação nêutrons secundários e radiação $\gamma$.

5. Espalhamento elástico: O nêutron colide com o núcleo do átomo elasticamente, alterando sua velocidade, direção e sentido de propagação. O núcleo do átomo permanece em seu estado estável. Esta reação é simbolizada na literatura por $(n, n)$. 
6. Espalhamento inelástico: Esta reação é simbolizada na literatura por (n,n’). O princípio de interação é idêntico ao da reação $(n, n)$, entretanto, o estado energético do núcleo é alterado. O núcleo excitado retorna a seu estado estável emitindo radiação $\gamma$ característica ao núcleo emissor e do seu estado excitado. Esta é a reação na qual a NSECT é fundamentada.

Esta reação possui um limiar energético $E^{*}$ para o nêutron incidente que é dependente do número de massa $A$ do núcleo do isótopo alvo e da energia de excitação $\varphi$ do núcleo irradiado, equação 1. A reação ocorrerá apenas se a energia $E$ do nêutron incidente for superior a $E^{*}$. Neste caso, a seleção da energia do nêutron incidente no meio irradiado deve ser escolhida tal que o limiar energético seja ultrapassado. Como exemplo, $E^{*}=4,80 \mathrm{MeV}$ para o isótopo ${ }^{12} \mathrm{C}$ cuja energia de excitação é 4,44 MeV.

$$
E^{*}=\frac{A+1}{A} \varphi
$$

\subsubsection{Grandezas quantificadas pelo código MCNP5}

A seguir serão descritas as grandezas quantificadas pelo código MCNP5 que foram utilizadas neste trabalho.

\subsubsection{Estimativa do fluxo de partículas}

O fluxo médio de partículas que se propagam em um volume $V$ é calculado pelo código MCNP5 de acordo com a seguinte definição:

$$
\bar{\phi}_{V}=\frac{1}{V} \int d E \int d V \int v N(\vec{r}, E, t) d t
$$

onde $N(\vec{r}, E, t)$ é a densidade de partículas localizadas pelo vetor $\vec{r}(\mathrm{~cm})$ com energia $\mathrm{E}(\mathrm{MeV})$ no tempo $t(\mathrm{~s})$ e velocidade $v(\mathrm{~cm} / \mathrm{s})$.

Por definição, $\bar{\phi}_{V}$ é calculado integrando os intervalos diferenciais $d E$ e $d V$ para o período $(t)$ compreendido pela criação da partícula simulada até sua finalização (absorção ou fuga). Entretanto, o código MCNP5 também permite a seleção 
de intervalos de integração pré-definidos para a dependência energética $d E$ e temporal $d t$. A grandeza $\bar{\phi}_{V}$, com unidade [partículas $\left./ \mathrm{cm}^{2}\right]$, é calculada individualmente pelo cartão F4 para o transporte de fótons, nêutrons e elétrons respectivamente como F4:P, F4:N e F4:E.

\subsubsection{Estimativa da energia depositada}

A estimativa da energia depositada média por partícula é calculada a partir da definição do fluxo médio de partículas apresentada na equação 2. A densidade de partículas $N(\vec{r}, E, t)$ é multiplicada pela seção de choque total $\sigma_{t}(E)$ e pela função de transferência de energia $H(E)$, ambas dependentes da energia $E(\mathrm{MeV})$ da partícula incidente. Dessa forma, a probabilidade de interação das partículas simuladas e a energia transferida ao meio de transporte relacionam a densidade de partículas com a energia depositada. A energia depositada $H_{t}$ é calculada como segue:

$$
H_{t}=\frac{\rho_{a}}{m} \int d E \int d V \int \sigma_{t}(E) H(E) v N(\vec{r}, E, t) d t
$$

onde $\rho_{a}$ e $m$ são respectivamente a densidade atômica (átomo/barn-centímetro) e massa (g) do meio de transporte.

A função $H(E)$ avalia a transferência de energia devido a interação da partícula incidente com o meio. Dessa forma, o transporte acoplado requer o cálculo de $H(E)$ individualmente para os diferentes tipos de partículas transportadas. O código MCNP5 quantifica a energia depositada $H_{t}$, em $[\mathrm{MeV} / \mathrm{g}]$, através do cartão F6 para o transporte de fótons e nêutrons como F6:P e F6:N. A energia depositada devido ao transporte de elétrons é automaticamente considerada no cartão F6:P. A energia depositada devido ao transporte acoplado das partículas é calculada pela soma de F6:N e F6:P obtidos através das seguintes funções de transferência de energia $H(E)$ : 
- Nêutrons

$$
H(E)=E-\sum_{i} p_{i}(E)\left[\bar{E}_{i, \text { out }}(E)-Q_{i}+\bar{E}_{i, \gamma}(E)\right]
$$

onde:

$p_{i}(E)=$ Probabilidade de ocorrência da i-ésima reação com o nêutron incidente com energia $E$;

$\bar{E}_{i, \text { out }}(E)=$ Energia média do nêutron produzido pela i-ésima reação a partir do nêutron incidente com energia $E$;

$\mathrm{Q}_{i}=$ Valor $Q$ da i-ésima reação; e

$\bar{E}_{i, \gamma}(E)=$ Energia média do fóton produzido pela i-ésima reação a partir do nêutron incidente com energia $E$.

- Fótons

$$
H(E)=E-\sum_{i}^{3} p_{i}(E)\left[\bar{E}_{i, \text { out }}(E)\right]
$$

onde:

$i=1$ implica na ocorrência de espalhamento pelo efeito Compton;

$i=2$ implica na ocorrência de produção de pares;

$i=3$ implica na ocorrência de efeito fotoelétrico;

$p_{i}(E)=$ Probabilidade de ocorrência da i-ésima reação com o fóton incidente com energia $E$; e

$\bar{E}_{i, \text { out }}(E)=$ Energia média do fóton produzido pela i-ésima reação a partir do fóton incidente com energia $E$. Para $i=2, \bar{E}_{i, \text { out }}(E)=2 \mathrm{~m}_{0} c^{2}$ (energia de repouso do elétron) e para $i=3, \bar{E}_{i, \text { out }}(E)=0$. 


\subsubsection{Estimativa da altura de pulso}

A estimativa da altura de pulso calculada pelo código MCNP5 modela a resposta da distribuição energética de pulsos criados em um detector de radiação real. A distribuição de pulsos é calculada em função da contagem acumulativa dos eventos que depositam energia discretizada em canais para cada partícula simulada. A altura de pulso é estimada pelo código MCNP5 através do cartão F8:P,E para o transporte acoplado de fótons e elétrons.

\subsection{Sistema tomográfico para a NSECT}

O sistema tomográfico para a NSECT é composto por detectores e uma fonte de nêutrons caracterizada por um feixe colimado monocromático cuja energia deve ser escolhida de acordo com a energia do estado excitado do isótopo de interesse. A disposição dos detectores ao redor do feixe deve ser realizada considerando simultaneamente dois critérios básicos: (i) maximizar a detecção de eventos gama e (ii) minimizar a interação de nêutrons pela incidência direta ou por espalhamento com o detector. Estes objetivos devem ser contemplados independentemente do tipo de detector empregado ou energia do feixe de nêutrons utilizado.

Um estudo foi realizado com base em uma simulação com o código MCNP5 para otimizar a posição e disposição dos detectores. Um objeto simulador cilíndrico de $70 \mathrm{~cm}$ de altura e $40 \mathrm{~cm}$ de diâmetro, composto por água e imerso em ar, foi irradiado no centro com um única projeção de um feixe de nêutrons colimado de $6 \mathrm{MeV}$ com uma seção quadrada de $1 \mathrm{~cm}^{2}$ e incidência perpendicular ao eixo do cilindro. O fluxo de nêutrons e fótons foi avaliado em esferas de prova contendo ar e dispostas ao redor da superfície circular do objeto simulador em posições equidistantes e na mesma altura de incidência do feixe (perfil radial). Os fluxos também foram calculados em posições equidistantes paralelas à superfície circular do objeto simulador e centralizadas com a posição de projeção (perfil axial 1 e 2). Nesta última configuração os fluxos foram calculados em posições anguladas $180^{\circ}$ entre si. A Fi- 
gura 2 apresenta uma representação 3D das esferas de prova dispostas em torno do objeto simulador.

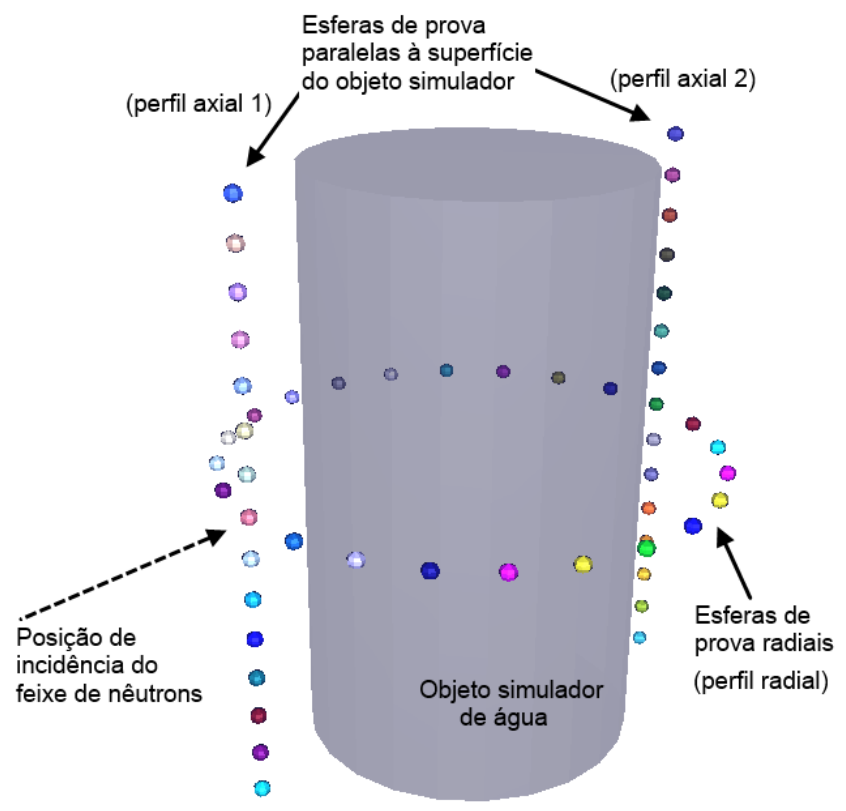

Figura 2 - Configuração de simulação para a avaliação da localização dos detectores no sistema tomográfico. Os perfis axial e radial com relação a posição de incidência do feixe de nêutrons são apresentados para o cálculo do fluxo de nêutrons e fótons.

O objeto simulador adotado representa um meio espalhador que simula o tronco humano e a energia do feixe de nêutrons escolhida é de interesse para a aplicação clínica da NSECT pois é suficiente para estimular isótopos em potencial para o diagnóstico (Viana et al., 2013; Viana \& Yoriyaz, 2011; Bender et al., 2007; Kapadia et al., 2008). Logo, o espalhamento de nêutrons e fótons avaliados nas posições adotadas descrevem o comportamento real do processo físico de emissão estimulada para NSECT. A Figura 3 apresenta os resultados obtidos com a simulação realizada. Os fluxos calculados foram normalizados para uma intensidade de fonte para $10^{7}$ nêutrons.

De acordo com os resultados obtidos com a simulação, a emissão de 
fótons é predominantemente orientada em sentido oposto à orientação de projeção do feixe incidente, apresentando espalhamento a partir da posição de projeção, Figura 3a. O fluxo de nêutrons calculado apresenta um comportamento onde apenas uma fração dos nêutrons $(\sim 0,05)$ produzidos pela fonte são retroespalhados, sendo predominantemente propagados na mesma direção e sentido de incidência do feixe, Figura 3b. Logo, a emissão estimulada de fótons e o espalhamento de nêutrons pelo objeto simulador possuem dependência angular com a posição de incidência do feixe, apresentada na Figura 3c.
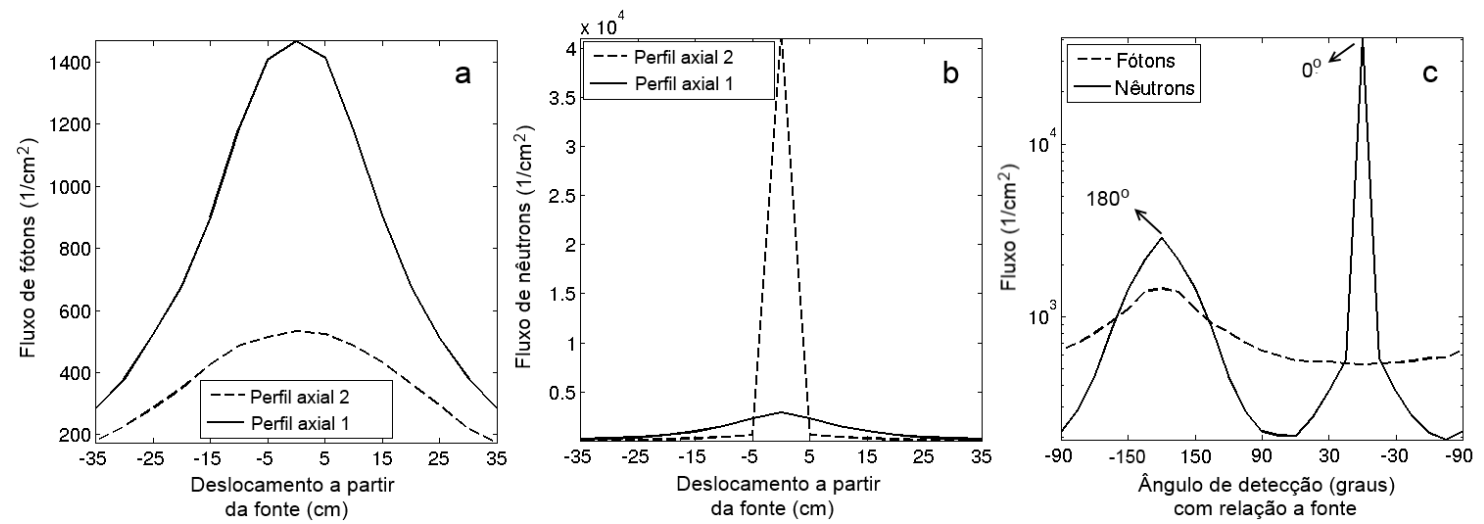

Figura 3 - Perfis axiais do fluxo de fótons (a) e nêutrons (b) calculados paralelamente a superfície circular do objeto simulador. Fluxo radial de fótons e nêutrons (c) calculados ao redor do objeto simulador com relação a posição de incidência do feixe de nêutrons.

Como observado, o fluxo de nêutrons calculado é máximo ao longo da mesma orientação e sentido de incidência do feixe $\left(0^{\circ}\right)$. O fluxo de nêutrons decai rapidamente e, após um intervalo angular de $\pm 180^{\circ}$, eleva-se novamente com uma menor intensidade, o que corresponde a uma localização situada atrás do feixe incidente. Esta mesma localização se refere a posição onde ocorre o maior fluxo de fótons emitidos pelo objeto simulador. Desta forma, de acordo com o perfil axial 1 para fótons e nêutrons, o arranjo de detectores na técnica NSECT deve estar posicionado atrás da fonte, minimizando o efeito de nêutrons espalhados e 
maximizando a detecção de eventos gama.

Dependendo do arranjo experimental de interesse, múltiplos detectores podem ser empregados a fim de aumentar a eficiência de detecção. Entretanto, a condição apresentada para a localização dos detectores com relação a posição do feixe deve ser satisfeita pois, a interação de nêutrons danifica os detectores além de aumentar o nível de ruído no sinal. De acordo com os resultados apresentados na Figura 3c, o arranjo de detectores deve estar localizado no intervalo definido por \pm 90 em relação a posição de incidência do feixe e próximo ao plano de projeção de acordo com as dimensões dos detectores. Essas condições satisfazem os critérios para a otimização do sistema de detecção e são adotadas nos arranjos de detectores, experimental e simulado via código MCNP5, empregados neste trabalho, como descrito na Seção 3.5.

\subsection{Reconstrução tomográfica de emissão}

O método de reconstrução tomográfica baseado no algoritmo EM ( $E x$ pectation - Maximization) é um dos métodos mais difundidos na literatura para a reconstrução de imagens de emissão. Sendo este um método estocástico, a função de verossimilhança pode ser modificada para a incorporação de características de interesse relacionados ao evento modelado, como por exemplo a eficiência de detecção para um conjunto de orientações ou detectores. Outra característica muito explorada é a capacidade de reconstrução de imagens a partir de um conjunto de dados subamostrados, sendo esta uma característica inerente ao conjunto de dados de entrada para as reconstruções tomográficas na NSECT. Métodos analíticos de reconstrução como o algoritmo de Retroprojeção Filtrada também poderiam ser empregados. Entretanto, considerando a subamostragem do sinal na NSECT, a qualidade de reconstrução das imagens devido a presença de artefatos seria inferior.

Devido à sua natureza estatística, este método permite a aquisição de imagens mesmo utilizando um conjunto limitado de dados pois a estimativa é relacionada simultaneamente com os dados de entrada e com a função de verossimi- 
lhança adotada pelo algoritmo. Diferentemente de outros métodos de reconstrução, a função de verossimilhança exercerá um papel fundamental no processo de estimativa reduzindo a incerteza associada ao cálculo pois, a priori, o comportamento físico do evento de interesse é conhecido e modelado. Logo, a natureza do evento de interesse que rege a estimativa dada pelo algoritmo não está restrita unicamente aos dados de entrada. A seguir será apresentada a formulação do algoritmo EM para a reconstrução tomográfica de emissão para a técnica NSECT.

A reconstrução tomográfica é considerada como uma representação visual dos órgãos/tecidos de interesse. Essa representação é feita em um espaço amostral onde a região anatômica irradiada é subdividida em unidades de área, conhecidas como pixels. Devido as propriedades da modelagem dos eventos de interesse, o objetivo do algoritmo é estimar a localização primária dos fótons emitidos pelo meio irradiado. O modelo estocástico empregado neste procedimento assume que as emissões de fótons são regidas por um processo de Poisson com parâmetro $\lambda$ desconhecido (a ser estimado), usualmente referido como densidade de emissão.

O espaço amostral, correspondendo ao Campo de Visão (Fiel of View - FOV) do sistema tomográfico, é virtualmente dividido em $n$ pixels, sendo que $\lambda_{i}$ é associado ao i-ésimo pixel $(i=1,2, \ldots, n)$. Seja então $y_{j}$ o número de contagens detectadas na j-ésima posição de projeção $(j=1,2, \ldots, d)$, onde $d$ denota o número de projeções. Para a aplicação na NSECT, $d$ é associado às posições de projeção do feixe de nêutrons, uma vez que o feixe de nêutrons estimulará a emissão de fótons. Dado o vetor $\lambda=\lambda_{1}, \lambda_{2}, \ldots, \lambda_{n}$, as contagens $y_{1}, y_{2}, \ldots, y_{d}$ são condicionalmente independentes para $Y_{j} \sim P\left(\mu_{j}\right)$, onde $\mu_{j}$ representada a densidade média de emissão na j-ésima posição de projeção e é calculado como:

$$
\mu_{j}=\sum_{i=1}^{n} \lambda_{i} p_{i j}
$$

$p_{i j}$ é conhecido na literatura como operador projeção e, formalmente, representa a distribuição de probabilidade condicional de que um fóton seja detectado na j-ésima 
projeção, dado que ele tenha sido emitido pelo meio irradiado na localização do iésimo pixel. Devido a sua importância, a formulação deste operador adotada nesta pesquisa será apresentada no decorrer desta seção.

O conjunto de dados completos $x$ é denotado por $x=(y, z)$, onde $z$ caracteriza os dados não observados, o que nesta formulação representa as contagens não detectadas. O vetor $z$ é composto por $z_{i j}$ entradas, definidas pelo número de fótons emitidos na posição do pixel $i$ e detectados na j-ésima projeção $(i=1,2, \ldots, n$; $j=1,2, \ldots, d)$. Para $\lambda=\lambda_{1}, \lambda_{2}, \ldots, \lambda_{n}, Z_{i j}$ são condicionalmente independentemente distribuídas com $Z_{i j} \sim P\left(\lambda_{i} p_{i j}\right)$. O logaritmo da função de verossimilhança de $Z_{i j}$ é expresso então por:

$$
L=\sum_{i=1}^{n} \sum_{j=1}^{d}\left\{-\lambda_{i} p_{i j}+z_{i j} \log \left(\lambda_{i} p_{i j}\right)-\log \left(z_{i j} !\right)\right\}
$$

\section{E-step}

Nesta etapa é calculada a esperança condicional de $Z_{i j}$ dado o vetor de dados observados $y$. Sendo $k$ o número de iterações do algoritmo, a distribuição condicional de $Z_{i j}$ dado $y$ e $\lambda^{(k+1)}$ admite uma distribuição binomial definida por:

$$
P\left(Z_{i j} \mid y, \lambda^{(k)}\right)=\frac{\lambda_{i} p_{i j}}{\sum_{i=1}^{n} \lambda_{i} p_{i j}},(i=1,2, \ldots, n ; j=1,2, \ldots, d)
$$

O valor esperado para uma variável binomialmente distribuído é calculado pelo produto entre sua probabilidade de ocorrência e o seu tamanho de amostra. Em decorrência desta definição, o tamanho da amostra de $Z_{i j}, y_{j}$, é multiplicado na equação 8, resultando na expressão:

$$
E_{\lambda^{(k)}}\left(Z_{i j} \mid y\right)=\frac{\lambda_{i}^{(k)} p_{i j} y_{j}}{\sum_{i=1}^{n} \lambda_{i}^{(k)} p_{i j}}=z_{i j}^{(k)} .
$$


2. M-step

Enquanto que $z_{i j}$ é atualizado no ciclo $k+1$, a equação 9 é maximizada pelo argumento que anula sua derivada parcial em $\lambda$, analogamente como descrito na equação 14 (Apêndice A). Desta forma, a estimativa de $\lambda^{(k+1)}$ é obtida iterativamente:

$$
\begin{gathered}
\lambda_{i}^{(k+1)}=q_{i}^{-1} \sum_{j=1}^{d} E_{\lambda^{(k)}}\left(Z_{i j} \mid y\right) \\
\lambda_{i}^{(k+1)}=\lambda_{i}^{(k)} q_{i}^{-1} \sum_{j=1}^{d} \frac{p_{i j} y_{j}}{\sum_{i=1}^{n} \lambda_{i}^{(k)} p_{i j}},(i=1,2, \ldots, n) \\
q_{i}=\sum_{j=1}^{d} p_{i j} .
\end{gathered}
$$

Outras aplicações do algoritmo EM podem ser encontradas em detalhes em McLachlan \& Krishnan (2007). Para mais detalhes sobre o algoritmo consulte o

\section{Apêndice B.}

\subsubsection{Operador projeção}

A teoria sobre reconstrução tomográfica de emissão baseada no algoritmo EM é muito explorada devido a sua flexibilidade e baixo custo computacional. Entretanto, o desempenho e qualidade da reconstrução tomográfica é dependente da definição do operador projeção $p_{i j}$. Nesta seção será apresentada a definição e formulação do operador projeção desenvolvido para as reconstruções tomográficas realizadas nesta pesquisa.

Como mencionado na seção anterior, o operador projeção $p_{i j}$ tem a função de correlacionar a projeção $j$ onde os fótons foram detectados com a localização $i$ mais provável no meio irradiado onde a emissão tenha ocorrido. Por se tratar de um método estocástico de reconstrução, o algoritmo EM é capaz de incorporar parâmetros específicos relacionados aos eventos físicos que regem a detecção 
de fótons, como por exemplo o uso da distribuição de Poisson para caracterizar o processo de emissão de fótons.

A metodologia desenvolvida é descrita com base no princípio básico da retroprojeção, que foi desenvolvido inicialmente para a reconstrução tomográfica de raios-x. Em termos gerais, a retroprojeção consiste em projetar as contagens detectadas de volta ao meio irradiado considerando a mesma direção e sentido de detecção. Desta forma, a imagem é obtida pela somatória das retroprojeções sobrepostas. O mesmo conceito foi adotado na formulação aqui desenvolvida, caracterizando o método proposto como determinístico. Isto é justificado devido a semelhança entre o fundamento teórico da NSECT e o método da retroprojeção, onde, de acordo com a teoria apresentada, a intensidade da emissão de fótons é proporcional ao estímulo causado pela interação do feixe de nêutrons rápidos com os isótopos presentes no caminho do feixe. Logo, desconsiderando o efeito da radiação espalhada, as contagens detectadas para uma dada projeção foram primariamente originadas pelo feixe projetado no meio irradiado. Então, sem perda de generalidade, as mesmas contagens podem ser redistribuidas ao longo do caminho de interação do feixe.

Considere inicialmente o FOV de um sistema tomográfico dividido virtualmente em $n$ pixels, caracterizando assim o espaço amostral da reconstrução tomográfica. A detecção de eventos gama pode ser interpretada de duas maneiras, e, de acordo com o Teorema da Reciprocidade (King, 1912), ambas são análogas, sendo elas: dado que um fóton tenha sido detectado na projeção $j$, qual teria sido sua localização $i$ mais provável de emissão (Figura 4a)? Similarmente, se um fóton foi emitido na posição $i$, em qual projeção $j$ o mesmo terá maior probabilidade de ser detectado (Figura 4b)?

Para a reconstrução tomográfica com a técnica NSECT, ambas as interpretações são regidas pela mesma distribuição de probabilidade, uma vez que os fótons emitidos são produzidos ao longo da projeção do feixe de nêutrons, e, independente do sistema de detecção adotado, as contagens dos eventos gama obtidos são associadas primariamente às projeções do feixe, sendo que a emissão é estimulada 


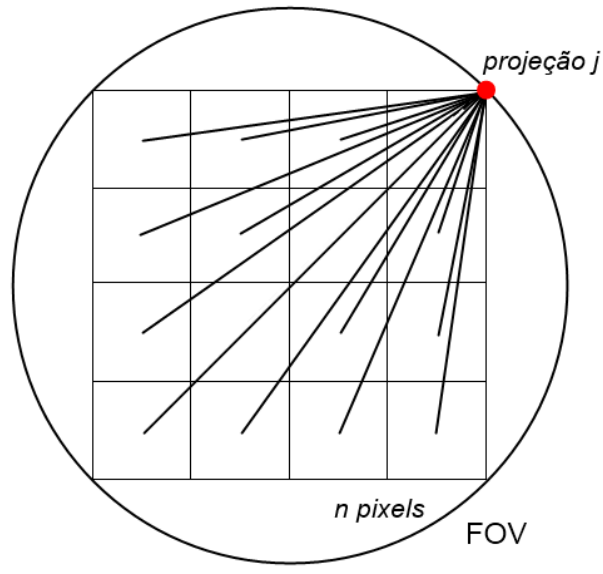

a

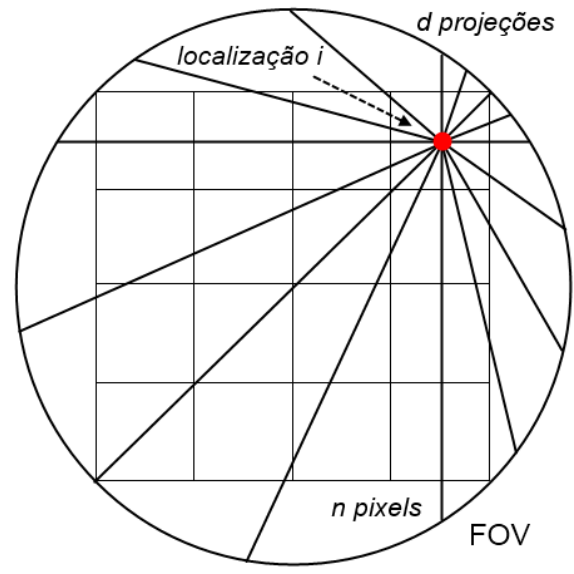

b

Figura 4 - Orientações de projeções e eventos gama detectados: contribuição da emissão na i-ésima localização para as contagens detectadas na projeção $j$ (a) e contribuição para as contagens detectadas nas $d$ projeções dada a localização de emissão $i$ (b).

apenas durante a interação do feixe com o meio irradiado. Logo, a adoção de um método que concilie essas duas interpretações é justificável e intuitiva. Dessa forma, deve-se considerar a contribuição de emissão, representada por $\lambda_{i}$, do i-ésimo pixel nas contagens detectadas na j-ésima projeção.

Para satisfazer simultaneamente as condições previamente apontadas, uma metodologia original foi desenvolvida utilizando-se a Transformada de Radon aplicada à imagens binárias com o objetivo de se obter a distribuição de probabilidade que relaciona a projeção de detecção com a localização da emissão. Por se tratar de uma imagem binária, onde apenas um pixel assume valor diferente de zero, o valor unitário representa a localização da emissão de fótons. Quando a Transformada de Radon é aplicada, as integrais de linha $f$ calculadas simulam o perfil de emissão assumindo que exista uma única fonte ou contribuição de fótons; sendo este procedimento repetido alterando a posição do valor unitário para os $n$ pixels. A integral de linha é calculada ao longo das $d$ projeções sendo que os respectivos $p_{i j}$ definem a probabilidade de emissão do pixel $i(i=1,2, \ldots, n)$ na projeção $j(j=1,2$, 
$\ldots, d)$. Quando estes perfis são ordenados de acordo com os índices $i$ e $j$ em $p_{i j}$, a distribuição de probabilidade que rege a emissão e a detecção de fótons é definida. O algoritmo desenvolvido para a obtenção do operador projeção $p_{i j}$ é apresentado a seguir. A Figura 5 exemplifica o resultado em cada etapa desse algoritmo para uma única iteração.

Passo 1 Defina o tamanho da malha composta por $n$ pixels onde será realizada a reconstrução tomográfica e o intervalo angular $\theta$ de amostragem entre rotações para a Transformada de Radon. $\theta$ são as posições angulares definidas na configuração de amostragem para a aquisição das contagens detectadas.

Passo 2 Crie a matriz binária $S(g, h)$ tal que, $g h=n$, isto é, contendo $n$ pixels definidos no passo anterior; sendo que inicialmente $S(1,1)=1$, Figura 5a. Aplique a Transformada de Radon em $S$ adotando $\theta$ como parâmetro de amostragem para o cálculo das integrais de linha, Figura 5b.

Passo 3 Vetorize o resultado do passo anterior normalizando-o pela valor da soma de seus elementos. Armazene o vetor normalizado na variável $p_{i j}$, onde $i=1$, $2, \ldots, n$ e $(j=1,2, \ldots, d)$.

Passo 4 Repita os Passos 2 e 3 alterando a posição do elemento unitário em $S(g, h)$ tal que $g h=n$.

Ao final do Passo 4, todos os $n$ pixels foram avaliados de acordo com a posição relativa das $d$ projeções calculadas, Figura 5c. Para exemplificar o conceito do algoritmo apresentado, considere a Figura 5 d como a representação bidimensional do vetor selecionado na Figura 5c. Este vetor apresenta unicamente a distribuição de probabilidades para que os eventos gama detectados numa dada posição angular $\theta$ sejam distribuídas entre os pixels contidos no caminho de projeção do feixe de nêutrons. De acordo com a formulação apresentada, esta é a região mais provável onde tenha ocorrido a emissão estimulada. 


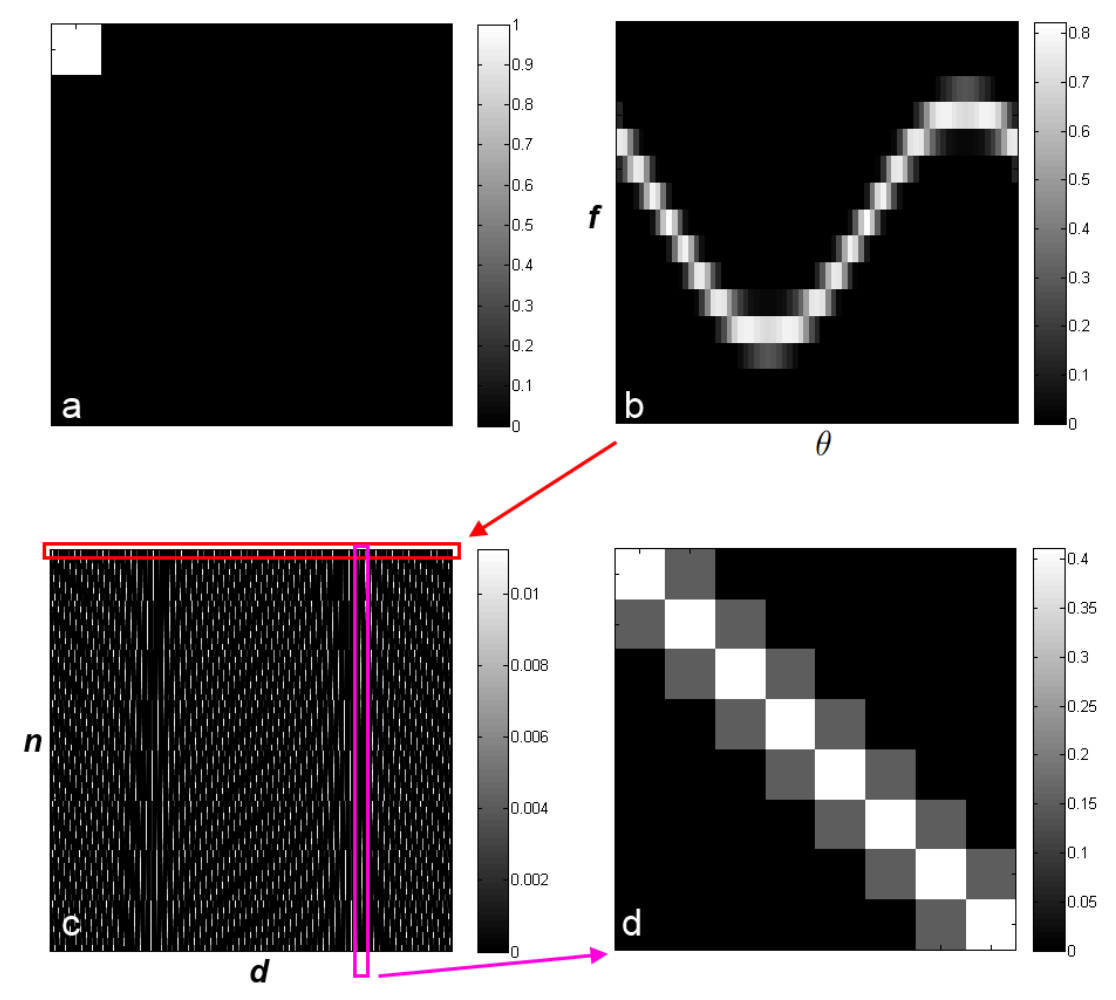

Figura 5 - Metodologia para construção do operador projeção $p_{i j}$ : matriz binária $S$ representando a emissão de fótons na localização $i$ (a), Transformada de Radon avaliada em $S$ (b), $p_{i j}$ calculado a partir da vetorização da Transformada de Radon avaliada em $S$ alterando a localização do valor unitário (c) e distribuição de probabilidade para as emissões ocorridas ao longo de uma dada projeção do feixe de nêutrons (d).

\subsection{Cálculo da dose efetiva}

A energia média depositada pelas interações das partículas foi calculada para o transporte acoplado de nêutrons, fótons e elétrons. A dose média [Gy $=\mathrm{J} / \mathrm{kg}]$ nos tecidos irradiados foi obtida convertendo a energia média $[\mathrm{MeV} / \mathrm{g}] \mathrm{uti}-$ lizando o fator de conversão $\mathrm{MeV} / \mathrm{J}\left(1 \mathrm{MeV}=1,6010^{-13} \mathrm{~J}\right)$. Em seguida, a dose equivalente média $[\mathrm{Sv}]$ foi calculada multiplicando a dose média pelo fator de peso 
da radiação $\mathrm{w}_{R}$ obtido a partir de uma distribuição contínua de acordo com a energia do nêutron incidente (ICRP103, 2007), Figura 6.

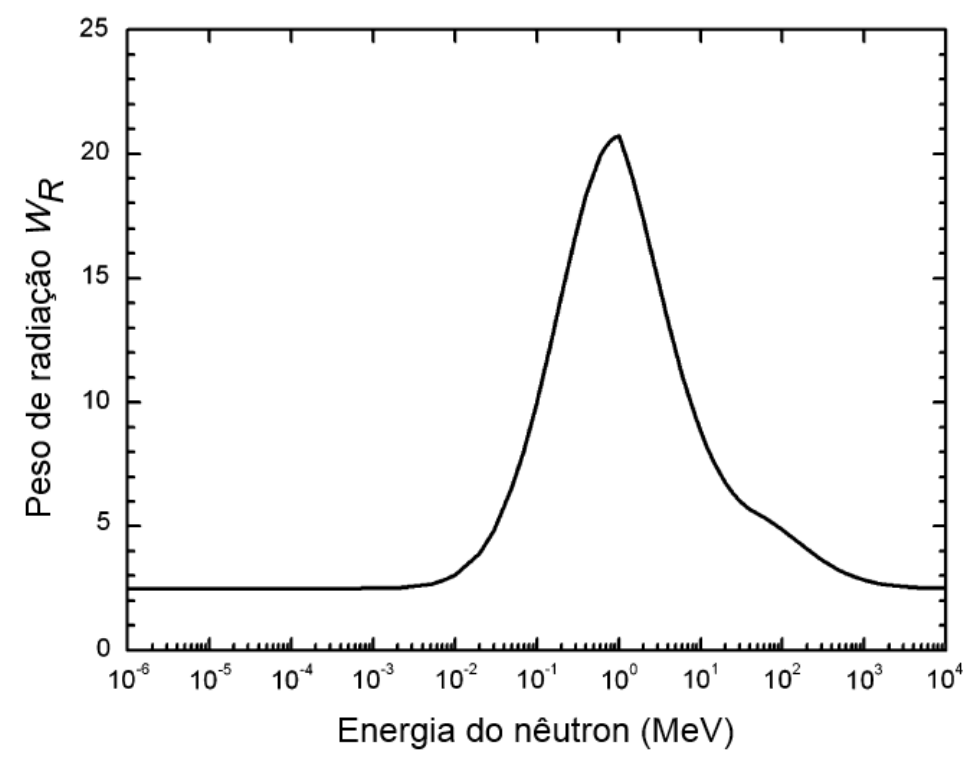

Figura 6 - Relação entre o fator de peso da radiação $\mathrm{w}_{R}$ e a energia $(\mathrm{MeV})$ do nêutron. Figura adaptada de (ICRP103, 2007).

Posteriormente, a dose efetiva média [Sv] é calculada pelo produto da dose equivalente média com os respectivos fatores de peso $\mathrm{w}_{T}$ dos tecidos irradiados, Tabela 1. A dose efetiva média é então reportada pela somatória dos valores calculados entre os tecidos modelados.

Os tecidos restantes, mencionados na Tabela 1, são: adrenal, região extratorácica, vesícula biliar, coração, rins, nodos linfáticos, músculo, mucosa oral, pâncreas, próstata, intestino delgado, baço, timo, útero. Para o cálculo da dose efetiva, a média aritmética das doses equivalentes avaliadas em cada tecido é multiplicada pelo fator 0,12 .

\footnotetext{
${ }^{2}$ Descrição apresentada no texto.
} 
Tabela 1. Fatores de peso $\mathrm{w}_{T}$ de tecidos recomendados pela ICRP103 (2007).

\begin{tabular}{ccc}
\hline Tecido & $\mathrm{w}_{T}$ & $\sum \mathrm{w}_{T}$ \\
\hline Medula óssea, cólon, estômago, pulmão, mama e tecidos restantes & 0,12 & 0,72 \\
Gônadas & 0,08 & 0,08 \\
Bexiga, esôfago, fígado, tireoide & 0,04 & 0,16 \\
Superfície óssea, cérebro, glândula salivar e pele & 0,01 & 0,04 \\
& & \\
& Total & 1 \\
\hline
\end{tabular}

\subsection{Novas aplicações e aperfeiçoamento da técnica NSECT}

\subsubsection{Espectroscopia}

\subsubsection{Detecção de microcalcificações mamárias}

Segundo Morgan et al. (2005), as microcalcificações mamárias são compostas por hidroxiapatita $\left(\mathrm{Ca}_{10}\left(\mathrm{PO}_{4}\right) \cdot 6 \mathrm{H}_{2} \mathrm{O}\right)$ ou oxalato de cálcio $\left(\mathrm{CaC}_{2} \mathrm{O}_{4} \cdot 2 \mathrm{H}_{2} \mathrm{O}\right)$, sendo a última predominantemente a composição de tumores benignos enquanto que a hidroxiapatita pode ser encontrada em tumores malignos e benignos. Nota-se então que a concentração de cálcio pode ser utilizada como indicador natural da presença de microcalcificações ou ainda como uma medida auxiliar para a classificação do tumor. Estas observações podem ser feitas assumindo que a concentração natural de cálcio presente na mama se altera localmente devido a presença e composição química das microcalcificações. A modalidade espectroscópica da NSECT foi empregada neste estudo para avaliar a mudança na concentração de cálcio devido a presença de microcalcificações mamárias assumindo as composições químicas já descritas. Um sistema para espectroscopia composto por fonte, detector e amostra foi simulado com o código MCNP5 e o mesmo é descrito a seguir.

Fonte: A fonte de nêutrons é caracterizada por um feixe colimado monocromático de seção quadrada de $1 \mathrm{~cm}^{2}$ e com energia de $5 \mathrm{MeV}$ incidindo diretamente no 
centro da amostra.

Detector: Foram utilizados dois detectores cilíndricos com $12 \mathrm{~cm}$ de diâmetro e $15 \mathrm{~cm}$ de altura cada e compostos por Germânio de alta pureza (High-purity Germanium - HPGe). Os detectores estão posicionados no plano y-z separados em $10 \mathrm{~cm}$ e angulados em 90, Figura 7. Nesta configuração, os detectores formam um ângulo de $45^{\circ}$ com a posição de projeção do feixe de nêutrons. A Tabela 2 apresenta a composição isotópica de ocorrência natural do HPGe.

Tabela 2. Composição isotópica do HPGe com densidade 5,32 g/ $\mathrm{cm}^{3}$.

\begin{tabular}{cccccc}
\hline Isótopo & ${ }_{32}^{70} \mathrm{Ge}$ & ${ }_{32}^{72} \mathrm{Ge}$ & ${ }_{32}^{73} \mathrm{Ge}$ & ${ }_{32}^{74} \mathrm{Ge}$ & ${ }_{32}^{76} \mathrm{Ge}$ \\
& & & & & \\
Fração em massa (\%) & 21,23 & 27,66 & 7,73 & 35,94 & 7,44 \\
\hline
\end{tabular}

Amostra: A amostra compreende uma mama modelada como um semi-elipsóide dado pelas dimensões $14 \times 12 \times 9 \mathrm{~cm}$ respectivamente para os eixos xyz. O eixo $\mathrm{z}$ da mama foi posicionado no plano $\mathrm{x}-\mathrm{y}$ paralelo a face dos detectores. A composição adotada para a mama é descrita em Bender et al. (2007) e apresentada na Tabela 3 .

As microcalcificações foram modeladas considerando duas abordagens distintas e complementares. Na primeira abordagem, 14 microcalcificações foram modeladas como esferas cujos diâmetros variam entre 1 e $14 \mathrm{~mm}$ e inseridas individualmente no centro da mama. Cada microcalcificação foi modelada assumindo a composição química da hidroxiapatita e do oxalato de cálcio respectivamente com as densidades $3,15 \mathrm{~g} / \mathrm{cm}^{3}$ e $2,20 \mathrm{~g} / \mathrm{cm}^{3}$. Dessa forma, a contribuição de cada microcalcificação pode ser avaliada independentemente no espectro de emissão de acordo com seu diâmetro e composição.

Na segunda abordagem, com o objetivo de simular um caso mais realístico onde a probabilidade de ocorrência de tumores malignos é proporcional ao número de microcalcificações (Hallgrimsson et al., 1988), um agrupamento contendo 16 
microcalcificações de hidroxiapatita cujos diâmetros variam entre 0,15 e 1,40 $\mathrm{mm}$ foram distribuídas em um volume de $1 \mathrm{~cm}^{3}$ no centro da mama. Desta forma, o agrupamento de microcalcificações está contido na seção transversal do feixe de nêutrons (Viana \& Yoriyaz, 2011).

Tabela 3. Composição do tecido mamário com densidade $0,93 \mathrm{~g} / \mathrm{cm}^{3}$.

\begin{tabular}{cc}
\hline Elemento & Fração em massa $(\%)$ \\
\hline $\mathrm{O}$ & $6,14 \mathrm{E}+01$ \\
$\mathrm{C}$ & $2,29 \mathrm{E}+01$ \\
$\mathrm{H}$ & $1,26 \mathrm{E}+01$ \\
$\mathrm{~N}$ & $2,57 \mathrm{E}+00$ \\
$\mathrm{Cl}$ & $1,98 \mathrm{E}-01$ \\
$\mathrm{Na}$ & $1,85 \mathrm{E}-01$ \\
$\mathrm{~K}$ & $8,94 \mathrm{E}-02$ \\
$\mathrm{Fe}$ & $9,80 \mathrm{E}-03$ \\
$\mathrm{Ca}$ & $8,29 \mathrm{E}-03$ \\
$\mathrm{Zn}$ & $1,17 \mathrm{E}-03$ \\
$\mathrm{Br}$ & $7,07 \mathrm{E}-04$ \\
$\mathrm{Al}$ & $6,67 \mathrm{E}-04$ \\
$\mathrm{Rb}$ & $5,98 \mathrm{E}-04$ \\
$\mathrm{Mn}$ & $3,88 \mathrm{E}-05$ \\
$\mathrm{Co}$ & $2,06 \mathrm{E}-05$ \\
$\mathrm{Ce}$ & $3,27 \mathrm{E}-07$ \\
\hline
\end{tabular}

O espectro da altura de pulso foi discretizado em intervalos de $1 \mathrm{keV}$. Os espectros detectados quando as microcalcificações foram inseridas individualmente na mama foram avaliados relacionando a altura de pulso referente a radiação gama emitida pelos isótopos de cálcio com os diâmetros das microcalcificações e suas respectivas composições. O espectro de altura de pulsos detectado para a abordagem onde o agrupamento de microcalcificações é inserido na mama foi comparado com o espectro da mama sem a presença de microcalcificações. Por se tratar de um estudo 
comparativo, o efeito do ruído de fundo é comum em ambos os espectros e por isso o mesmo não foi suprimido. A Figura 7 apresenta a configuração básica do sistema para a espectroscopia simulada.

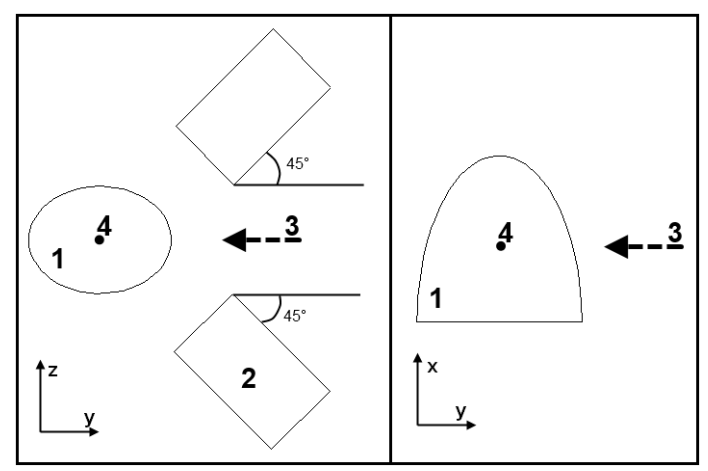

Figura 7 - Sistema para espectroscopia simulado com o código MCNP5: mama (1), HPGe (2), feixe de nêutrons (3) e localização das microcalcificações (4).

\subsubsection{Avaliação experimental da composição de tecidos renais}

O princípio teórico da técnica NSECT consiste em, através da assinatura energética dos isótopos estáveis estimulados pela reação (n,n’), detectar e quantificar a concentração de elementos de interesse no meio irradiado que são associados à fisiologia de alguma patologia. Logo, um experimento foi proposto para avaliar a diferença entre os espectros de emissão pela NSECT em função da composição elementar de duas amostras de tecido humano, contendo respectivamente Carcinoma de Célula Renal (CCR) e tecido renal saudável. A descrição do sistema para a espectroscopia experimental composto pela fonte, amostra, detector e colimador é apresentada a seguir.

Fonte: O experimento realizado foi conduzido nas instalações do laboratório de física nuclear TUNL (Triangle Universities Nuclear Laboratory) situado na Duke University, Carolina do Norte - EUA. A fonte de nêutrons é caracterizada por um feixe de nêutrons pulsátil produzido através da reação ${ }^{2} \mathrm{H}(\mathrm{d}, \mathrm{n})^{3} \mathrm{He}$ em um 
acelerador tandem Van-de-Graaf de 10 MV onde íons deutério são acelerados em direção à uma célula pressurizada contendo gás deutério. Cada interação entre os núcleos produz um átomo de ${ }^{3} \mathrm{He}$ e um nêutron livre com energia mínima $\mathrm{E}_{\min }=2,45 \mathrm{MeV}(\mathrm{Q}=3,27 \mathrm{MeV})$. Os íons deutério monoenergéticos perdem energia enquanto interagem na célula em função da concentração molar do gás deutério que é dependente da sua pressão e temperatura. Como resultado, ocorre a produção de um espectro predominantemente monoenergético de nêutrons que também é dependente da seção de choque diferencial angular da reação. A Figura 8 mostra a dependência entre a energia do feixe de nêutrons produzido com a energia do íon deutério incidente e com o ângulo de ejeção no sistema de referência (Liskien \& Paulsen, 1973).
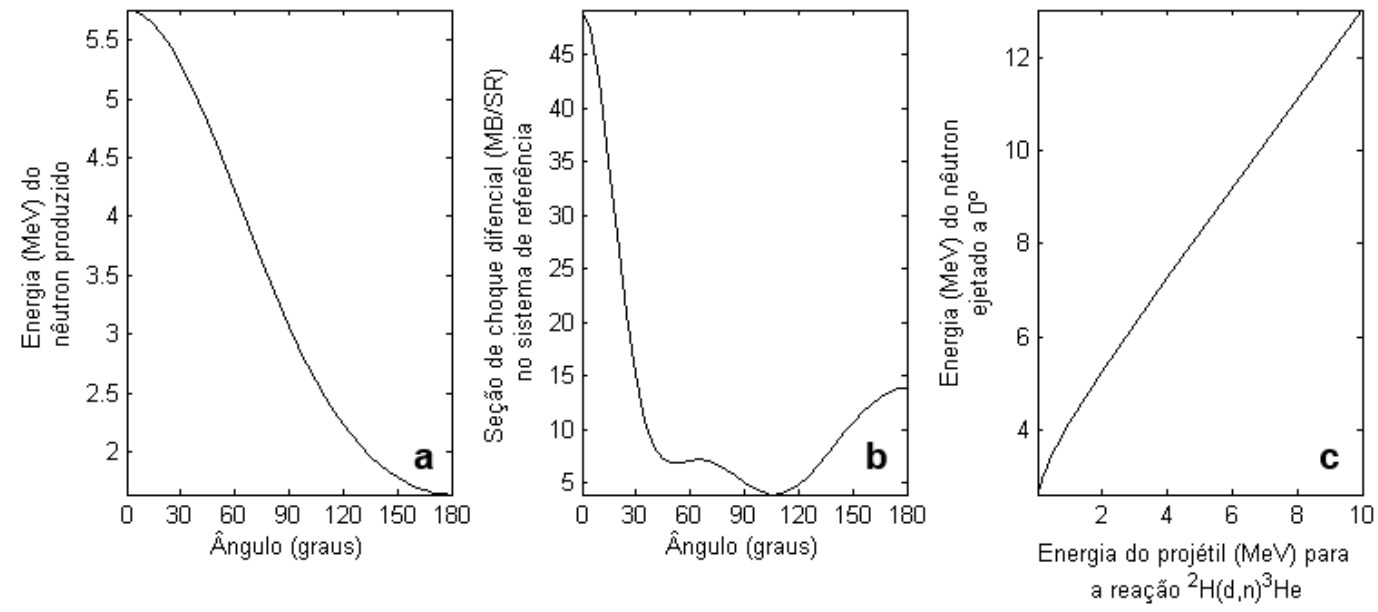

Figura 8 - Energia do nêutron produzido (a) e seção de choque diferencial angular (b) para íons deutério incidentes de 2,5 MeV. Dependência entre a energia do projétil incidente na célula de gás e a energia do nêutron produzido pela reação ${ }^{2} \mathrm{H}(\mathrm{d}, \mathrm{n})^{3} \mathrm{He}(\mathrm{c})$.

Amostra: Em colaboração com a Faculdade de Medicina da Universidade Estadual Paulista - UNESP, campus de Botucatu, as amostras de tecido renal foram seccionadas do mesmo rim de um paciente diagnosticado com CCR. Desta forma, a fisiologia do paciente é um fator em comum entre as amostras, as- 
sociando a diferença entre as composições elementares dos tecidos apenas ao desenvolvimento da patologia. As amostras foram liofilizadas e maceradas em um moinho criogênico, resultando em 4,40 g de CCR e 3,31 g de tecido renal saudável. Após esse procedimento, as amostras foram acondicionadas em frascos devidamente rotulados. O termo de consentimento assinado pelo paciente aprovando o uso das amostras de tecido renal para pesquisa é apresentado no

\section{Anexo A.}

Detector: O sistema de detecção utilizado em um típico experimento para NSECT é composto por detectores de HPGe devido sua resolução energética favorável à identificação e distinção entre picos no espectro de emissão (Kapadia et al., 2008). Entretanto, estes detectores são degradados quando o cristal interage com nêutrons o que reduz sua vida útil. Além de seu custo elevado, a instalação do detector requer o uso de uma unidade criogênica para refrigerar o cristal. Estes fatores limitam a empregabilidade dos detectores HPGe através do comprometimento entre eficiência de contagem, custo e instalação do sistema de detecção.

Uma outra alternativa para compor o sistema de detecção seria o uso de detectores de Brometo de Lantânio dopado com Cério $\left(\mathrm{LaBr}_{3}(\mathrm{Ce})\right)$, como utilizado no experimento conduzido no presente trabalho. Quatro detectores de $\mathrm{LaBr}_{3}(\mathrm{Ce})$ foram empregados pela primeira vez em um sistema tomográfico para NSECT justamente para se avaliar suas propriedades, uma vez que os mesmos não requerem resfriamento, são mais resistentes à interação com nêutrons e mais baratos. Entretanto, a resolução energética (FWHM $\sim 3 \%$ em $662 \mathrm{keV}$ para ${ }^{137} \mathrm{Cs}$ ) é inferior à resolução do $\mathrm{HPGe}$, o que pode inviabilizar a distinção entre picos devido à convolução do sinal detectado dependendo da proximidade das energias de interesse (Chewpraditkul \& Moszynski, 2011). Os detectores possuem $5 \times 5 \times 20 \mathrm{~cm}$ cada e foram montados num arranjo $2 \times 2$ envoltos por uma estrutura de alumínio. 
Colimador: O feixe de nêutrons produzido se propaga na mesma direção de incidência do íon deutério incidente na célula de gás. Entretanto, há uma distribuição angular na qual o nêutron produzido pela reação ${ }^{2} \mathrm{H}(\mathrm{d}, \mathrm{n})^{3} \mathrm{He}$ pode ser emitido, como exemplificado na Figura 8a. Com o objetivo de colimar o feixe produzido e direcioná-lo a posição de irradiação das amostras, uma estrutura cúbica de polietileno de alta densidade foi montada entre a célula de gás e a posição de irradiação das amostras. Essa estrutura de volume de $1 \mathrm{~m}^{3}$ contém um recorte central com seção quadrada de $16 \mathrm{~cm}^{2}$ por onde o feixe de nêutrons é colimado. A Figura 9 mostra uma representação 3D do colimador empregado no experimento.

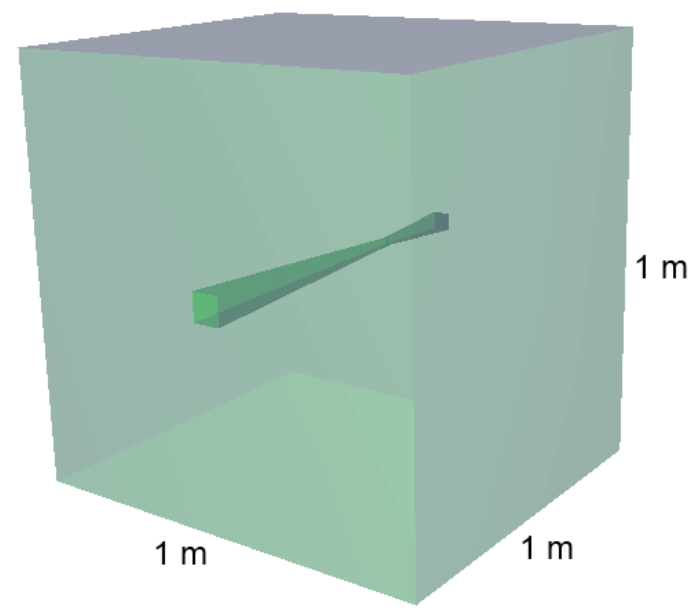

Figura 9 - Estrutura cúbica de polietileno de alta densidade. O feixe é colimado por um recorte feito no interior da estrutura que se estende desde a célula de gás até a posição de irradiação das amostras.

Cada amostra foi exposta ao feixe de nêutrons de 5,5 MeV por um período de 12 horas sob uma intensidade de $(1,020 \pm 0,003) 10^{5} \mathrm{n} / \mathrm{s}$. O mesmo período de exposição foi empregado na aquisição do espectro de fundo sem a presença das amostras na posição de irradiação. A configuração do experimento realizado é apresentado na Figura 10. Os espectros adquiridos foram processados como descrito a seguir. 


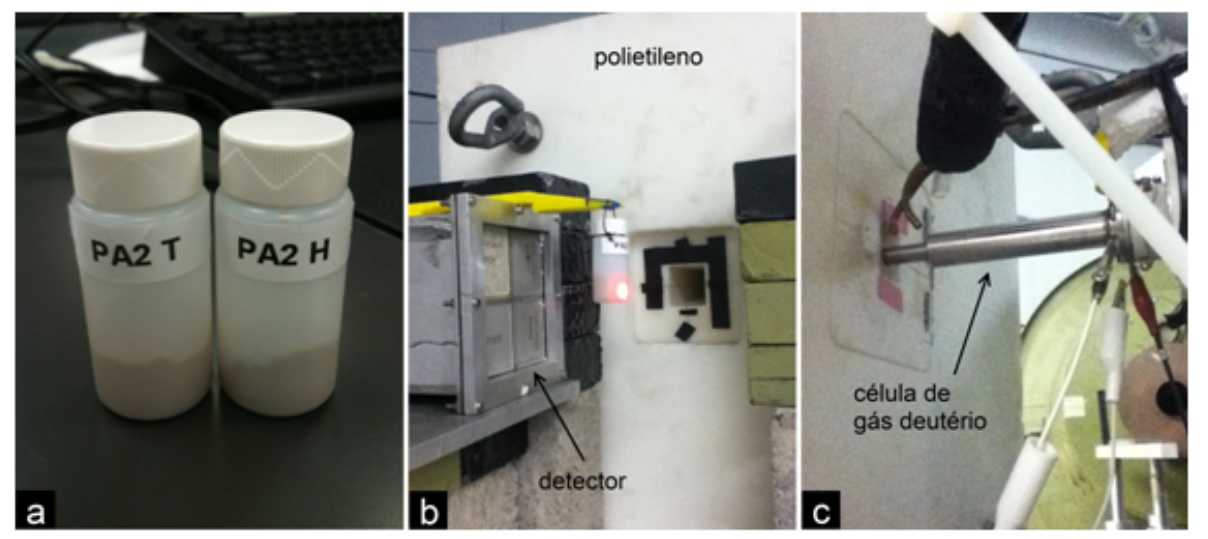

Figura 10 - Amostras (a) utilizadas no experimento: CCR (PA2 T) e tecido renal saudável (PA2 H). Posição de irradiação das amostras (b) com relação ao detector e colimador. Célula de gás deutério (c) onde ocorre a reação ${ }^{2} \mathrm{H}(\mathrm{d}, \mathrm{n})^{3} \mathrm{He}$.

Calibração dos espectros e supressão de ruído

O sistema de detecção foi calibrado utilizando um ajuste linear correlacionando os picos de energia gama para captura radioativa no hidrogênio $(2,22 \mathrm{MeV})$ e para os fótons emitidos pela produção de pares $(511 \mathrm{keV})$ com os seus respectivos canais. Posteriormente, os espectros adquiridos foram processados para supressão de ruído de fundo de acordo com a metodologia proposta em Hakansson (1999).

O feixe de nêutrons produzido é pulsátil e o período entre pulsos consecutivos é conhecido. Logo, o tempo de voo do pulso do feixe pode ser correlacionado com o tempo gasto $\Delta t$ até o mesmo atingir a amostra através da velocidade média de propagação, sendo esta velocidade dependente da energia do feixe $\left(E=\mathrm{mc}^{2}\right)$. Devido a diferença de magnitude entre as velocidades de propagação do nêutron e dos fótons emitidos, eventos gama detectados em um tempo diferente de $\Delta t$ são considerados como ruído, caracterizado por eventos gama que atingiram os detectores por retroespalhamento ou eventos gama produzidos pelos detectores devido a interação com nêutrons. Logo, restringir a contagem de fótons detectados em $\Delta t$ implica em considerar apenas os eventos gama originados predominantemente devido ao estímulo 
produzido pela reação (n,n'). A Figura 11 exemplifica este conceito onde um pico de contagens para eventos gama é correlacionado com o tempo de voo do feixe de nêutrons.

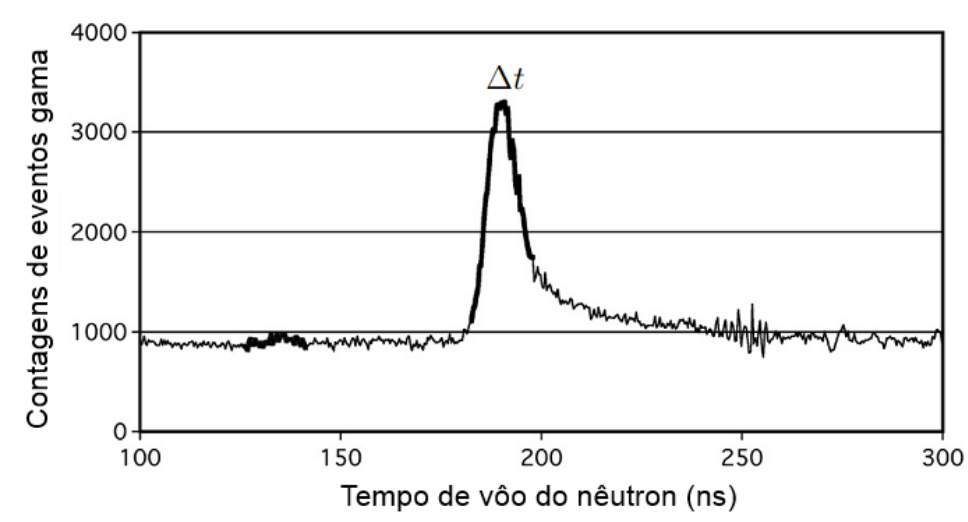

Figura 11 - Técnica de supressão de ruído utilizando o tempo de voo do nêutron (Floyd et al., 2007). Eventos gama detectados fora da região de aceitação definida por $\Delta t$ são considerados como ruído.

O espectro de fundo e os espectros das amostras de tecido renal foram adquiridos utilizando a técnica de supressão de ruído descrita. Posteriormente o espectro de fundo foi subtraído dos espectros das amostras. As contagens presentes nos espectros resultantes desta operação são relacionadas então apenas com a composição das amostras irradiadas, uma vez que a contaminação das contagens pelo laboratório, comum entre os espectros, é descartada.

Como última etapa do processo de supressão de ruído, as contagens produzidas a partir do efeito Compton nos detectores estão presentes como ruído residual nos espectros corrigidos pelo espectro de fundo. Logo, dependendo da magnitude das contagens nas energias de interesse, a identificação dos picos pode ser inviável por não haver distinção das contagens produzidas pelo efeito Compton.

Segundo Kapadia (2007), um ajuste polinomial pode ser aplicado no espectro resultante tal que a curva calculada modela a comportamento exponencial do efeito Compton apresentado predominantemente em baixas energias. Esta curva é 
então subtraída do espectro resultante a fim de suprimir o efeito Compton no espectro de emissão detectado. O mesmo procedimento foi adotado nesta pesquisa utilizando um ajuste gaussiano contendo dois kernels. As curvas obtidas pelos ajustes realizados foram então respectivamente subtraídas dos espectros das amostras já processados para supressão de ruído.

Reconstrução e identificação de picos

Após a supressão de ruído, os picos nos espectros corrigidos foram reconstruídos utilizando um Modelo de Misturas Gaussianas (MMG). Essa abordagem pode ser justificada devido a forma de sino do alargamento dos picos em função da energia do canal que, por sua vez, é dependente da resolução energética do detector $\mathrm{LaBr}_{3}(\mathrm{Ce})$ empregado no experimento.

Utilizada anteriormente para a reconstrução de picos em outras aplicações (Stuttle \& Gales, 2002; Kalambet et al., 2011), a adoção de um MMG é favorável à aplicação no experimento realizado pois o mesmo é capaz de reconhecer os picos de emissão em meio a flutuações estatísticas das contagens utilizando um conjunto de funções gaussianas com diferentes parâmetros e proporções entre si. Para mais detalhes sobre o MMG consulte o Apêndice C.

A NSECT é capaz de avaliar a composição do meio irradiado através da assinatura energética dos elementos estimulados. Logo, a identificação dos picos deve ser orientada pelo conhecimento a priori da presença de elementos de interesse ou da composição do meio irradiado. Por se tratar de um experimento dirigido, a composição elementar das amostras foi quantificada previamente. Este procedimento foi realizado em parceria com o Laboratório de Materiais e Feixes Iônicos - LAMFI da Universidade de São Paulo - USP. A composição das amostras foi obtida utilizando a técnica PIXE (Particle Induced X-ray Emission). A Tabela 4 apresenta a composição das amostras avaliadas de tecido renal. 
Tabela 4. Composição das amostras de tecido renal. A incerteza máxima associada às medidas é $5 \%$.

\begin{tabular}{cccc}
\hline Elemento & Amostra PA2 H $(\mathrm{ppm})$ & Amostra PA2 T $(\mathrm{ppm})$ & Razão (PA2 H/PA2 T) \\
\hline $\mathrm{Cu}$ & 9 & 7 & 1,29 \\
$\mathrm{Zn}$ & 137 & 84 & 1,63 \\
$\mathrm{Fe}$ & 246 & 522 & 0,47 \\
$\mathrm{~S}$ & 5970 & 5521 & 1,08 \\
$\mathrm{~K}$ & 6394 & 8288 & 0,77 \\
$\mathrm{P}$ & 7051 & 5759 & 1,22 \\
$\mathrm{Ca}$ & 42471 & 575 & 73,86 \\
\hline
\end{tabular}

Uma vez conhecida a composição das amostras, as energias dos fótons gama emitidos pelos isótopos dos elementos apresentados na Tabela 4 foram identificados nos espectros corrigidos das amostras. Desta forma, a identificação foi realizada quando possível de acordo com a concentração do elemento avaliado e a sensibilidade de detecção do sistema de espectroscopia adotado.

\section{Análise estatística}

De acordo com o princípio da técnica NSECT, a concentração do elemento presente no meio irradiado é diretamente proporcional a altura de pulso cuja energia identifica o isótopo emissor. Logo, a última etapa do processamento dos espectros consiste em avaliar a diferença entre as contagens dos picos identificados, testando a hipótese de que as amostras possuem composições distintas.

As alturas de pulso dos picos de interesse identificados nos espectros foram calculadas através da integral das contagens. A significância estatística das alturas de pulso entre as amostras foi avaliada utilizando o teste t bi-caudal para diferença de médias $(\alpha=5 \%)$. Por se tratar de um estudo comparativo, a eficiência intrínseca do sistema de detecção não foi avaliada uma vez que os mesmos canais foram comparados entre os espectros. 


\subsubsection{Simulação da avaliação experimental para o cálculo de dose na espectroscopia}

Devido as propriedades da técnica NSECT, a detecção e quantificação de elementos de interesse podem ser realizadas através da aquisição de imagens tomográficas, que mostra a distribuição espacial dos elementos avaliados, ou através da espectroscopia do meio irradiado utilizando uma única projeção do feixe de nêutrons.

Estudos conduzidos utilizando a abordagem espectroscópica já foram realizados com sucesso onde a técnica NSECT foi avaliada para o diagnóstico de tumor de mama (Bender et al., 2007) e hemocromatose hepática (Kapadia et al., 2008). Com o objetivo de quantificar a deposição de dose em órgãos localizados fora do feixe primário de nêutrons, um experimento foi proposto onde uma única projeção de feixe é empregada, simulando assim a espectroscopia de tecidos com a técnica NSECT (Kapadia et al., 2012).

O experimento realizado consistiu em irradiar com um feixe de nêutrons um objeto simulador de resina moldado à forma do abdômen humano com $24 \mathrm{~cm}$ de altura, onde estão inseridos dois dosímetros PRESAGE ${ }^{\mathrm{TM}}$ (Guo et al., 2006) de diferentes tamanhos imersos em água. Os dosímetros possuem forma cilíndrica, sendo o maior com $8 \mathrm{~cm}$ de altura e $10 \mathrm{~cm}$ de diâmetro e o menor com 3,5 $\mathrm{cm}$ de altura e 5 cm de diâmetro; ambos instalados nas posições respectivamente referentes ao fígado e rim.

O dosímetro PRESAGE ${ }^{\mathrm{TM}}$ é uma versão comercial de um dosímetro em gel que se polimeriza quando exposto a radiação ionizante, alterando sua opacidade proporcionalmente a dose absorvida. A dose (Gy) foi avaliada em ambos os dosímetros após a exposição ao feixe através de uma curva de calibração obtida a partir de imagens de tomografia ótica (Oldham, 2006). A Figura 12 apresenta os dosímetros e a configuração de irradiação adotados no experimento.

O feixe de nêutrons foi produzido através da reação ${ }^{2} \mathrm{H}(\mathrm{d}, \mathrm{n})^{3} \mathrm{He}$ com energia máxima de $8 \mathrm{MeV}$ posicionado a $3,5 \mathrm{~cm}$ da superfície do objeto simula- 
dor de resina, incidindo ortogonalmente em direção ao dosímetro de maior tamanho localizado na posição do fígado. A mesma fonte de nêutrons empregada neste experimento foi também utilizada em outro estudo cuja metodologia é apresenta na

\section{Seção 3.5.1.2.}

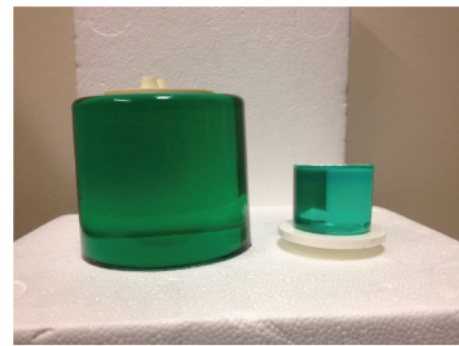

a

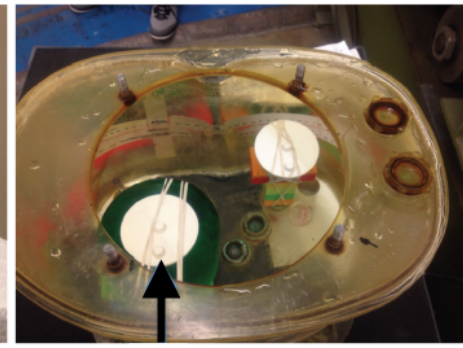

b

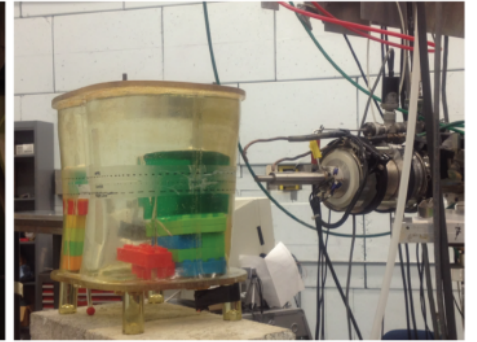

C

Figura 12 - Dosímetros PRESAGE ${ }^{\mathrm{TM}}$ utilizados no experimento (a). Posicionamento dos dosímetros no interior do objeto simulador de resina (b). A seta indica a posição de incidência do feixe de nêutrons. Arranjo experimental de irradiação com o feixe de nêutrons (c) (Kapadia et al., 2012).

O experimento proposto em Kapadia et al. (2012) previamente descrito foi simulado utilizando o código MCNP5. A fonte de nêutrons foi modelada como um feixe colimado monocromático de $8 \mathrm{MeV}$ com uma seção transversal de $3 \times 3 \mathrm{~cm}^{2}$. O abdômen humano foi modelado assumindo a forma de um elipsóide plano com os semi-eixos definidos de acordo com as dimensões do objeto simulador de resina utilizado no experimento, sendo eles $10 \mathrm{~cm}$ e $14 \mathrm{~cm}$. Os dosímetros foram modelados como cilindros com as dimensões descritas anteriormente para os dosímetros PRESAGE ${ }^{\mathrm{TM}}$ e imersos em água. A composição dos dosímetros é apresentada na Tabela 5 .

Os dosímetros foram modelados e posicionados dentro do tronco fielmente às localizações adotadas no experimento, estando o centro dos dosímetros centralizado em altura com o feixe de nêutrons que incide diretamente no centro do maior dosímetro enquanto que o menor dosímetro é irradiado apenas pela radiação 
espalhada pelo meio. A taxa de dose $(\mathrm{Gy} / \mathrm{h})$ foi calculada em ambos os dosímetros e comparada com os valores obtidos no experimento.

Tabela 5. Composição dos dosímetros modelados com densidade 1,07 g/ $\mathrm{cm}^{3}$ (Guo et al., 2006).

\begin{tabular}{cc}
\hline Elemento & Fração em massa (\%) \\
\hline $\mathrm{Cl}$ & 0,12 \\
$\mathrm{Br}$ & 0,33 \\
$\mathrm{~S}$ & 0,40 \\
$\mathrm{~N}$ & 5,11 \\
$\mathrm{H}$ & 9,38 \\
$\mathrm{O}$ & 21,22 \\
$\mathrm{C}$ & 63,42 \\
\hline
\end{tabular}

\subsubsection{Imageamento}

\subsubsection{Imageamento $3 \mathrm{D}$ de tumor renal}

A modalidade tomográfica da NSECT foi empregada neste estudo como uma abordagem original aplicada na aquisição de imagens para o diagnóstico in vivo de tumor renal. Um sistema tomográfico e um objeto simulador representando o corpo humano contendo CCR foram simulados com o código MCNP5, como descrito a seguir.

Detector: O sistema de detecção é composto por dez cilindros com $10 \mathrm{~cm}$ de altura e $5 \mathrm{~cm}$ de raio, sendo estes dispostos ao redor do objeto simulador em dois semi-círculos com $22 \mathrm{~cm}$ de raio contendo 5 cilindros cada. Os detectores estão posicionados atrás da fonte de nêutrons e angulados $30^{\circ}$ entre si em cada semi-círculo e estes por sua vez estão separados por $4 \mathrm{~cm}$. Este espaçamento compreende o caminho por onde o feixe de nêutrons é projetado entre os de- 
tectores em direção ao objeto simulador (linha pontilhada na Figura 13). Os detectores foram modelados com a composição do HPGe descrita na Tabela 2. A disposição dos detectores adotada atende os dois critérios básicos para a construção do sistema tomográfico, sendo eles: (i) maximização da detecção de eventos gama e (ii) minimização da interação de nêutrons com os detectores; além de minimizar o efeito do espalhamento de fótons entre os detectores o que aumenta o ruído no sinal.

Fonte: A fonte de nêutrons foi modelada como um feixe colimado monocromático de seção quadrada de $1 \mathrm{~cm}^{2}$ e com energia de $5 \mathrm{MeV}$. A energia do feixe foi determinada para estimular a emissão de fótons pelos elementos de interesse, dentre eles o ${ }^{12} \mathrm{C}$. A dimensão do feixe adotada possibilita uma resolução suficiente para a reconstrução das estruturas anatômicas no objeto simulador além de permitir um fluxo de nêutrons praticável em um experimento real da NSECT (Kapadia et al., 2008).

Objeto simulador: O objeto simulador empregado neste estudo foi proposto por Cristy \& Eckerman (1987). Conhecido na literatura como objeto simulador matemático, os órgãos humanos são modelados por meio de equações para representar a anatomia humana, tais como elipses, esferas e cilindros. A composição padrão dos órgãos modelados foi adotada para um homem adulto de acordo com a ICRU (1992) e ICRP110 (2009). A composição do tecido que preenche o tronco humano foi modelado como tecido mole.

O rim esquerdo foi modelado contendo inteiramente uma lesão de CCR, cuja composição foi obtida alterando a composição padrão do tecido renal humano de acordo com a composição do tecido renal saudável e tumoral apresentada em Calvo et al. (2009). Segundo Cohen \& McGovern (2005), lesões de CCR em estágio avançado apresentam um grande volume em comparação com as dimensões do rim. Como exemplo, um CCR diagnosticado com estágio II pode exceder $7 \mathrm{~cm}$ em sua maior dimensão. Logo, o estágio avançado de CCR pode 
ser modelado de forma representativa assumindo o próprio volume do tecido renal. A Tabela 6 apresenta a composição balanceada do tecido renal (saudável e tumoral) modelada.

Tabela 6. Composição (fração em massa \%) dos tecidos renais modelados. As densidades do tecido renal saudável e do CCR foram adotadas como a densidade do rim de um indivíduo adulto (1,05 g/ $\left.\mathrm{cm}^{3}\right)$ (ICRU, 1992).

\begin{tabular}{ccc}
\hline Elemento & $\mathrm{CCR}$ & Tecido renal saudável \\
\hline $\mathrm{Al}$ & $8,10 \mathrm{E}-04$ & $4,60 \mathrm{E}-06$ \\
$\mathrm{C}$ & $1,33 \mathrm{E}+01$ & $1,30 \mathrm{E}+01$ \\
$\mathrm{Ca}$ & $5,10 \mathrm{E}-02$ & $3,30 \mathrm{E}-02$ \\
$\mathrm{Cd}$ & $2,30 \mathrm{E}-04$ & $1,40 \mathrm{E}-03$ \\
$\mathrm{Cl}$ & $2,00 \mathrm{E}-01$ & $2,00 \mathrm{E}-01$ \\
$\mathrm{Cr}$ & $1,30 \mathrm{E}-04$ & $5,00 \mathrm{E}-07$ \\
$\mathrm{Cu}$ & $8,00 \mathrm{E}-04$ & $8,30 \mathrm{E}-04$ \\
$\mathrm{Fe}$ & $2,50 \mathrm{E}-02$ & $3,20 \mathrm{E}-02$ \\
$\mathrm{H}$ & $1,03 \mathrm{E}+01$ & $1,02 \mathrm{E}+01$ \\
$\mathrm{~K}$ & $5,00 \mathrm{E}-03$ & $1,60 \mathrm{E}-02$ \\
$\mathrm{Mg}$ & $6,60 \mathrm{E}-03$ & $9,90 \mathrm{E}-03$ \\
$\mathrm{Mn}$ & $9,80 \mathrm{E}-05$ & $9,20 \mathrm{E}-05$ \\
$\mathrm{~N}$ & $3,00 \mathrm{E}+00$ & $3,00 \mathrm{E}+00$ \\
$\mathrm{Na}$ & $1,00 \mathrm{E}-02$ & $1,60 \mathrm{E}+00$ \\
$\mathrm{O}$ & $7,28 \mathrm{E}+01$ & $7,16 \mathrm{E}+01$ \\
$\mathrm{P}$ & $6,30 \mathrm{E}-02$ & $4,30 \mathrm{E}-03$ \\
$\mathrm{~Pb}$ & $1,70 \mathrm{E}-04$ & $5,00 \mathrm{E}-06$ \\
$\mathrm{~S}$ & $2,00 \mathrm{E}-01$ & $2,00 \mathrm{E}-01$ \\
$\mathrm{Zn}$ & $2,50 \mathrm{E}-02$ & $7,00 \mathrm{E}-06$ \\
\hline & &
\end{tabular}

O protocolo de irradiação adotado para reconstrução tomográfica foi inspirado na primeira geração de tomógrafos. O feixe de nêutrons e detectores foram rotacionados ao redor do objeto simulador em 10 intervalos angulares discretos entre 
$0^{\circ}$ e $180^{\circ}$ com incrementos de $20^{\circ}$. Em cada posição angular, o feixe de nêutrons foi transladado paralelamente por $60 \mathrm{~cm}$ em intervalos de $1 \mathrm{~cm}$ (60 translações) entre os detectores enquanto que estes permaneceram imóveis. Ao final da última translação, o sistema tomográfico foi rotacionado em $20^{\circ}$ até a próxima posição angular, onde os movimentos de translação se repetem.

Uma característica em particular da técnica NSECT é que, como o feixe de nêutrons estimula a emissão pelos elementos que estão no caminho de projeção, a aquisição em $360^{\circ}$ diminui a influência do ruído no sinal detectado, porém, o mesmo se torna redundante após o arco de $180^{\circ}$. Em decorrência desta característica, a dose efetiva e o tempo de irradiação podem ser reduzidos de acordo com o objetivo do protocolo de irradiação, i.e. reconstrução tomográfica com baixa ou alta resolução.

A configuração de aquisição descrita foi utilizada para a irradiação do volume encerrado pelos rins, o que compreende uma altura de $10 \mathrm{~cm}$ do tronco humano. Para cobrir esta altura, o protocolo foi aplicado 10 vezes deslocando o sistema tomográfico ao longo do tronco considerando uma espessura de feixe de 1 cm, totalizando assim 6000 projeções em toda a irradiação (60 translações x 10 rotações x 10 deslocamentos). O sistema tomográfico e o objeto simulador estão imersos em ar e são apresentados na Figura 13. Os espectros de emissão adquiridos foram processados como descrito a seguir. 


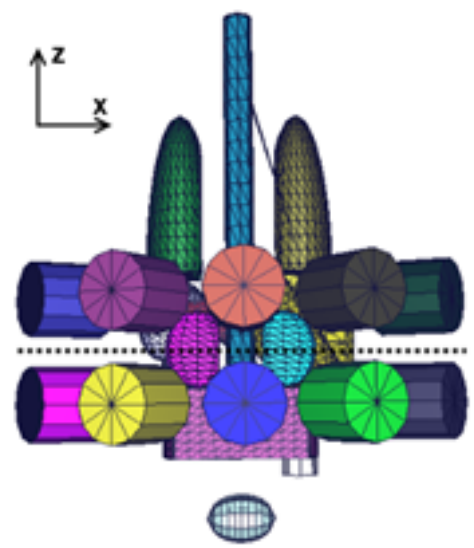

a

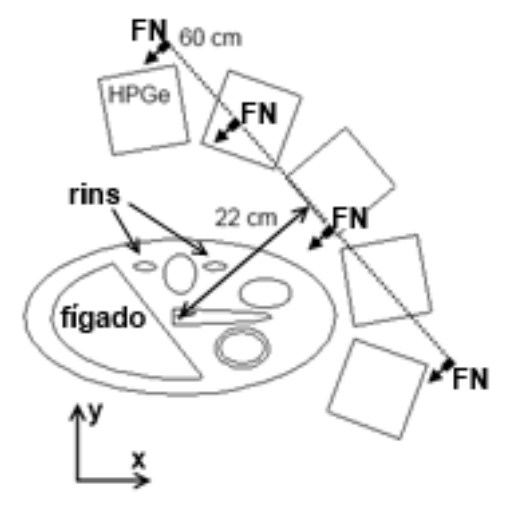

b

Figura 13 - Modelo 3D do objeto simulador e sistema tomográfico (a). A superfície do tronco foi removida para evidenciar a presença dos órgãos modelados. A linha pontilhada entre os detectores corresponde ao caminho de translação do feixe de nêutrons (FN). Modelo 2D do sistema tomográfico quando o mesmo é rotacionado $40^{\circ}$ com relação ao eixo x (b).

Supressão de ruído

Os espectros de emissão adquiridos pelas projeções do feixe de nêutrons são compostos não só pelos fótons produzidos no meio irradiado devido a reação (n,n') mas também por fótons produzidos por interações secundárias tais como: captura radioativa, efeito Compton, produção de pares e outras; além de fótons produzidos pela reação (n,n’) que ocorre nos detectores. Entretanto, os fótons detectados não-relacionados com o meio irradiado e produzidos por interações secundárias são considerados como ruído e estes afetam a sensibilidade da técnica NSECT.

Com o objetivo de reduzir a contribuição do ruído nos espectros adquiridos, a metodologia proposta em Floyd et al. (2007) foi adotada neste estudo. Um meio espalhador composto por água foi modelado à forma do tronco humano juntamente com o sistema tomográfico empregado na aquisição dos espectros de emissão do objeto simulador. O mesmo protocolo de irradiação descrito anteriormente foi empregado e os espectros de emissão adquiridos (espectros de fundo) foram sub- 
traídos dos espectros de emissão do objeto simulador. Dessa forma, o ruído comum entre os espectros (fundo e objeto simulador) é suprimido, tornando predominante a contribuição dos fótons originados pela reação (n,n') a partir do objeto simulador.

Seleção e identificação de elementos de interesse

A seleção dos elementos de interesse no espectro de emissão é dependente de um conhecimento prévio da composição elemental do meio irradiado. Uma vez que a técnica NSECT é fundamentada na assinatura energética dos elementos através das suas energias de estados excitados, a identificação e a quantificação dos elementos presentes no meio irradiado pode ser conduzida identificando os picos de emissão das energias dos estados excitados e suas respectivas alturas de pulso.

A composição descrita na Tabela 6 apresenta a distribuição dos elementos encontrados no tecido renal. Dentre estes, alguns elementos são comumente encontrados nos demais tecidos humanos sem grandes variações em concentração, como exemplo C, N, O e S. Entretanto, existem elementos que se encontram em diferentes concentrações o que permite a diferenciação entre os tecidos renais. De acordo com a composição modelada, os elementos K e Na são encontrados em maior concentração no tecido renal saudável (rim direito) enquanto que P está presente em maior concentração no CCR (rim esquerdo). Esta tendência observada entre as composições foi utilizada para a identificação e diferenciação entre o tecido renal saudável e CCR.

Após a correção dos espectros de emissão para supressão do ruído, as contagens nos canais dos espectros de pulsos referentes as energias dos estados excitados dos elementos $\mathrm{P}, \mathrm{K}$ e $\mathrm{Na}$ foram utilizadas na reconstrução das imagens tomográficas, descritas a seguir. Além dos elementos utilizados para a identificação do tecido renal, os elementos $\mathrm{C}, \mathrm{N}$ e $\mathrm{S}$ foram empregados a fim de reconstruir as relações anatômicas dos órgãos simulados com a lesão de CCR. A Tabela 7 apresenta os isótopos dos elementos utilizados nesta simulação e suas respectivas energias de estado excitado avaliadas nos espectro de emissão (NuDat2.6, 2014). 
Tabela 7. Energias de estado excitado dos isótopos utilizados na identificação dos tecidos renais e reconstrução da anatomia dos tecidos irradiados.

\begin{tabular}{cccc}
\hline Isótopo & \multicolumn{3}{c}{ Energia $(\mathrm{MeV})$} \\
\hline${ }^{32} \mathrm{~S}$ & 1,548 & 2,230 & 4,281 \\
${ }^{31} \mathrm{P}$ & 1,266 & 2,233 & \\
${ }^{39} \mathrm{~K}$ & 2,522 & 2,814 & \\
${ }^{12} \mathrm{C}$ & 4,439 & & \\
${ }^{14} \mathrm{~N}$ & 2,312 & & \\
${ }^{23} \mathrm{Na}$ & 0,440 & & \\
\hline
\end{tabular}

Reconstrução tomográfica

Como mencionado previamente, a altura de pulso dos canais energéticos referentes as energias de estado excitado dos isótopos descritos na Tabela 7 foram utilizados para a reconstrução das imagens tomográficas. Este procedimento foi realizado através da aquisição do perfil espacial de emissão conhecido na literatura como sinograma.

O sinograma possui uma notação matricial $\Im_{m x n}$ onde cada elemento representa a contagem dos eventos gama detectados cuja emissão foi estimulada por uma projeção do feixe de nêutrons localizado na translação $m$ e rotação $n$. Uma vez que a projeção do feixe de nêutrons estimula a emissão de um espectro de fótons, um número finito de sinogramas pode ser adquirido a partir do mesmo conjunto de espectros através da seleção da altura de pulso de acordo com o isótopo de interesse. Este procedimento foi realizado para as energias descritas na Tabela 7, resultando assim na obtenção dos sinogramas para os isótopos selecionados. O espectro da altura de pulso foi discretizado em intervalos de $1 \mathrm{keV}$ para a aquisição dos sinogramas.

Os sinogramas obtidos pelo protocolo de irradiação adotado foram utilizados como dados de entrada pelo algoritmo EM para reconstrução de imagens tomográficas (McLachlan \& Krishnan, 2007). As imagens obtidas foram reconstruídas 
com 128 x 128 pixels considerando 15 iterações do algoritmo e corrigidas para a atenuação do feixe de nêutrons de acordo com a Lei de Beer-Lambert-Bouguer (Agasthya \& Kapadia, 2009). O conjunto de imagens de cada isótopo selecionado foi renderizado utilizando o software MATLAB (Matlab, 2012), resultando na visualização volumétrica dos tecidos irradiados no objeto simulador.

\section{Reconstrução da anatomia renal}

As reconstruções tomográficas obtidas a partir da técnica NSECT fornecem uma informação fisiológica utilizando a composição do meio irradiado através da variação dos valores de pixel na imagem. Entretanto, a menos que a localização do elemento de interesse seja restrita a um órgão específico, as relações anatômicas entre os órgãos irradiados não é preservada. Logo, dependendo da variação de concentração do elemento entre os órgãos, os mesmos podem não ser identificados de forma clara. De acordo com os argumentos apresentados, uma metodologia foi desenvolvida para recuperar a anatomia renal nas imagens dos elementos selecionados neste estudo para a diferenciação entre os tecidos renais: P, K e Na.

Utilizando as mesmas propriedades já descritas das imagens tomográficas obtidas com a técnica NSECT, uma combinação entre as imagens do isótopos ${ }^{12} \mathrm{C},{ }^{32} \mathrm{~S}$ e ${ }^{14} \mathrm{~N}$ foi criada para segmentar a anatomia dos rins onde está inserida a lesão de CCR.

De acordo com a composição dos tecidos modelados, a concentração em massa do isótopo ${ }^{12} \mathrm{C}$ está presente no rim saudável, baço e tecido mole respectivamente em 13,0\%, 11,1\% e 25,6\%. Logo, a distribuição dos valores de pixel na imagem reconstruída representa a concentração do isótopo entre os órgãos irradiados. Analogamente, a inversão dos valores de pixel representa a distribuição complementar da concentração do elemento entre os órgãos. Numericamente, a inversão dos valores de pixel consiste em apresentar o valor complementar, tal que a soma do valor atual e seu complementar resulte no valor de pixel máximo na imagem. Portanto, os rins podem ser identificados diretamente na imagem reconstruída a partir do isótopo ${ }^{12} \mathrm{C}$ 
assim como na sua imagem complementar através da inversão do padrão dos valores de pixel, i.e. para uma imagem em tons de cinza, regiões escuras se tornam claras. As imagens dos elementos ${ }^{32} \mathrm{~S}$ e ${ }^{14} \mathrm{~N}$ foram utilizadas para diminuir a incerteza associado ao procedimento proposto.

As inversões dos valores de pixel foram calculadas para as imagens dos três isótopos selecionados resultando em imagens onde o padrão da distribuição da concentração do elementos está invertida. Posteriormente, as imagens obtidas foram multiplicadas elemento a elemento, resultando em uma imagem composta onde a localização dos rins é naturalmente segmentada. Em seguida, imagens binárias foram obtidas aplicando um limiar aos valores de pixel, resultando na criação de uma máscara 3D utilizada para segmentar os rins nas imagens dos elementos que diferenciam os tecidos renais.

Análise estatística

A distribuição espacial dos valores de pixel nas imagens reconstruídas reflete, de acordo com os fundamentos teóricos da NSECT, a concentração dos elementos selecionados entre os tecidos irradiados. Logo, a análise realizada consiste em avaliar: (i) se a diferença dos valores de pixel são estatisticamente diferentes entre as imagens dos isótopos empregados na identificação dos tecidos renais e (ii) se a tendência de concentração dos isótopos entre os tecidos renais é observada nas imagens reconstruídas.

Para a realização deste teste, após a segmentação dos rins nas reconstruções tomográficas para os elementos $\mathrm{P}, \mathrm{K}$ e Na, três regiões de interesse (ROIs) compostas por $3 \times 3 \times 10$ pixels cada foram aplicadas nas imagens renderizadas. As ROIs foram posicionadas respectivamente nos centros da lesão de CCR e do rim contendo tecido renal saudável e na região abdominal composta por tecido mole. Estas localizações foram adotadas para evitar potenciais efeitos de borda nas interfaces entre órgãos e tecidos.

A distribuição dos valores de pixel contido em cada ROI foi avaliada nas imagens tomográficas reconstruídas a partir dos isótopos ${ }^{31} \mathrm{P},{ }^{23} \mathrm{Na}$ e ${ }^{39} \mathrm{~K}$ utilizando 
o teste $\mathrm{t}$ bi-caudal para diferença de médias $(\alpha=5 \%)$. A comparação entre as ROIs tem por objetivo avaliar a significância estatística da diferença entre as concentrações dos elementos avaliados nos tecidos renais e na região abdominal através dos valores de pixel, eliminando assim a ocorrência de um falso positivo na identificação do RCC. As imagens obtidas para o isótopo ${ }^{32} \mathrm{~S}$ não foram empregadas na análise estatística uma vez que estas não foram utilizadas na diferenciação entre os tecidos renais.

\subsection{Tomografia de emissão estimulada associada com a} informação do tempo de voo do nêutron

Devido a sua potencial aplicação apresentada previamente na Seção 2.1.1, a técnica NSECT associada à informação do tempo de voo do nêutron (Agasthya, 2013) também foi empregada neste estudo utilizando o mesmo sistema tomográfico e objeto simulador já descritos. Entretanto, algumas modificações foram feitas para avaliar propriedades de interesse para a aplicação clínica de acordo com particularidades desta modalidade de aquisição no diagnóstico de CCR, dentre elas, a diminuição da dose efetiva em razão da redução do número de projeções do feixe de nêutrons empregado na aquisição das imagens tomográficas. A seguir são descritas as modificações consideradas nesta nova simulação.

Sistema tomográfico: Na simulação descrita anteriormente, a energia depositada pelos fótons que interagem com os detectores são gravadas e os pulsos gerados são apresentados no espectro de altura de pulsos. Nesta nova simulação, o espectro de emissão deve ser discretizado em energia e tempo, exigindo do sistema de detecção que a energia depositada pelo fóton e seu respectivo tempo de chegada no detector sejam acompanhados durante a simulação. Entretanto, devido a uma limitação do código MCNP5, o cálculo do espectro de altura de pulso não permite a discretização com o tempo. Logo, o fluxo de fótons discretizado em energia e tempo foi calculado nos volumes dos detectores como uma aproximação. 
Outra modificação adotada é relacionada com a composição dos detectores. Como mencionado na Seção 3.5.1.2, devido a sua resolução energética favorável à distinção entre picos no espectro de emissão, os detectores de HPGe são indicados para compor o sistema tomográfico. Entretanto, estes detectores não apresentam a resolução temporal adequada para a modalidade de aquisição simulada. Dessa forma, os detectores foram modelados como sendo ideais, assumindo em sua composição vácuo assim como o meio onde o sistema tomográfico e o objeto simulador estão inseridos. A fonte de nêutrons e os detectores foram modelados assumindo a mesma forma geométrica e disposição ao redor do objeto simulador empregados anteriormente.

Objeto simulador: A composição dos órgãos modelados e da lesão de CCR foram mantidas como descrito na simulação anterior, assim como o objeto simulador. Entretanto, o tamanho da lesão de CCR, inserida no centro do rim esquerdo, foi modificado para assumir a forma de um elipsóide com dimensão 3 x 1 x 4,5 cm. De acordo com Cohen \& McGovern (2005), essa dimensão pode ser considerada representativa para um caso onde o tumor é diagnosticado em seus estágios iniciais.

Quando a técnica NSECT é aplicada utilizando a informação de tempo de voo do nêutron, o tempo de detecção de fótons está associado primariamente com o tempo decorrido entre a emissão de fótons pela reação (n,n') e a interação com os detectores. Esta suposição é feita com base na diferença entre a velocidade de propagação de nêutrons e fótons. Uma vez que a velocidade dos nêutrons incidentes é em torno de uma ordem de grandeza menor que a velocidade de propagação dos fótons, o tempo de chegada para o registro dos fótons emitidos é usado para localizar (em profundidade) o núcleo onde a reação (n,n’) ocorreu ao longo do feixe de nêutrons. Como exemplo deste cálculo, um feixe de nêutrons de $5 \mathrm{MeV}$ tem uma velocidade média de propagação dentro do meio irradiado de aproximadamente 3,125 cm/ns. Logo, considerando a diferença entre a velocidade de propagação do nêutron 
e a velocidade do fóton ( $~ 30 \mathrm{~cm} / \mathrm{hs})$, é assumido que os eventos gama detectados em intervalos de 1 ns foram originados pela reação (n,n') em núcleos separados entre si por 3,125 cm ao longo do caminho de projeção.

Uma consequência direta desta técnica é que, devido a restrição imposta ao tempo de detecção, eventos gama detectados em um tempo superior ao da resolução temporal não são considerados no espectro de emissão. Em outras palavras, devido ao tempo superior de interação envolvido, fótons produzidos pelo espalhamento Compton ou produção de pares são suprimidos ou descartados do espectro de emissão. Desta forma, a supressão de ruído é inerente a esta modalidade de aquisição, não requisitando o pós-processamento do espectro de emissão adquirido.

\section{Imagem tomográfica}

O protocolo de irradiação adotado é similar ao protocolo descrito previamente. Entretanto, diferentemente da simulação anterior, o sistema tomográfico não é rotacionado ao redor do paciente. O feixe de nêutrons monocromático de 5 $\mathrm{MeV}$ e com seção quadrada $1 \mathrm{~cm}^{2}$ foi projetado paralelamente ao eixo y e transladado 10 vezes entre os detectores e sem sobreposição por $10 \mathrm{~cm}$, incidindo diretamente no rim que contém a lesão de CCR. Após a última posição de translação, o sistema tomográfico foi deslocado sete vezes em altura ao longo do tronco humano. O movimento de translação do feixe foi repetido em cada posição de deslocamento, irradiando assim apenas a região compreendida pela lesão de CCR utilizando 70 projeções (10 translações x 7 deslocamentos). A Figura 14 apresenta a região do rim irradiado.

De acordo com os fundamentos da técnica NSECT, a altura dos picos formados nos espectros de emissão detectados é proporcional à concentração dos isótopos de interesse selecionados (Tabela 7). Logo, para cada projeção do feixe é obtido um perfil linear (unidimensional) de concentração ao longo do caminho de interação no objeto simulador com base na amplitude do sinal em cada canal energético do espectro. 


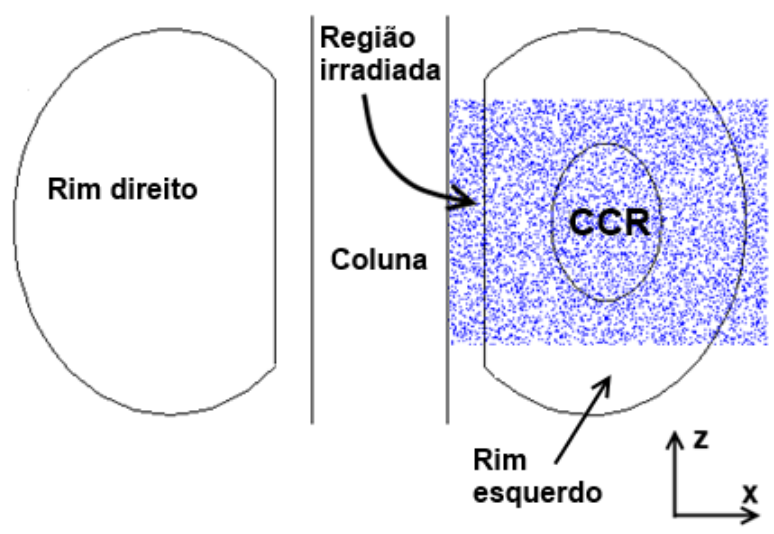

Figura 14 - Lesão de CCR contida no rim. A área sombreada compreende as projeções do feixe de nêutrons empregadas na simulação.

A imagem tomográfica pode ser obtida relacionando os perfis de concentração dos isótopos avaliados com as posições de projeção do feixe. Os espectros de emissão foram discretizados em energia, com intervalos de $1 \mathrm{keV}$, e em tempo, em intervalos de 0,1 ns e 0,3 ns, sendo essa a resolução temporal típica de detectores $\mathrm{LaBr}_{3}$ indicados para esta finalidade (Kuhn et al., 2005).

As imagens formadas dos isótopos avaliados foram renderizadas e submetidas à análise estatística como descrita na simulação anterior. Entretanto, as ROIs foram modificadas para conter apenas o volume da lesão de CCR.

\subsubsection{Otimização da amostragem do sinograma para NSECT}

O protocolo de aquisição do sinograma é de vital importância pois assume um fator decisivo na aplicação da técnica NSECT, uma vez que a taxa de amostragem do sinograma é responsável pela qualidade da imagem reconstruída e também pela energia depositada no meio irradiado.

Desde sua introdução na literatura (Floyd et al., 2006), a técnica NSECT vem sendo aplicada utilizando um número limitado de projeções nas reconstruções tomográficas. Assim como apresentado em Kapadia (2007), imagens tomográficas podem ser adquiridas utilizando apenas oito posições angulares pelo 
sistema tomográfico. Os protocolos de aquisição empregados nesta referência são responsáveis por depositar uma dose efetiva em torno de $0,5 \mathrm{mSv}$ enquanto que a dose efetiva típica de um CT convencional para a aquisição de uma imagem abdominal é 10 - 20 mSv (RSNA, 2014). Entretanto, a visualização de estruturas nas imagens reconstruídas pode ser comprometida devido ao número reduzido de projeções descrito nos protocolos adotados.

Neste estudo é apresentado um método analítico aplicado na otimização dos parâmetros de amostragem do sinograma para a NSECT: largura de projeção (a), espaçamento entre translações (b) e espaçamento entre rotações do feixe de nêutrons (c). Estes parâmetros de amostragem compreendem a configuração básica nos quais os protocolos de aquisição podem ser modificados. Outros fatores secundários como o fluxo de nêutrons e geometria de detecção também podem afetar a qualidade das imagens reconstruídas devido a intensidade do sinal detectado. Entretanto, estes não foram considerados neste estudo. A seguir é descrita a metodologia proposta.

Simulação das reconstruções tomográficas das imagens de referência

As imagens de referência empregadas pelo método proposto devem representar a composição elemental do meio simulado para cada elemento de interesse selecionado. Para satisfazer essa condição, a concentração dos elementos deve ser fielmente representada através dos valores de pixel distribuídos nas imagens. As imagens de referência adotadas neste estudo foram obtidas a partir da seção transversal do tronco humano modelado pelo objeto simulador proposto por Cristy \& Eckerman (1987). Os seguintes órgãos/tecidos podem ser identificados na seção do tronco humano selecionado: coluna, fígado, rins, baço, estômago e vesícula biliar.

Motivado por estudos apresentados por Kapadia et al. (2008) e Agasthya et al. (2012), três lesões contendo a composição de hemocromatose hepática (sobrecarga de ferro no fígado) também foram inseridas no fígado modelado. As lesões foram modeladas como esferas de 1, 2 e $3 \mathrm{~cm}$ de diâmetro contendo respectivamente 2, 1 e 0,2 \% em massa de ferro. As concentrações adotadas são de relevância 
clínica para o diagnóstico da patologia em questão e foram posicionadas na mesma altura da seção do tronco humano selecionado.

Os seguintes elementos foram selecionados para análise neste estudo: C, Na, Fe e Mg. A Tabela 8 apresenta a distribuição da concentração dos elementos avaliados entre as estruturas anatômicas da seção do tronco humano. A composição do tecido que preenche o tronco foi modelado como tecido mole. Todas as composições estão de acordo com a ICRU (1992) e ICRP110 (2009).

Tabela 8. Composição (fração em massa \%) dos elementos avaliados utilizados para criar as imagens de referência. As localizações dos tecidos estão devidamente identificadas na Figura 15.

\begin{tabular}{ccccccc}
\hline Tecido & Identificação & $\mathrm{C}$ & $\mathrm{Na}$ & $\mathrm{Fe}$ & $\mathrm{Mg}$ & Densidade $\left(\mathrm{g} / \mathrm{cm}^{3}\right)$ \\
\hline Tecido mole & 1 & 25,6 & 0,1 & - & - & 1,03 \\
Fígado & 2 & 13,9 & 0,2 & - & - & 1,06 \\
Rins & 3 & 12,4 & 0,2 & - & - & 1,05 \\
Coluna & 4 & 15,5 & 0,1 & - & 0,2 & 1,92 \\
Baço & 5 & 11,1 & 0,1 & 0,1 & - & 1,04 \\
Parede do estômago & 6 & 11,4 & 0,1 & - & - & 1,04 \\
Conteúdo do estômago & 7 & 22,2 & 0,1 & - & - & 1,04 \\
Vesícula biliar & 8 & 17,0 & 0,1 & 0,1 & - & 1,03 \\
Lesão de hemocromatose & 9 & 13,9 & 0,2 & 1,0 & - & 1,06 \\
Lesão de hemocromatose & 10 & 13,9 & 0,2 & 0,2 & - & 1,06 \\
Lesão de hemocromatose & 11 & 13,9 & 0,2 & 2,0 & - & 1,06 \\
\hline
\end{tabular}

A dispersão dos valores de pixel nas quatro imagens de referência adquiridas representam reciprocamente a variação da concentração dos elementos no meio simulado, neste estudo, a seção do tronco humano. A Figura 15 apresenta a geometria do tronco humano selecionada e as imagens de referência obtidas para os elementos $\mathrm{C}$ e Fe. 


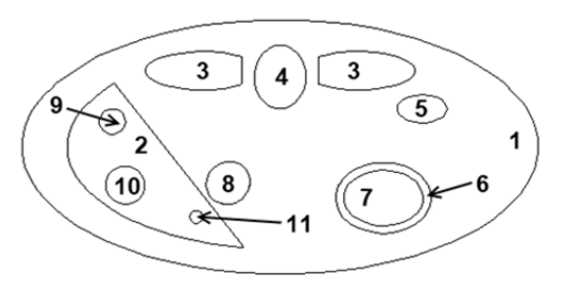

a

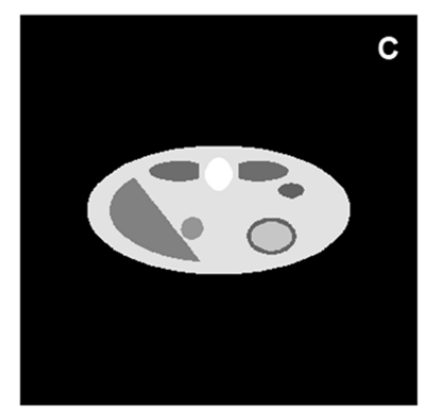

b

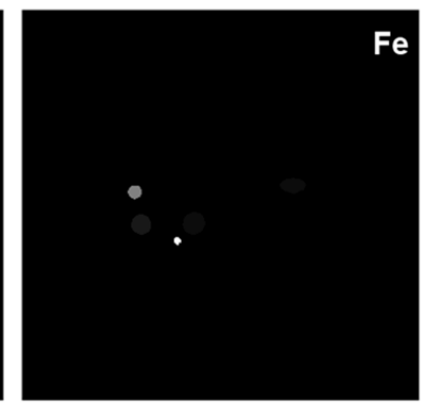

C

Figura 15 - Geometria do tronco humano (a) utilizadas para criar as imagens de referência respectivamente para C (b) e Fe (c). A variação dos valores de pixel refletem a distribuição da concentração dos elementos apresentada na Tabela 8 .

Protocolos de aquisição

A abordagem analítica descrita nesta metodologia consiste em aplicar a Transformada de Radon (TR) nas imagens de referência obtidas. Por definição, a TR calcula a integral de linha avaliada nos valores de pixel da imagem ao longo de projeções lineares, tal que quanto maior o valor numérico do pixel na imagem, maior o valor calculado pela TR. Analogamente à técnica NSECT, a intensidade dos fótons emitidos é diretamente proporcional à concentração do elemento avaliado presente no caminho do feixe de nêutrons. Desconsiderando a atenuação e espalhamento de fótons, a TR foi utilizada como método para simular os sinogramas adquiridos pela técnica NSECT, uma vez que ambas as técnicas possuem características em comum.

As quatro imagens de referência que representam a distribuição dos elementos $\mathrm{C}$, Fe, $\mathrm{Na}$ e Mg foram amostradas pela TR considerando 54 combinações entre projeções e rotações. As posições angulares de projeção foram avaliadas para seis incrementos entre $0^{\circ}$ e $360^{\circ}: 5^{\circ}, 10^{\circ}, 15^{\circ}, 20^{\circ}, 25^{\circ}$ e $30^{\circ}$. As posições de translação foram estabelecidas com base na largura de projeção para 2, 1, 0,5 e 0,25 cm. Os protocolos de amostragem obtidos neste estudo representam um cenário realístico na qual a NSECT pode ser aplicada em sua implementação real. 
De acordo com a configuração de amostragem (translação x projeção) inspirada na primeira geração de tomógrafos na qual a NSECT é baseada, a subamostragem do sinograma é uma característica inerente assim como a presença de artefatos de reconstrução. Segundo Joseph et al. (1980), a taxa de amostragem pode ser elevada considerando a sobreposição entre projeções, o que resulta na supressão de ruído no sinal detectado. Logo, as projeções com $2 \mathrm{~cm}$ de largura foram também amostradas nas imagens de referência com 1 e 0,5 cm de sobreposição, enquanto que as demais larguras foram amostradas com a sobreposição de suas respectivas meias larguras. As larguras de projeção adotadas também foram amostradas linearmente sem sobreposição, totalizando 9 configurações de translação avaliadas. A Tabela 9 resume as configurações de amostragem de translação empregadas nos protocolos de aquisição pela TR. Cada configuração de translação apresentada foi aplicada nas seis amostragens das posições angulares.

Tabela 9. Configuração de translação dos sinogramas adquiridos pela TR utilizando as imagens de referência. O símbolo '-' corresponde à configuração onde não há sobreposição entre projeções.

\begin{tabular}{ccc}
\hline Identificação & Largura de projeção $(\mathrm{cm})$ & Sobreposição $(\mathrm{cm})$ \\
\hline Configuração 1 & 2,00 & - \\
Configuração 2 & 2,00 & 1,000 \\
Configuração 3 & 2,00 & 0,500 \\
Configuração 4 & 1,00 & - \\
Configuração 5 & 1,00 & 0,500 \\
Configuração 6 & 0,50 & - \\
Configuração 7 & 0,50 & 0,250 \\
Configuração 8 & 0,25 & - \\
Configuração 9 & 0,25 & 0,125 \\
\hline
\end{tabular}

Os sinogramas obtidos pelos protocolos avaliados foram utilizados como dados de entrada pelo algoritmo EM para reconstrução de imagens tomográficas 
(McLachlan \& Krishnan, 2007). As imagens obtidas foram reconstruídas com 128 x 128 pixels considerando 15 iterações do algoritmo.

Análise das imagens: similaridade entre as imagens reconstruídas e a imagem de referência

As imagens tomográficas obtidas a partir dos protocolos de aquisição simulados com a TR foram comparadas com suas respectivas imagens de referência para os quatro elementos selecionados. A comparação entre as imagens foi conduzida utilizando o nível de similaridade entre as imagens obtido pelo cálculo da Informação Mútua Normalizada (IMN) (Studholme et al., 1999).

A IMN foi desenvolvida originalmente para o registro de imagens. Sem perda de generalidade, duas imagens podem ser fundidas tal que regiões similares são sobrepostas. Com o resultado, a imagem obtida neste procedimento possui informações compartilhadas pelas imagens originais. Uma descrição contendo mais informações sobre a IMN é fornecida no Apêndice D.

No estudo proposto, a similaridade entre a imagem de referência e as reconstruções tomográficas obtidas a partir dos diferentes protocolos de amostragem foi calculada para cada elemento selecionado. Dessa forma, a presente análise propõe a avaliação da qualidade de reconstrução em função da similaridade entre as imagens tomográficas e a imagem ideal (imagem de referência) que representa o meio irradiado. A Figura 16 apresenta um exemplo do cálculo da IMN em função da taxa de amostragem de sinogramas.

De acordo com a teoria de registro de imagens, quanto maior o nível de similaridade entre o par de imagens comparadas, maior o valor calculado pela IMN. Em outras palavras, quanto maior o valor da IMN, mais fidedigna é a imagem reconstruída com relação a imagem de referência. Considerando apenas a inspeção visual nas Figuras 16 (b) e (c), nota-se que a similaridade entre as reconstruções comparadas é dependente da amostragem do sinograma utilizado. Esse comportamento é verificado pelo cálculo da IMN. 

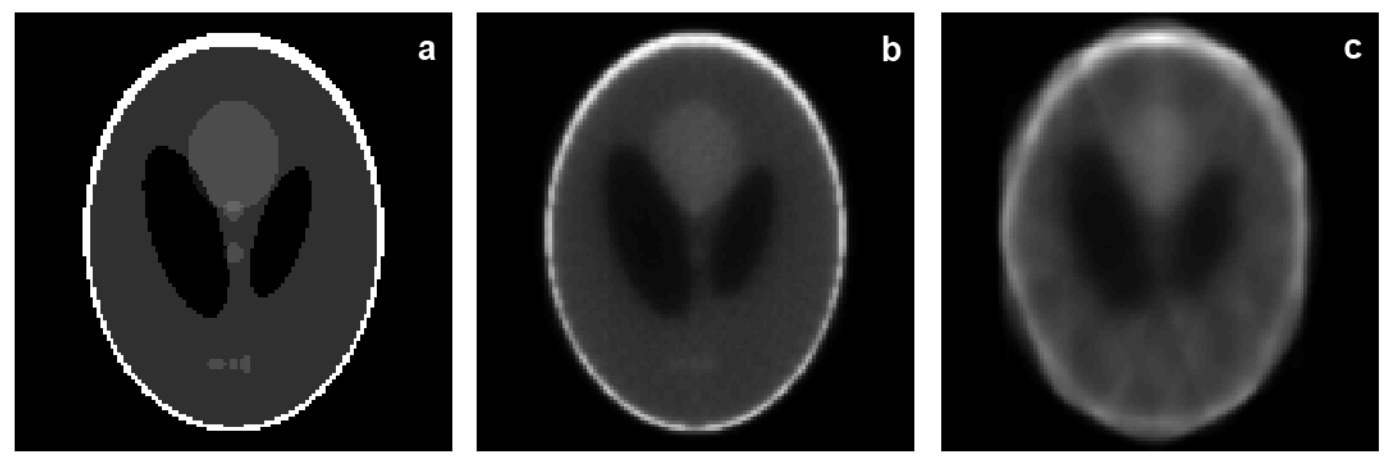

Figura 16 - Imagem de referência (a) utilizada para reconstrução tomográfica com super amostragem (b) e subamostragem (c). O valor obtido pela IMN quando os pares de imagem a/b é 1,42 enquanto que a/c resulta em 1,35.

Além de otimizar os protocolos de aquisição com base na qualidade de reconstrução, o nível de similaridade entre as imagens pode ser selecionado tal que a dose efetiva associada ao protocolo de irradiação não ultrapasse um limiar definido. Ambas as abordagens foram empregadas neste estudo.

\section{Validação do método}

O método proposto neste estudo foi validado utilizando simulações realizadas com o código MCNP5. O tronco humano proposto por Cristy \& Eckerman (1987) foi modelado juntamente com o sistema de tomográfico descrito previamente

na Seção 3.5.2.1, incluindo a composição dos detectores e tecidos humanos (ICRU, 1992).

A mesma seção transversal do tronco humano utilizado para a aquisição das imagens de referência foi irradiada por um feixe monocromático de $5 \mathrm{MeV}$. Os sinogramas foram adquiridos utilizando os protocolos aplicados na TR através da seleção das energias de estado excitado dos isótopos que identificam os elementos de interesse, sendo eles: $\mathrm{C}, \mathrm{Na}, \mathrm{Fe}$ e $\mathrm{Mg}$. A espessura de feixe foi mantida em $1 \mathrm{~cm}$ para todas as larguras modeladas. A Tabela 10 mostra a energia dos isótopos selecionados (NuDat2.6, 2014). Após a aquisição dos sinogramas, a técnica de supressão de ruído foi aplicada como descrito na seção anterior (Floyd et al., 2007). 
Tabela 10. Energias de estado excitado dos isótopos selecionados para a validação do método proposto.

\begin{tabular}{ccc}
\hline Isótopo & Energia & $(\mathrm{MeV})$ \\
\hline${ }^{12} \mathrm{C}$ & 4,438 & \\
${ }^{23} \mathrm{Na}$ & 0,440 & \\
${ }^{56} \mathrm{Fe}$ & 0,846 & 1,238 \\
${ }^{24} \mathrm{Mg}$ & 1,368 & 2,754 \\
\hline
\end{tabular}

As imagens da seção do tronco humano irradiado foram reconstruídas para os elementos selecionados utilizando os sinogramas processados. Posteriormente, a similaridade entre as imagens tomográficas reconstruídas e suas respectivas imagens de referência para os elementos descritos na Tabela 8 foram avaliadas através do cálculo da IMN. 


\section{RESULTADOS E DISCUSSÃO}

Nesta seção são apresentados e discutidos os resultados obtidos em decorrência da metodologia empregada. Para a melhor compreensão dos objetivos propostos, será adotada a classificação dos resultados de acordo com as abordagens da técnica NSECT, como descrito na Seção 3.5, sendo elas: espectroscopia e imageamento. A avaliação dosimétrica é apresentada de acordo com as abordagens adotadas.

\subsection{Espectroscopia}

\subsubsection{Espectroscopia de emissão estimulada empregada na avaliação de microcalcificações associadas ao câncer de mama}

Como descrito na Seção 3.5.1.1, duas abordagens foram propostas para se avaliar o espectro de emissão do tecido mamário em função da presença de microcalcificações associadas ao desenvolvimento do câncer de mama. Bender et al. (2007) apresenta uma metodologia similar utilizando a NSECT para a detecção do câncer de mama explorando a variação da própria composição entre os tecidos mamários (saudável e tumor). Entretanto, mesmo apresentando características favoráveis para a aplicação na NSECT, tais como densidade superior à densidade do tecido mole e elevada seção de choque para a reação (n,n’) para o isótopo ${ }^{40} \mathrm{Ca}$, o desenvolvimento de microcalcificações não foi explorado até então através da análise do espectro de emissão.

Na primeira abordagem, 14 microcalcificações foram modeladas como esferas cujos diâmetros variam entre 1 e 14 mm e inseridas individualmente no centro 
da mama modelada assumindo as composições químicas da hidroxiapatita e do oxalato de cálcio respectivamente com as densidades $3,15 \mathrm{~g} / \mathrm{cm}^{3}$ e 2,20 g/ $\mathrm{cm}^{3}$. Foram adquiridos 14 espectros de emissão para cada composição de microcalcificação. Em cada espectro foram selecionados as alturas de pulso referentes às energias de emissão do isótopo ${ }^{40} \mathrm{Ca}$. A Figura 17 apresenta os perfis de contagem obtidos para os espectros de emissão normalizados pela energia de captura radioativa no hidrogênio $(2,22$ $\mathrm{MeV})$.
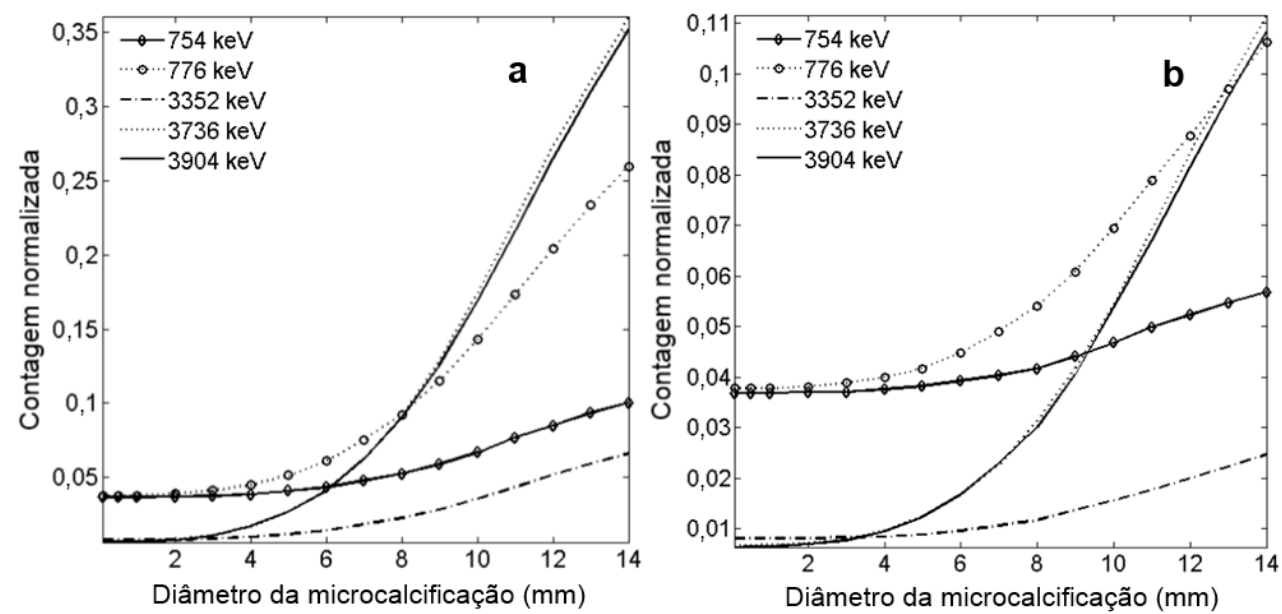

Figura 17 - Contagens normalizadas em função do diâmetro de microcalcificações para a composição de hidroxiapatita (a) e oxalato de cálcio (b). As energias dos fótons selecionados são emitidas pelo isótopo ${ }^{40} \mathrm{Ca}$ (Viana \& Yoriyaz, 2011).

Como esperado, a primeira característica claramente observável nos perfis de emissão adquiridos é a dependência da altura de pulso com a composição das microcalcificações. Isto se deve à diferença entre as densidades modeladas e a proporção dos átomos de Ca entre as formulações químicas da hidroxiapatita e do oxalato de cálcio (10:1).

A segunda característica é a tendência observada entre o diâmetro das microcalcificações e a altura de pulso detectada. Devido as propriedades de emissão da técnica NSECT, a intensidade do sinal é proporcional à quantidade de nuclídeos 
presentes no caminho de interação do feixe de nêutrons. Logo, é possível estabelecer um limiar de detecção em função do tamanho da microcalcificação modelada. Considerando as condições de simulação modeladas, o limiar de detecção obtido referente à inclinação dos perfis de emissão é $3 \mathrm{~mm}$ para as duas composições químicas modeladas. Como prova conceitual, a partir deste diâmetro, a contribuição de contagens dos fótons emitidos pelo isótopo ${ }^{40} \mathrm{Ca}$ é crescente em função do aumento do diâmetro da microcalcificação.

De acordo com a literatura, o reconhecimento de lesões malignas através de métodos invasivos é determinado por características químicas e morfológicas enquanto que a mamografia é o método não-invasivo mais empregado para este diagnóstico. Entretanto, assim como a mamografia, o emprego de outros métodos não-invasivos como o ultrassom de alta frequência tem como limitação o próprio tamanho das lesões (Moon et al., 2000). Como método auxiliar, devido a relação apresentada entre a dependência da composição química da microcalcificação com o desenvolvimento da câncer de mama, o diagnóstico pode ser efetuado através da análise da altura de pulso do espectro de emissão explorando a diferença de contagens através de espectros de referência (mama saudável), uma vez que microcalcificações com oxalato de cálcio são predominantemente associadas com tumores benignos.

Assim como na primeira abordagem onde o diâmetro da microcalcificação é relacionado com a altura de pulso para as energias que identificam a presença do isótopo ${ }^{40} \mathrm{Ca}$, a segunda abordagem contempla um caso clínico para a detecção de um agrupamento contendo 16 microcalcificações esféricas de hidroxiapatita com diâmetros variando entre 0,15 e 1,40 mm. Como apontado na abordagem anterior, é observado um aumento das contagens para as energias selecionadas a partir de lesões isoladas na mama com diâmetro superior a $3 \mathrm{~mm}$. Neste estudo, a presença de conjunto de microcalcificações é detectado no espectro de emissão quando comparado com o espectro da mama saudável sem a presença de microcalcificações. Os espectros obtidos são apresentados na Figura 18. 


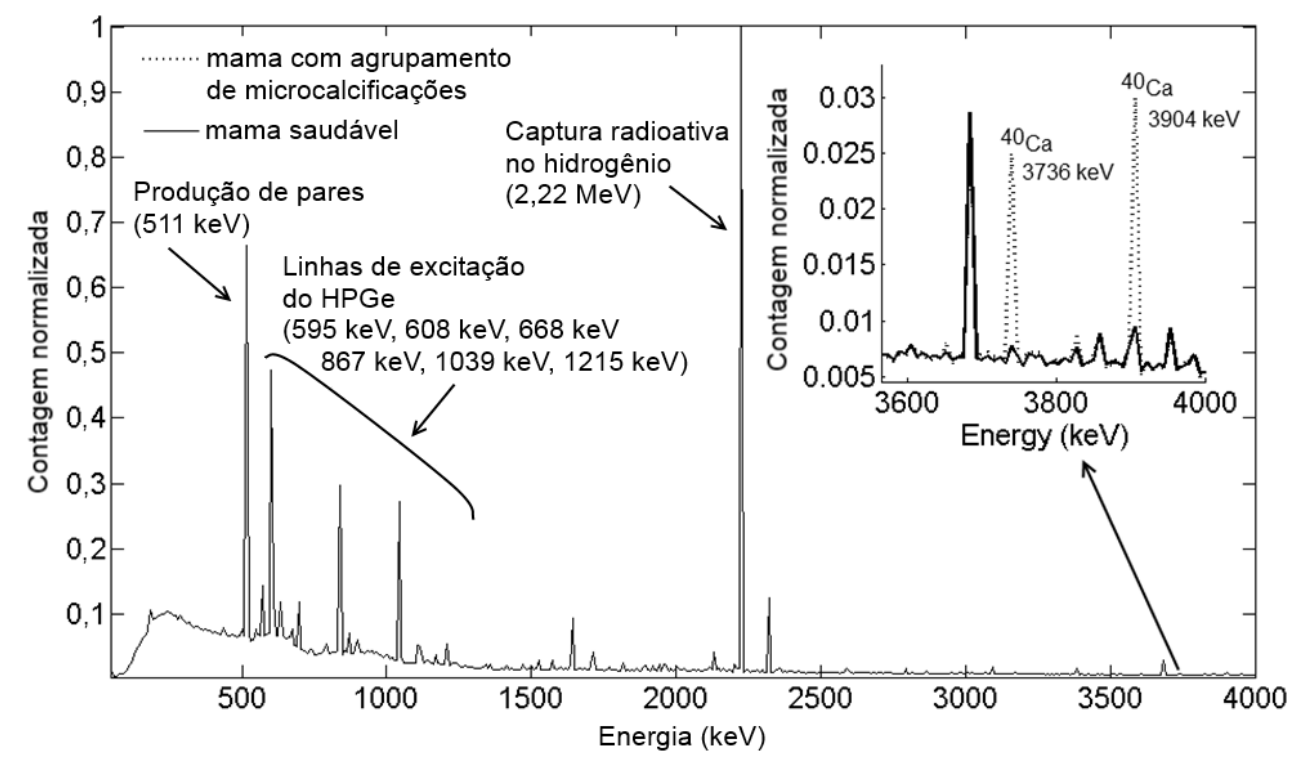

Figura 18 - Espectros de emissão de fótons da mama saudável e da mama com agrupamento de microcalcificações. A região do espectro entre $3600 \mathrm{keV}$ e $4000 \mathrm{keV}$ é ampliada para a visualização dos picos de ${ }^{40} \mathrm{Ca}$ (Viana \& Yoriyaz, 2011). Alguns picos são identificados no espectro a partir da energia de emissão: produção de pares, captura radioativa no hidrogênio e espalhamento inelástico nos detectores HPGe.

Assim como observado na primeira abordagem, a presença de microcalcificações altera a concentração local de cálcio da mama devido ao aumento da concentração isotópica de ${ }^{40} \mathrm{Ca}$. Quando os espectros adquiridos são comparados, a diferença entre os tecidos irradiados se torna evidente para os picos que identificam a presença de cálcio. Logo, a espectroscopia da mama aponta o desenvolvimento de microcalcificações com diâmetros inferiores ao limite observado para a detecção de microcalcificações isoladas (3 mm). Dessa forma, a espectroscopia do tecido mamário com agrupamento de microcalcificações pode apontar mudanças, consideradas precoces devido ao tamanho da lesão $\sim 0,15 \mathrm{~mm}$, na concentração de cálcio mesmo para lesões com diâmetro inferior a 1,40 mm. 


\subsubsection{Dosimetria}

A dose depositada (Gy) para a análise espectroscópica descrita foi calculada considerando uma intensidade de fonte de $10^{5} \mathrm{n} / \mathrm{s}$, o que de acordo com Agasthya (2013), é a intensidade típica de um feixe de nêutrons monocromático produzido por um acelerador tandem Van-de-Graaf. Utilizando a metodologia descrita previamente na Seção 3.4, a taxa de dose média absorvida na mama foi calculada em $7,410^{-5} \mathrm{mGy} / \mathrm{s}$ com um erro relativo associado de $3 \%$.

Segundo Kapadia et al. (2008), o espectro de emissão para NSECT pode ser adquirido utilizando um total de $10^{7}$ nêutrons emitidos pela fonte o que implicaria em um tempo de exposição de 100 segundos ( 1,6 minutos), desconsiderando os efeitos da eficiência da geometria de detecção entre os sistemas de espectroscopia modelados. Logo, a dose depositada resultante nesta abordagem seria de $7,410^{-3} \mathrm{mGy}$.

Outro cenário abordado nesta avaliação dosimétrica é dependente de uma comparação realizada entre a taxa de dose depositada calculada e a dose média glandular para mamografia recomendada pela ACR (1999) em 3 mGy. De acordo com os resultados obtidos, seriam necessários aproximadamente 11,5 horas para que o limite de dose estabelecido fosse ultrapassado, o que tornaria a espectroscopia impraticável. Entretanto, o tempo de exposição poderia ser reduzido para $\sim 7$ minutos se empregado uma intensidade de $10^{7} \mathrm{n} / \mathrm{s}$ comum em geradores de nêutrons encontrados comercialmente (Kapadia, 2007). Dessa forma, a espectroscopia se tornaria viável sob o ponte de vista do posicionamento e conforto do paciente além de reduzir a incerteza do espectro detectado devido ao número de nêutrons emitidos pela fonte (4,2 $10^{9}$ nêutrons). 


\subsubsection{Avaliação experimental da composição de CCR utilizando a espec- troscopia de emissão estimulada}

A técnica NSECT é fundamentada na reação (n,n') onde os elementos que compõem os meio irradiado são identificados através das suas respectivas energias de excitação. Neste estudo, os espectros de emissão de duas amostras contendo CCR (PA2 T) e tecido renal saudável (PA2 H) foram avaliadas de acordo com a metodologia descrita na Seção 3.5.1.2.

O procedimento descrito para supressão de ruído consiste em reduzir a contribuição de contagens no espectro de emissão não relacionadas com a emissão de fótons pelo meio irradiado através da reação (n,n'). Dentre eles, a metodologia adotada contempla a supressão de fótons produzidos pelo efeito Compton assim como fótons produzidos pela reação (n,n') nos detectores por nêutrons espalhados.

O espectro de fundo foi adquirido sem a presença das amostras na posição de irradiação e posteriormente foi subtraído dos espectros de emissão das amostras. Como exemplo do procedimento descrito, a Figura 19a apresenta o espectro corrigido a partir da subtração dos espectros de fundo e da amostra PA2 H (Figura 19b). Os picos que identificam as energias $511 \mathrm{keV}$ e 2,22 MeV referentes respectivamente à produção de pares e captura radioativa no hidrogênio são claramente identificados no espectro de fundo.

Posteriormente, o espectro obtido foi processado para a supressão de ruído residual devido ao efeito Compton inerente ao detectores. Este procedimento foi realizado através de um ajuste gaussiano que modela o efeito exponencial para a deposição de contagens para baixas energias. A Figura 19c apresenta o ajuste realizado a partir do espectro corrigido para supressão de ruído utilizando o espectro de fundo. Como resultado deste procedimento, é possível identificar os picos no espectro de emissão predominantemente relacionados com as composições das amostras irradiadas, Figura 19d. 


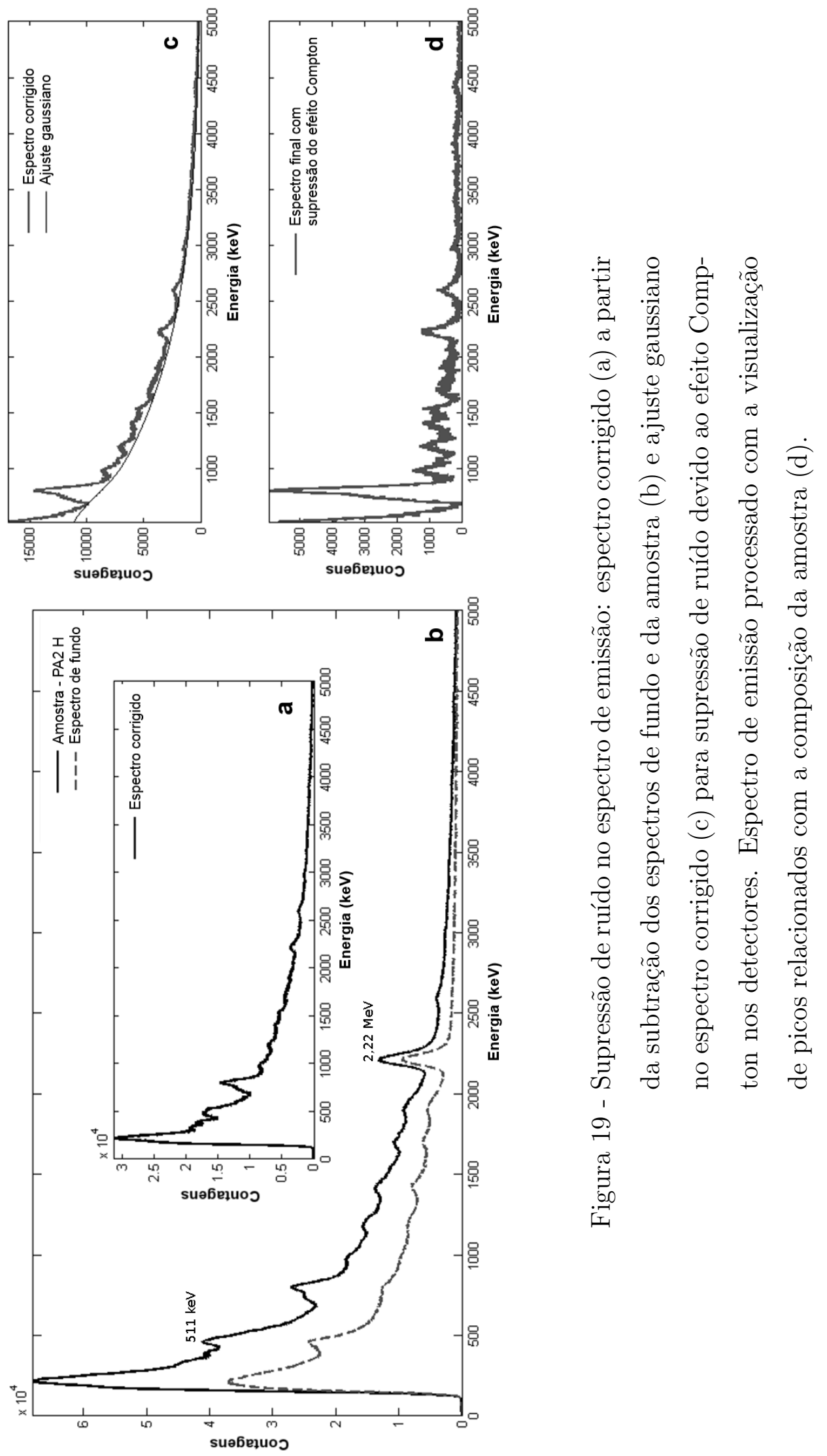


Após o processamento dos espectros de emissão das amostras para supressão de ruído, os picos presentes nos espectros obtidos foram reconstruídos utilizando um Modelo de Misturas Gaussianas (MMG). Com o objetivo de evitar a reconstrução de ruído nos espectros devido ao overfitting, i.e. as flutuações estatísticas não são distinguidas pelo modelo estatístico, 150 funções gaussianas foram empregadas pelo MMG de acordo com o Critério de Informação Bayesiano (Bayesian Information Criterion - BIC) (Schwarz, 1978). De acordo com este critério, o MMG contém o número mínimo de graus de liberdade (parâmetros a serem estimados) que descrevem o comportamento modelado. A Figura 20 apresenta o MMG aplicado no espectro da amostra PA2 H processado para supressão de ruído.

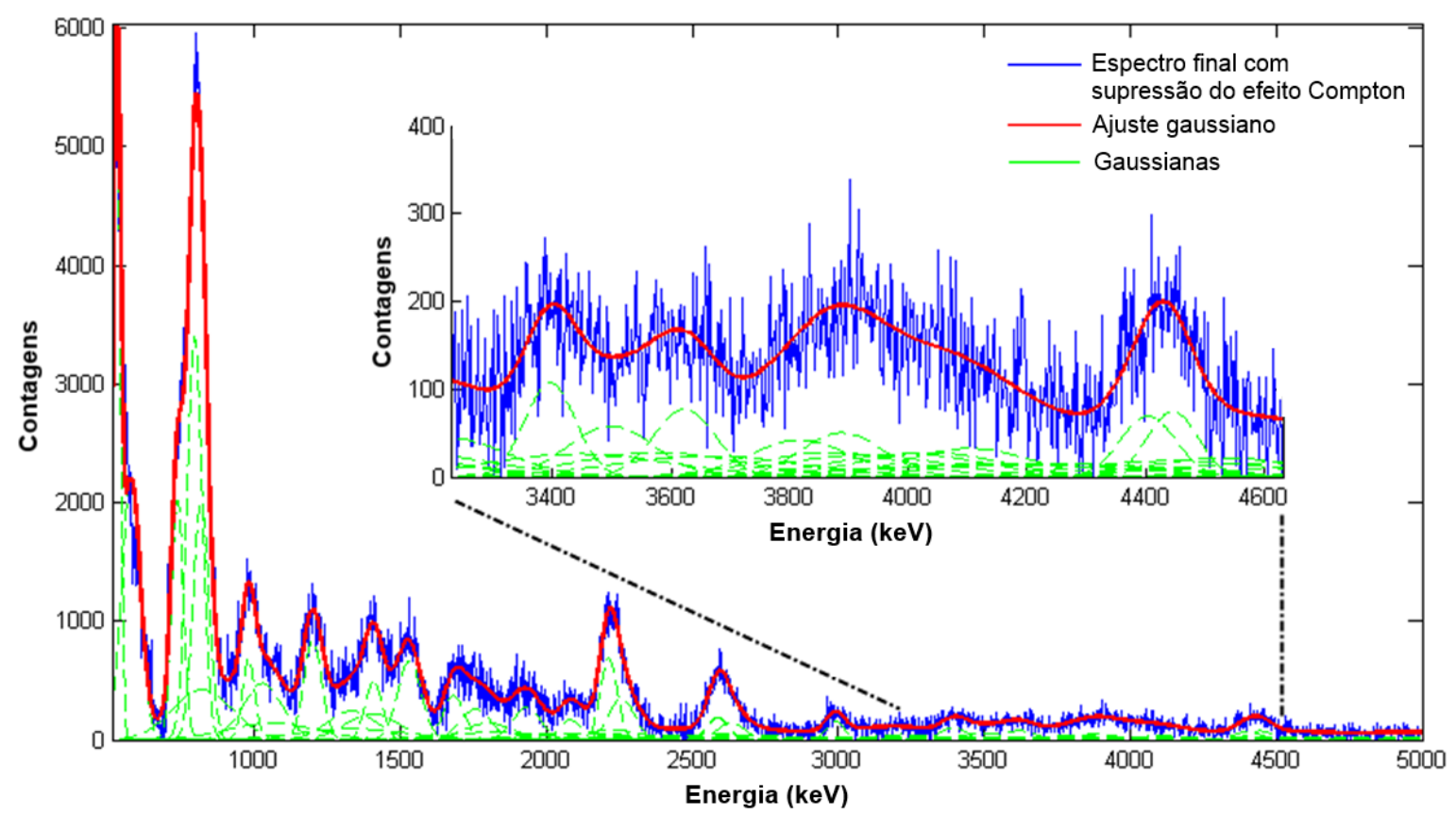

Figura 20 - Reconstrução dos picos no espectro de emissão através do MMG.

Como observado, o alargamento dos picos reconstruídos é reconhecido pelo MMG de acordo com a combinação de funções gaussianas adotadas mesmo para picos de energias próximas. Essa característica é exemplificada na região amplificada entre as energias $3400 \mathrm{keV}$ e $4600 \mathrm{keV}$ na Figura 20. As energias dos picos 
reconstruídos foram então comparadas com as energias que identificam os elementos presentes nas amostras irradiadas de acordo com a composição apresentada na Tabela 4. Entretanto, devido ao limite de detecção do sistema de espectroscopia, apenas os elementos $\mathrm{P}$ e Ca foram identificados através dos seus isótopos ${ }^{31} \mathrm{P}$ e ${ }^{40} \mathrm{Ca}$. Os elementos $\mathrm{C}, \mathrm{Cl}, \mathrm{N}$, e $\mathrm{S}$ também foram identificados nos espectros processados através de suas energias de excitação (NuDat2.6, 2014) mesmo não sendo observados durante a análise da composição elementar das amostras realizada com a técnica PIXE. A Figura 21 apresenta os elementos identificados nos espectros processados das duas amostra de tecido renal (PA2 T e PA2 H).

Devido a resolução energética dos detectores $\mathrm{LaBr}_{3}(\mathrm{Ce})$ empregados no experimento, picos com energias próximas foram reconstruídos como um único pico ou foram quase sobrepostos. Essa característica pode ser observada nos espectros de emissão das amostras em torno das energias 1,7 MeV, 2,2 MeV e 3,9 MeV.

A principal contribuição de contagens para eventos gama no pico identificado próximo a 2,2 MeV é a captura radioativa no hidrogênio em 2224 keV devido a presença de polietileno utilizado para colimar o feixe de nêutrons. Outras energias também foram reconhecidas através dos fótons emitidos pelos isótopos ${ }^{32} \mathrm{~S},{ }^{31} \mathrm{P}$ e ${ }^{14} \mathrm{~N}$ respectivamente para as energias $2230 \mathrm{keV}, 2233 \mathrm{keV}$ e $2312 \mathrm{keV}$. Como observado, estas quatro energias foram reconstruídas como um único pico alargado impossibilitando sua discretização.

Ainda, devido a proximidade entre as energias detectadas e a amplitude dos pulsos criados, a convolução no espectro resultou na reconstrução de picos onde não há uma distinção clara entre as energias dos elementos emissores, como observado para ${ }^{14} \mathrm{~N},{ }^{35} \mathrm{Cl},{ }^{40} \mathrm{Ca}$ e o pico de escape do ${ }^{12} \mathrm{C}$ respectivamente em $1635 \mathrm{keV}, 1763$ keV, $3904 \mathrm{keV}$ e $3931 \mathrm{keV}$. 

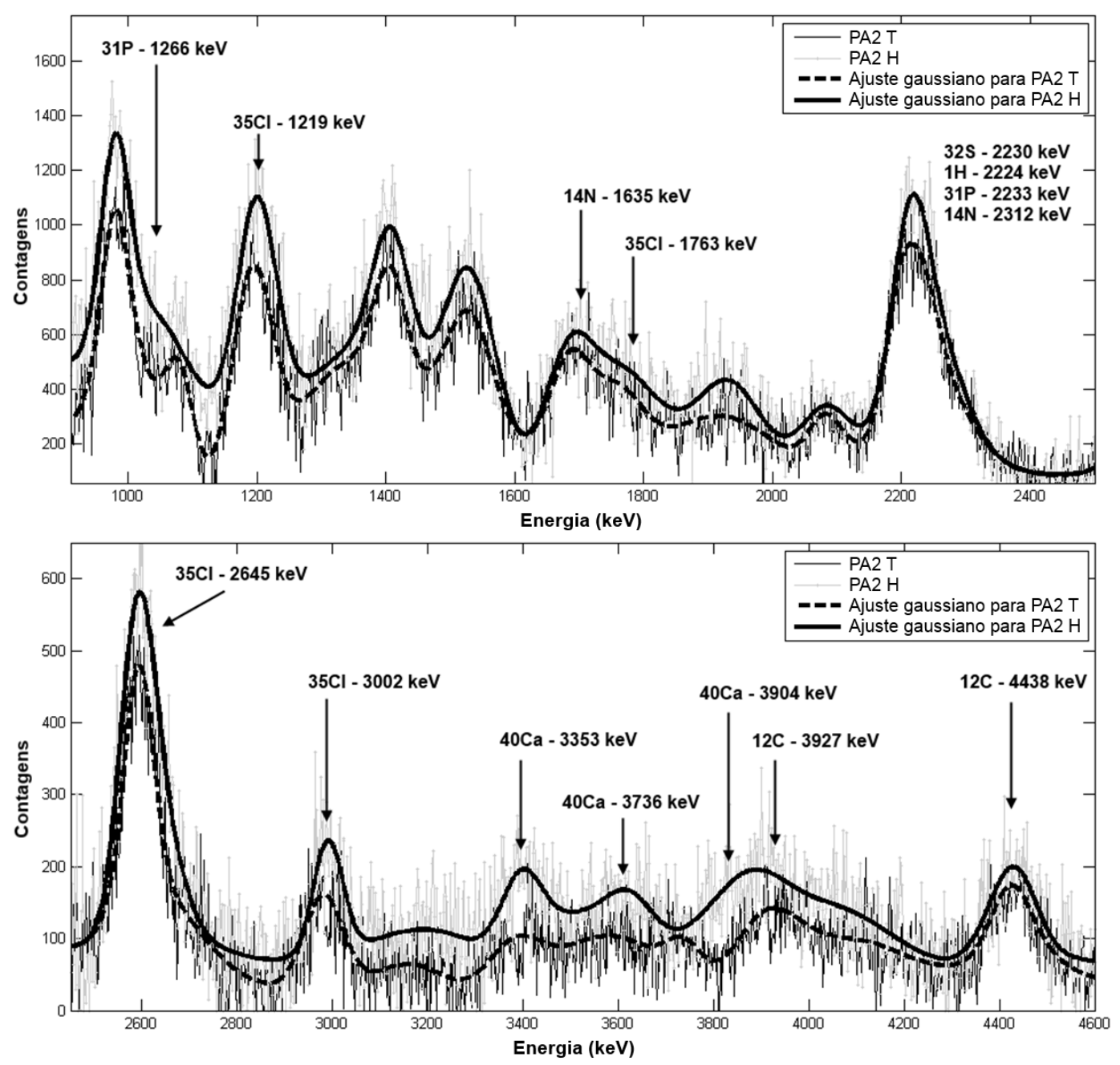

Figura 21 - Picos identificados no espectro de emissão das amostras PA2 T e PA2 H. Os picos identificados para os elementos Ca e P estão em concordância com a composição das amostras irradiadas de acordo com a Tabela 4.

As alturas de pulso dos picos identificados nos espectros de emissão foram utilizadas para a diferenciação das amostras irradiadas. Em particular, os picos referentes aos elementos Ca e P recebem uma atenção especial nesta análise uma vez que os mesmos foram apontados na Tabela 4 como possíveis indicadores biológicos devido a diferença de concentração entre as amostras. As contagens obtidas nos picos identificados foram comparadas entre os espectros das amostras através do teste $t$ bi-caudal para diferença de médias $(\alpha=5 \%)$. A Tabela 11 resume os valores obtidos 
nesta análise.

Tabela 11. Elementos identificados nas amostras de tecido renal (PA2 H e PA2 T) irradiadas e comparação das alturas de pulso dos picos reconstruídos entre os espectros. O valor médio $\bar{x}$ das contagens e o desvio padrão da média $s$ calculado como a raiz quadrada das contagens são apresentados.

\begin{tabular}{cccccc}
\hline Elemento & Energia $(\mathrm{keV})$ & p-valor & $\bar{x} \pm \mathrm{s}(\mathrm{PA} 2 \mathrm{H})$ & $\bar{x} \pm \mathrm{s}(\mathrm{PA} 2 \mathrm{~T})$ & $\frac{\bar{x}_{P A 2 H}}{\bar{x}_{P A 2 T}}$ \\
\hline $\mathrm{C}$ & 4442 & $<110^{-3}$ & $(6,83 \pm 0,02) 10^{4}$ & $(5,76 \pm 0,02) 10^{4}$ & 1,19 \\
$\mathrm{~N}$ & 1636 & $<110^{-3}$ & $(8,70 \pm 0,03) 10^{4}$ & $(7,60 \pm 0,03) 10^{4}$ & 1,14 \\
$\mathrm{Cl}$ & 1763 & $<110^{-4}$ & $(7,91 \pm 0,03) 10^{4}$ & $(6,48 \pm 0,02) 10^{4}$ & 1,22 \\
$\mathrm{Cl}$ & 1219 & $<110^{-4}$ & $(1,91 \pm 0,01) 10^{5}$ & $(1,48 \pm 0,01) 10^{5}$ & 1,29 \\
$\mathrm{Cl}$ & 2646 & $<110^{-6}$ & $(8,30 \pm 0,03) 10^{4}$ & $(6,49 \pm 0,02) 10^{4}$ & 1,28 \\
$\mathrm{Cl}$ & 3004 & $<110^{-5}$ & $(4,53 \pm 0,02) 10^{4}$ & $(3,50 \pm 0,02) 10^{4}$ & 1,30 \\
$\mathrm{Ca}$ & 3352 & $<110^{-13}$ & $(4,49 \pm 0,02) 10^{4}$ & $(3,14 \pm 0,02) 10^{4}$ & 1,43 \\
$\mathrm{Ca}$ & 3736 & 0 & $(5,10 \pm 0,02) 10^{4}$ & $(3,75 \pm 0,02) 10^{4}$ & 1,36 \\
$\mathrm{P}$ & 1266 & $<110^{-2}$ & $(9,28 \pm 0,03) 10^{4}$ & $(8,27 \pm 0,03) 10^{4}$ & 1,19 \\
\hline
\end{tabular}

Como o primeiro experimento realizado explorando o diagnóstico de CCR com base na espectroscopia de emissão através da reação (n,n’), os resultados obtidos apontam que as amostras podem ser distinguidas através das alturas de pulso dos picos reconstruídos. Além de se observar a presença de elementos comumente encontrados no tecido humano, tais como $\mathrm{C}, \mathrm{N}$ e $\mathrm{Cl}$, em concentrações estatisticamente diferentes, os elementos $\mathrm{P}$ e Ca foram identificados nos espectros de emissão de acordo com a tendência esperada para as concentrações entre as amostras (Tabela $4)$.

Como avaliado previamente através da composição elementar das amostras irradiadas, Ca e P estão presentes em maior concentração na amostra de tecido renal saudável (PA2 H) e este comportamento, intrínseco à amostra, é observado no espectro de emissão (Figura 21) e na comparação entre as alturas de pulso (Tabela 11) para as energias que identificam estes elementos. Os demais elementos 
encontrados na composição elementar das amostras $(\mathrm{Cu}, \mathrm{Zn}, \mathrm{Fe}, \mathrm{S}$ e $\mathrm{K})$ não foram identificados entre os espectros de emissão devido às suas respectivas baixas concentrações que podem estar abaixo do limite de detecção do sistema de espectroscopia adotado. Nota-se que o elemento S está presente nas amostras irradiadas com uma razão de concentração $\sim 1$ entre os tecidos renais e está identificado nos espectros de emissão. Entretanto, devido à resolução energética dos detectores empregados, a distinção entre as amostras não pode ser realizada utilizando este elemento.

Devido ao limiar de detecção do sistema de espectroscopia, mesmo observando que a tendência de concentração (proporcional à altura de pulso) dos elementos $\mathrm{P}$ e Ca entre as amostras está de acordo com a tendência esperada, a razão entre as contagens médias para as energias que identificam estes elementos está em desacordo com os valores esperados segundo a Tabela 4. De acordo com a composição elemental avaliada para os tecidos renais, o elemento Ca está presente nas amostras numa proporção aproximadamente 73:1 entre o tecido renal saudável e CCR. Como calculado, a maior razão de concentração obtida para este elemento entre os tecidos foi de 1,43. O mesmo comportamento é observado para o elemento P, onde é esperado uma proporção entre concentrações de 1,22 enquanto que o valor calculado foi de 1,19 (erro de 2,46\%).

\subsubsection{Simulação da distribuição de dose absorvida em órgão adjacente ao órgão irradiado na espectroscopia de emissão estimulada}

O cálculo da dose absorvida em procedimentos que envolvem o emprego de radiação ionizante é caracterizado como um procedimento padrão considerando os limites de dose permissíveis na prática clínica. Neste estudo, a deposição de energia pelo feixe de nêutrons colimado na espectroscopia de emissão estimulada foi avaliada no órgão adjacente ao órgão alvo.

O estudo realizado contempla a simulação de um experimento realizado por Kapadia et al. (2012) onde dois dosímetros localizados num objeto simulador de resina, respectivamente na posição do fígado - 'A' e rim (esquerdo) - 'B', são 
empregados para quantificar a dose absorvida em um procedimento onde o fígado é irradiado diretamente pelo feixe de nêutrons. Neste caso, devido a colimação do feixe de nêutrons, o rim é irradiado indiretamente pela radiação espalhada.

Segundo os dados apresentados em Kapadia et al. (2012), os dosímetros localizados nas posições do fígado e rim esquerdo foram irradiados respectivamente por $4,5 \mathrm{~h}$ e $20 \mathrm{~h}$. A diferença entre os tempos de exposição justifica-se pela proximidade com o feixe e consequentemente pela redução da incerteza do cálculo de dose. Após a irradiação, os dosímetros foram avaliados em função da mudança de suas densidades óticas devido à interação com a radiação ionizante. A taxa de dose obtida para os dosímetros 'A' e 'B' foram respectivamente 1,89 Gy/h e 0,0125 Gy/h com uma incerteza máxima de $7 \%$ sobre os valores calculados. Logo, a partir de experimento realizado, a dose absorvida no rim devido a radiação espalhada é aproximadamente 150 vezes menor que a dose absorvida no fígado, sendo este o órgão alvo da espectroscopia.

Com base na teoria do método Monte Carlo aplicado ao transporte de radiação, todos os resultados calculados pelo código MCNP5 são normalizados pela intensidade da fonte de radiação simulada. No caso do experimento simulado, a dose absorvida média (Gy) calculada nos dosímetros 'A' e 'B' deveriam ser multiplicada pela intensidade dada pelo número de nêutrons emitidos pela fonte durante a exposição ao feixe. Entretanto, esta grandeza não foi medida experimentalmente, inviabilizando a conversão direta dos dados normalizados para valores absolutos. A taxa de dose média absorvida para os dosímetros 'A' e 'B' foi calculada respectivamente como $1,3410^{-13} \mathrm{~Gy} / \mathrm{n}^{-1} \mathrm{~h}^{-1}$ e $8,8010^{-16} \mathrm{~Gy} / \mathrm{n}^{-1} \mathrm{~h}^{-1}$, onde $\mathrm{n}$ denota o número de nêutrons emitidos pela fonte. Nota-se que as taxas calculadas estão normalizadas pelos tempos de exposição empregados respectivamente na irradiação de cada dosímetro. O erro relativo associado à estes cálculos é inferior a $0,1 \%$.

Com o objetivo de comparar os resultados obtidos a partir da simulação com os valores experimentais, a alternativa adotada para se obter o valor de dose absoluta consiste na normalização dos dados calculados na simulação com a taxa de 
dose experimental para o dosímetro 'B' (0,0125 Gy/h). A partir deste procedimento, a intensidade da fonte foi estimada como $1,4210^{13} \mathrm{n} / \mathrm{h}$. Utilizando esta intensidade como fator de normalização, as taxas de dose calculadas com as simulações foram 1,90 Gy/h e 0,0125 Gy/h respectivamente para os dosímetros 'A' e 'B'. O erro relativo associado ao cálculo da dose absorvida no dosímetro 'A' (1,90 Gy/h) quando comparado com o valor esperado dado pela dose experimental (1,89 Gy/h) é da ordem de 0,53\%. O erro associado ao dosímetro 'B' não foi avaliado uma vez que este foi utilizado no cálculo da estimativa da intensidade da fonte.

Os resultados, experimentais e simulados, comprovam que o feixe colimado é capaz de depositar a dose no meio predominantemente ao longo dos tecidos irradiados diretamente pelo feixe. Essa afirmação é feita com base na razão entre as doses absorvidas no órgão alvo escolhido neste estudo e no rim, sendo observado uma diminuição acentuada ( 150 vezes) na absorção de dose a medida que se afasta do feixe incidente. Logo, o emprego da espectroscopia de emissão estimulada utilizando o feixe de nêutrons é viável, do ponto de vista da proteção radiológica, desde que parâmetros como a intensidade da fonte e o tempo de exposição sejam controlados a fim de garantir o comprometimento entre a dose absorvida e a estatística suficiente para o espectro de emissão detectado. A mesma lógica se aplica na abordagem tomográfica da técnica NSECT, uma vez que a espectroscopia é empregada em diferentes posições ao redor do meio reconstruído, produzindo o sinograma utilizado nas reconstruções através da seleção das energias que identificam os isótopos de interesse.

\subsection{Imageamento}

\subsubsection{Detecção de CCR através de imagens tomográficas 3D adquiridas pela técnica NSECT}

A detecção da lesão de CCR foi realizada explorando os espectros de emissão do objeto simulador modelado de acordo com a tendência de concentração dos elementos $\mathrm{P}, \mathrm{Ca}$, e $\mathrm{K}$ entre os tecidos renais apresentada na Tabela 6 . 
Como apresentado na Seção 3.5.2.1, com base nas informação da composição dos tecidos obtida com a técnica NSECT, a detecção da lesão de CCR por imagem requer: (i) a segmentação dos rins e (ii) a detecção do padrão de concentração dos elementos que identificam os tecidos renais (CCR e tecido renal saudável).

A segmentação do tecido renal foi realizada através da aplicação de uma máscara binária adquirida a partir do produto, elemento a elemento, entre as imagens dos isótopos ${ }^{12} \mathrm{C},{ }^{32} \mathrm{~S}$ e ${ }^{14} \mathrm{~N}$ cujos valores de pixel foram invertidos para destacar o volume renal por meio da diferença de concentração dos elementos entre os tecidos (Figura 23a). A Figura 22(a-c) apresenta a imagem central reconstruída do volume do tronco irradiado para os elementos ${ }^{12} \mathrm{C},{ }^{14} \mathrm{~N}$ e ${ }^{32} \mathrm{~S}$ e suas respectivas inversões de valores de pixel em (d-f).

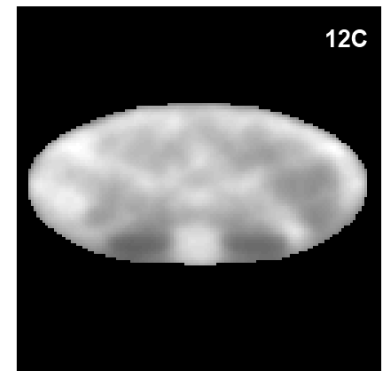

a

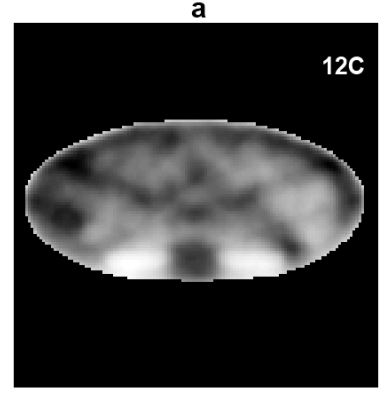

d

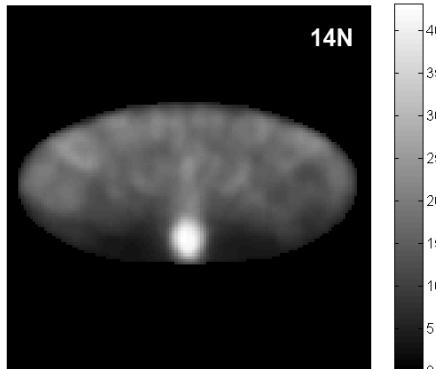

b

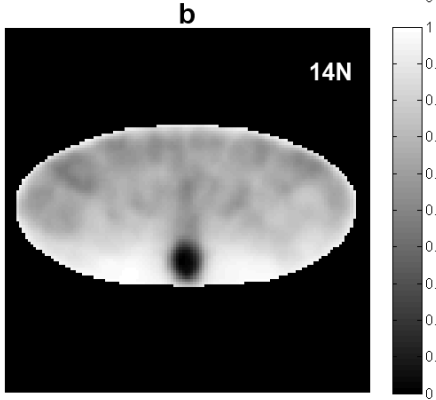

e
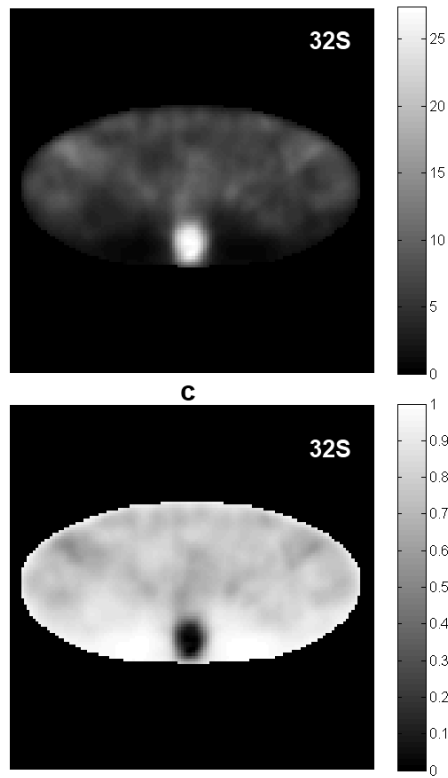

f

Figura 22 - Imagens tomográficas reconstruídas para os isótopos ${ }^{12} \mathrm{C},{ }^{32} \mathrm{~S}$ e ${ }^{14} \mathrm{~N}$ (ac) e suas respectivas inversões de valores de pixel (d-f) empregadas na segmentação do volume renal (Viana et al., 2013).

Posteriormente, o processo de binarização das imagens obtidas foi realizado aplicando-se um limiar aos valores de pixel para eliminar ruídos da recons- 
trução e fornecer a melhor representação visual do órgão reconstruído, exemplificado na Figura 23b. Em seguida, as imagens binárias foram renderizadas para se obter a representação tridimensional do rins segmentados, Figura 23c. Nota-se que foram utilizados elementos comumente encontrados no tecido humano e estes não estão relacionados com o diagnóstico.

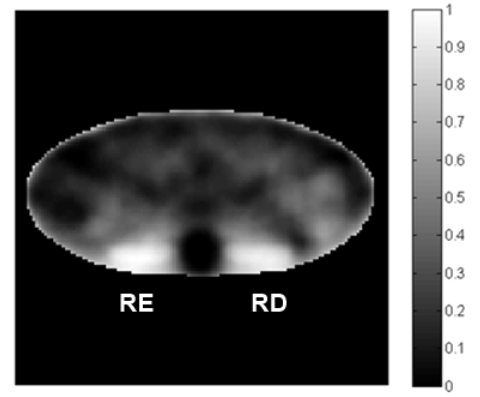

a

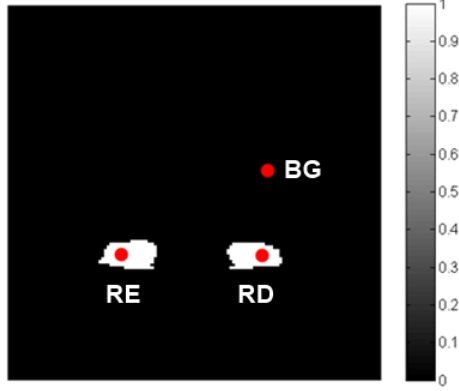

b

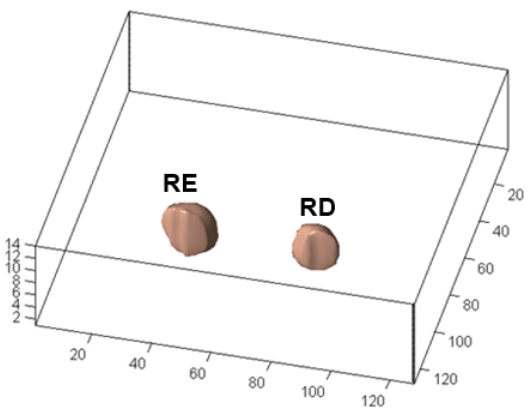

C

Figura 23 - Segmentação do volume renal: (a) imagem normalizada obtida a partir da combinação das imagens de ${ }^{12} \mathrm{C},{ }^{14} \mathrm{~N}$ e ${ }^{32} \mathrm{~S}$, (b) binarização da imagem obtida e (c) renderização das imagens processadas reconstruindo o volume renal. Os três pontos em vermelho representam as localizações onde as ROIs foram avaliadas no teste estatístico: rim direito (RD), rim esquerdo (RE) e tecido mole (BG) (Viana et al., 2013).

A máscara binária 3D foi aplicada nas imagens dos elementos utilizadas na identificação dos tecidos renais, sendo eles $\mathrm{P}, \mathrm{K}$ e Na de acordo com a tendência entre as concentrações apresentada na Tabela 6. Os valores de pixel contidos nos rins segmentados foram submetidos respectivamente à análise qualitativa, através da renderização das imagens reconstruídas, e à análise quantitativa, por meio do teste t bi-caudal para diferença entre médias avaliado nas ROIs indicadas na Figura 23b.

\section{Análise qualitativa}

As imagens adquiridas dos isótopos ${ }^{31} \mathrm{P},{ }^{39} \mathrm{~K}$ e ${ }^{23} \mathrm{Na}$ foram segmentadas utilizando a máscara 3D e renderizadas para se obter a representação volumétrica 
dos rins irradiados. Devido à segmentação do volume renal, as imagens do isótopo ${ }^{32} \mathrm{~S}$ também foram empregadas nesta análise para fornecer o contorno do tronco irradiado. As imagens renderizadas dos isótopos ${ }^{31} \mathrm{P},{ }^{39} \mathrm{~K}$ e ${ }^{23} \mathrm{Na}$ foram sobrepostas, uma por vez, com a imagem renderizada do isótopo ${ }^{32} \mathrm{~S}$, introduzindo dessa forma a informação anatômica do meio irradiado independente do diagnóstico do CCR. As imagens tomográficas resultantes da superimposição dos elementos são apresentadas na Figura 24(a-c) para a região central do tronco irradiado. A imagem do isótopo ${ }^{32} \mathrm{~S}$ é apresentada em verde enquanto que os demais isótopos são apresentados em vermelho.

A tendência das concentrações entre os elementos K, P e Na selecionados para a diferenciação entre os tecidos renais é observada nas imagens sobrepostas. De acordo com a composição modelada apresentada na Tabela 6, os elementos $\mathrm{K}$ e Na são encontrados em maior concentração no tecido renal saudável (rim direito) enquanto que P está presente em maior concentração no CCR (rim esquerdo). A prevalência da concentração destes elementos nos tecidos renais é exemplificada através do cálculo do valor médio dos pixels entre as imagens sobrepostas e através das imagens renderizadas apresentadas respectivamente nas Figuras 24(d-f) e Figura 24(g-i), onde os rins segmentados estão apresentados em vermelho.

Como observado nas Figuras 24(d-f), as intensidades dos valores de pixel para região do tronco (isótopo ${ }^{32} \mathrm{~S}$ ) permanecem quase constantes entre as imagens reconstruídas enquanto que as intensidades na região dos rins segmentados se alteram de acordo com as concentrações dos isótopos ${ }^{31} \mathrm{P},{ }^{39} \mathrm{~K}$ e ${ }^{23} \mathrm{Na}$ modelados. O mesmo comportamento é observado nas imagens renderizadas, apresentadas nas Figuras 24(g-i), onde é possível a identificação do volume renal. A superfície externa do tronco (rosa) foi renderizada utilizando as imagens do isótopo ${ }^{32} \mathrm{~S}$ enquanto que a renderização das imagens dos demais isótopos é apresentada em vermelho. 


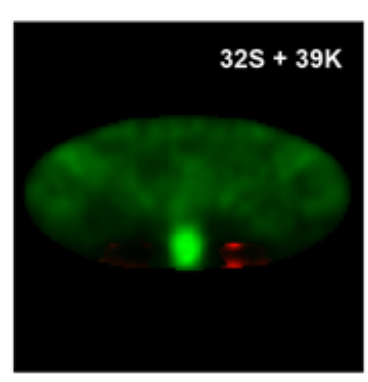

a

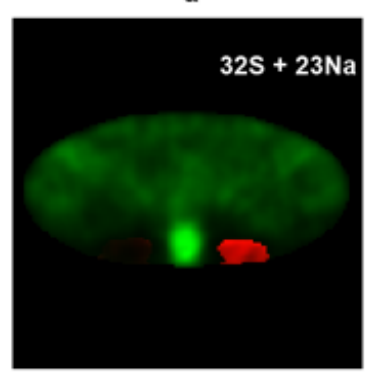

b

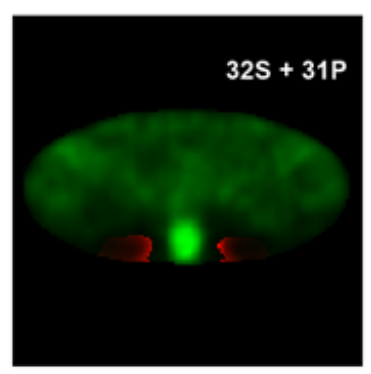

c

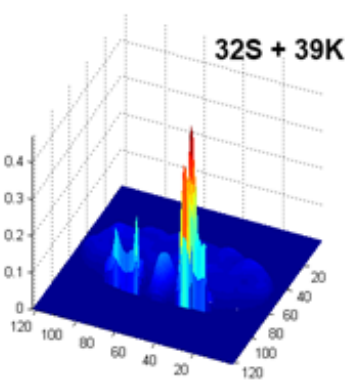

d

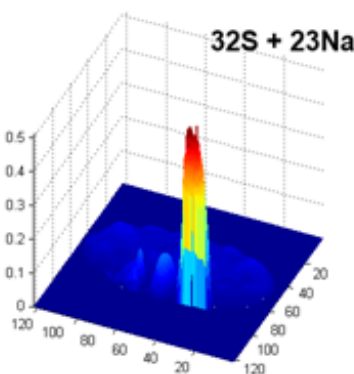

e

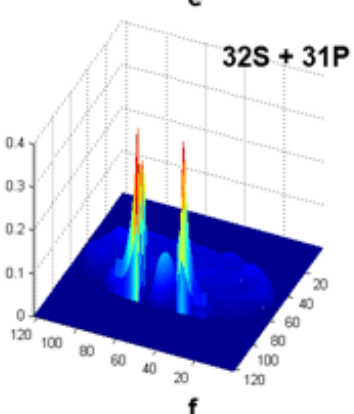

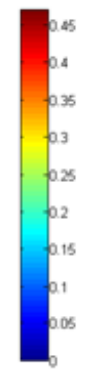

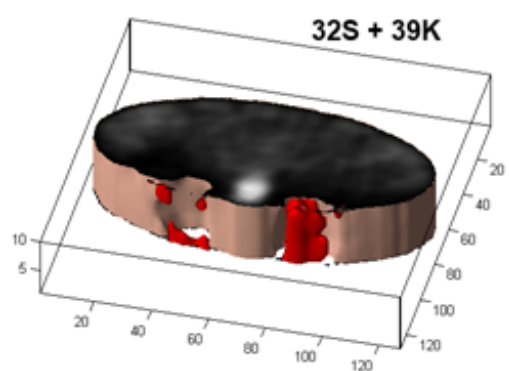

g
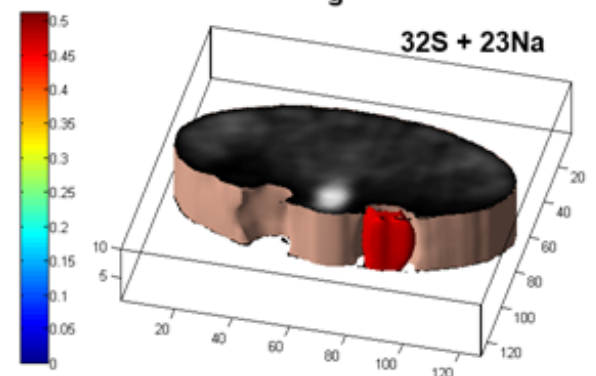

h
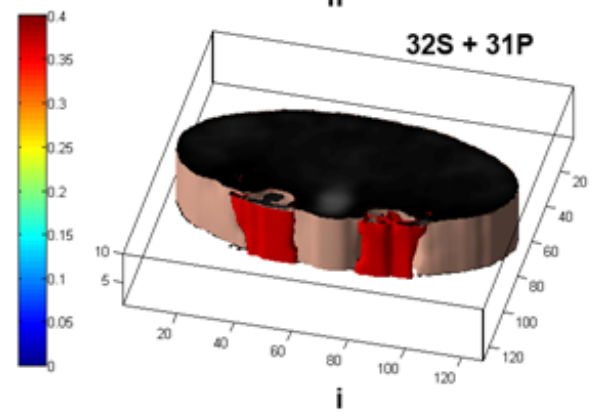

Figura 24 - Composição 2D (esquerda), valor médio dos pixels (meio) e imagens renderizadas (direita) a partir da combinação das imagens dos isótopos ${ }^{32} \mathrm{~S},{ }^{31} \mathrm{P},{ }^{39} \mathrm{~K}$ e ${ }^{23} \mathrm{Na}$ (Viana et al., 2013).

\section{Análise quantitativa}

As imagens apresentadas na Figura 24 permitem a análise qualitativa da identificação dos tecidos renais com base na composição do tronco irradiado, em particular, para os isótopos ${ }^{31} \mathrm{P},{ }^{39} \mathrm{~K}$ e ${ }^{23} \mathrm{Na}$. Em complemento, a análise quantitativa das imagens reconstruídas foi realizada para se avaliar a significância estatística dos valores de pixel acerca da distribuição da concentração dos elementos selecionados entre os tecidos modelados. 
A análise quantitativa foi realizada através da comparação entre os valores de pixel contidos nas ROIs localizadas conforme apresentado na Figura 23b. Para cada elemento avaliado, a média $(\bar{x})$ e o desvio padrão da média $(s)$ dos valores de pixel foram calculados e utilizados na comparação entre as composições entre as ROIs: (i) entre os tecidos renais (RE:RD) e (ii) entre os tecidos renais e tecido mole na região abdominal (RE:BG e RD:BG). A Tabela 12 apresenta o resultados obtidos na análise quantitativa das imagens reconstruídas.

Tabela 12. Análise quantitativa para diferença de médias entre os valores de pixel nas ROIs.

\begin{tabular}{cccccc|cc}
\hline Isótopo & ROI & $\bar{x}$ & $s$ & Teste & p-valor & Razão calculada $\frac{\bar{x}_{R E}}{\bar{x}_{R D}}$ & Razão teórica $\frac{\bar{x}_{R E}}{\bar{x}_{R D}}$ \\
\hline \multirow{2}{*}{${ }^{39} \mathrm{~K}$} & $\mathrm{RE}$ & 0,01 & 0,01 & RE:BG & $<0,05$ & & \\
& $\mathrm{RD}$ & 0,12 & 0,07 & $\mathrm{RD}: \mathrm{BG}$ & $<0,05$ & 0,08 & 0,31 \\
& $\mathrm{BG}$ & 0,42 & 0,14 & $\mathrm{RE}: \mathrm{RD}$ & $<0,05$ & & \\
\hline \multirow{2}{*}{${ }^{31} \mathrm{P}$} & $\mathrm{RE}$ & 0,66 & 0,14 & $\mathrm{RE}: \mathrm{BG}$ & $<0,05$ & & 14,65 \\
& $\mathrm{RD}$ & 0,38 & 0,15 & $\mathrm{RD}: \mathrm{BG}$ & $<0,05$ & \multirow{2}{*}{1,74} & \\
& $\mathrm{BG}$ & 18,50 & 1,46 & $\mathrm{RE}: \mathrm{RD}$ & $<0,05$ & & \\
\hline \multirow{2}{*}{${ }^{23} \mathrm{Na}$} & $\mathrm{RE}$ & 0,40 & 0,15 & $\mathrm{RE}: \mathrm{BG}$ & $<0,05$ & & $6,2510^{-3}$ \\
& $\mathrm{RD}$ & 5,27 & 1,25 & $\mathrm{RD}: \mathrm{BG}$ & $<0,05$ & 0,07 & \\
& $\mathrm{BG}$ & 4,14 & 0,73 & $\mathrm{RE}: \mathrm{RD}$ & $<0,05$ & & \\
\hline
\end{tabular}

Como apresentado na Tabela 12, os valores calculados para as médias dos valores de pixel foram consideradas estatisticamente diferentes entre as ROIs para os elementos avaliados. Entretanto, a razão calculada dos valores de pixel, proporcional à concentração dos elementos, nos tecidos tecidos renais (RE e RD) não está em concordância com a razão teórica calculada a partir da composição descrita na Tabela 6.

Devido ao limiar de detecção ainda não estudado para estes elementos nesta aplicação, a acurada quantificação com relação à composição adotada não foi realizada. Como exemplo, o isótopo ${ }^{23} \mathrm{Na}$ é encontrado em uma concentração 
(fração em massa) de 0,01\%, 0,1\% e 1,60\% respectivamente no tecido renal saudável, tecido mole e CCR. Mesmo que ainda sejam diferentes, as menores concentrações podem estar abaixo do limiar de detecção inerente ao sistema tomográfico, o que inviabiliza a detecção de acordo com a linearidade entre a concentração do elemento e a intensidade do sinal. Agasthya et al. (2012) estima que, pela técnica NSECT, o limiar de detecção de ferro no diagnóstico de hemacromatose hepática varie entre 0,05\% e 0,20\% dependendo do tamanho do paciente e do número de detectores empregados no sistema tomográfico.

\subsubsection{Tomografia de emissão associada ao tempo de voo do nêutron}

As imagens apresentadas na seção anterior foram adquiridas com um sistema tomográfico de primeira geração. A mesma composição da lesão de CCR também foi adotada em um outro estudo onde foi empregado uma nova modalidade de aquisição de imagens para NSECT com base na informação do tempo de voo do nêutron. Neste estudo em particular, a lesão de CCR foi modelada com um tamanho reduzido e inserida no centro do rim esquerdo.

As imagens tomográficas foram adquiridas conforme o protocolo de irradiação apresentado na Seção 3.5.2.1.1, onde os perfis de concentração em profundidade dos elementos são obtidos a partir dos espectros resolvidos em tempo através da relação linear com a velocidade média de propagação do nêutron no meio irradiado. A Figura 25 apresenta respectivamente as imagens centrais do volume irradiado para os isótopos ${ }^{31} \mathrm{P}$ (a) e ${ }^{23} \mathrm{Na}$ (b) e os perfis de concentração destes isótopos para a projeção do feixe de nêutrons que irradia o centro da lesão de CCR (c), ambos com resolução de 0,1 ns. Para a melhor visualização, os valores apresentados para os perfis foram normalizados individualmente pelo seu respectivo maior valor.

De acordo com a teoria apresentada, o espectro resolvido em tempo detectado para a NSECT é capaz de calcular a localização do sítio de emissão ao longo da projeção do feixe de nêutrons onde a reação (n,n') tenha ocorrido. Logo, é possível identificar as interfaces entre os tecidos irradiados no perfil de concentração 
para os isótopos de interesse. Essa característica é apresentada na Figura 25c pelas bordas do rim saudável (xi e xiii) e para a lesão de CCR (xii) modelada no centro do rim, observadas a partir dos espectros de emissão para os isótopos ${ }^{31} \mathrm{P}$ e ${ }^{23} \mathrm{Na}$.
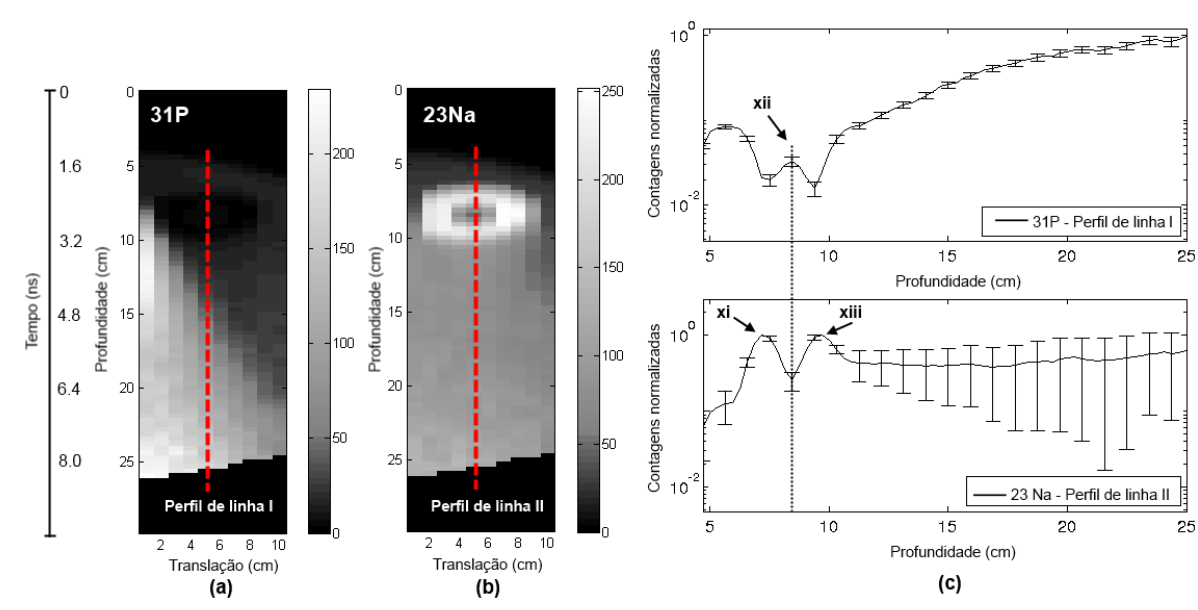

Figura 25 - Conversão entre o tempo de detecção de fótons e a localização de emissão em profundidade. As contagens e suas incertezas são apresentadas em escala logarítmica.

Assim como nas imagens tomográficas reconstruídas apresentadas na seção anterior, a tendência de concentração dos isótopos avaliados entre os tecidos renais está em concordância como a composição modelada (Tabela 6). Essa afirmação é feita com base na variação de concentração dos isótopos na posição IId referente ao centro da lesão de CCR. Como esperado, a concentração de ${ }^{23} \mathrm{Na}$ é maior no tecido renal saudável enquanto que ${ }^{31} \mathrm{P}$ está presente em maior concentração na lesão de CCR.

Observa-se que após a localização xiii ocorre um aumento das contagens normalizadas para os isótopos avaliados. Isto se deve primariamente a dois fatores, sendo eles: baixa concentração dos isótopos e espalhamento pelo tecido ósseo na coluna. Dado a diferença de densidades e concentrações entre os tecidos, fótons produzidos por nêutrons espalhados que atingem a coluna podem ser detectados no mesmo intervalo de tempo que os fótons produzidos diretamente pela projeção do 
feixe avaliado. Como a concentração dos elementos é baixa, o ruído produzido por este efeito pode ter a mesma magnitude ou magnitude superior ao real sinal produzido pelos isótopos presentes no caminho de projeção do feixe. O mesmo efeito é observado nas imagens tomográficas como um sombreamento apresentado nas Figuras 25(a,b). Como exemplo, o isótopo ${ }^{31} \mathrm{P}$ é modelado na composição da coluna $\left(1,92 \mathrm{~g} / \mathrm{cm}^{3}\right) \mathrm{com}$ uma fração em massa de 10,3 \% enquanto que o mesmo está presente no tecido renal saudável $\left(1,05 \mathrm{~g} / \mathrm{cm}^{3}\right)$ e tecido mole $\left(1,03 \mathrm{~g} / \mathrm{cm}^{3}\right)$ com respectivamente 4,30 $10^{-3} \%$ e $0,20 \%$. Entretanto, devido a proximidade entre o rim e a superfície do tronco, a análise proposta neste estudo não foi comprometida.

Ainda como um característica desta modalidade de aquisição, a localização e a extensão de lesões ou tecidos podem ser quantificadas através da conversão do espectro de emissão (resolvido em tempo) em profundidade. Como exemplo deste cálculo, a espessura renal e a distância entre a lesão de CCR e a superfície do rim, ambas as medidas consideradas na mesma posição de projeção do feixe, foram calculados a partir dos perfis de concentração apresentado na Figuras 25 e foram comparados com os valores reais através das geometrias modeladas. De acordo com o objeto simulador, a espessura renal e a distância entre as bordas do rim e a lesão de CCR são respectivamente $3,0 \mathrm{~cm}$ e $1,5 \mathrm{~cm}$, enquanto que os valores calculados foram 2,50 cm e 1,25 cm; resultando em uma margem de erro de 16,6\% para ambas as medidas. Cabe ressaltar que a acurácia deste cálculo é dependente da resolução temporal do espectro de emissão detectado e da espessura de interface entre os tecidos.

As imagens tomográficas adquiridas a partir dos isótopos ${ }^{23} \mathrm{Na}$ e ${ }^{31} \mathrm{P}$ foram renderizadas para se obter a visualização volumétrica dos tecidos renais irradiados e da extensão da lesão de CCR. A Figuras 26 e 27 apresentam respectivamente as imagens adquiridas com uma resolução temporal de 0,1 ns e 0,3 ns para os planos de visão: sagital, coronal e transverso. Para fins de visualização, apenas o volume renal no tronco irradiado é apresentado.

A renderização das imagens adquiridas com um resolução temporal de 0,1 ns mostram claramente a diferença de concentração entre os tecidos renais através 
da mudança dos valores de pixel proporcional à composição modelada. Assim como observado nas imagens tomográficas apresentadas na seção anterior, a tendência de concentração dos isótopos ${ }^{23} \mathrm{Na}$ e ${ }^{31} \mathrm{P}$ é preservada e evidenciada pela interface entre a lesão de CCR e o tecido renal saudável.

A resolução temporal exerce um papel fundamental nesta modalidade de aquisição para a NSECT, uma vez que a identificação em profundidade do sítio de emissão de fótons, e consequentemente a quantificação da localização e espessura de tecidos, é relacionada com o tempo de detecção dos eventos gama. A resolução de 0,1 ns representa um caso ideal onde os sítios de emissão ao longo do feixe projetado são identificados a cada $0,3 \mathrm{~cm}$. Como as dimensões da lesão de CCR e do rim são superiores, as interfaces entre os tecidos é claramente observada em todos os planos de visão da Figura 26. Mesmo sendo um estudo teórico, esta resolução temporal pode ser encontrada de acordo com a concentração de dopagem com Ce no detector $\mathrm{LaBr}_{3}(\mathrm{Ce})$ (Glodo et al., 2005).

O efeito da resolução temporal nas imagens tomográficas adquiridas pode ser observado nas imagens renderizadas na Figura 27 para a resolução temporal de 0,3 ns. Como as dimensões da lesão e do rim se aproximam da distância entre os sítios de emissão reconhecida no espectro $(\sim 0,9 \mathrm{~cm})$, a interface entre os tecidos renais não é clara como na Figura 26. Entretanto, ainda observa-se a heterogeneidade na composição dos isótopos devido ao volume da lesão de CCR (a lesão foi modelada como um elipsóide). Para simplificar a análise feita nesta seção, as imagens adquiridas para o elemento K não são apresentadas uma vez que estas possuem as mesmas características das imagens do elemento $\mathrm{Na}$ com relação a tendência de concentração entre os tecidos renais; assim como apresentado nas imagens tomográficas apresentadas na seção anterior. 


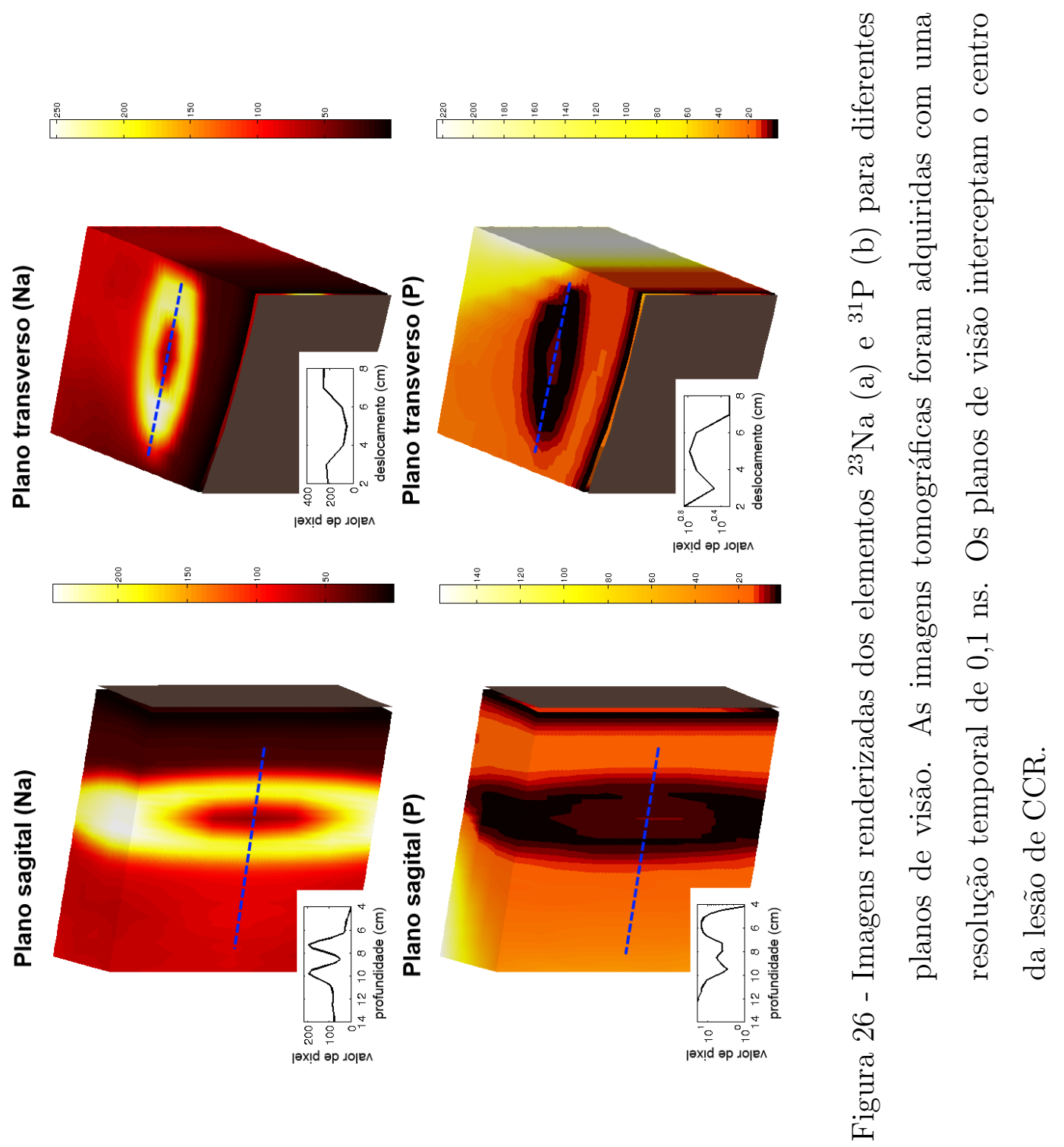




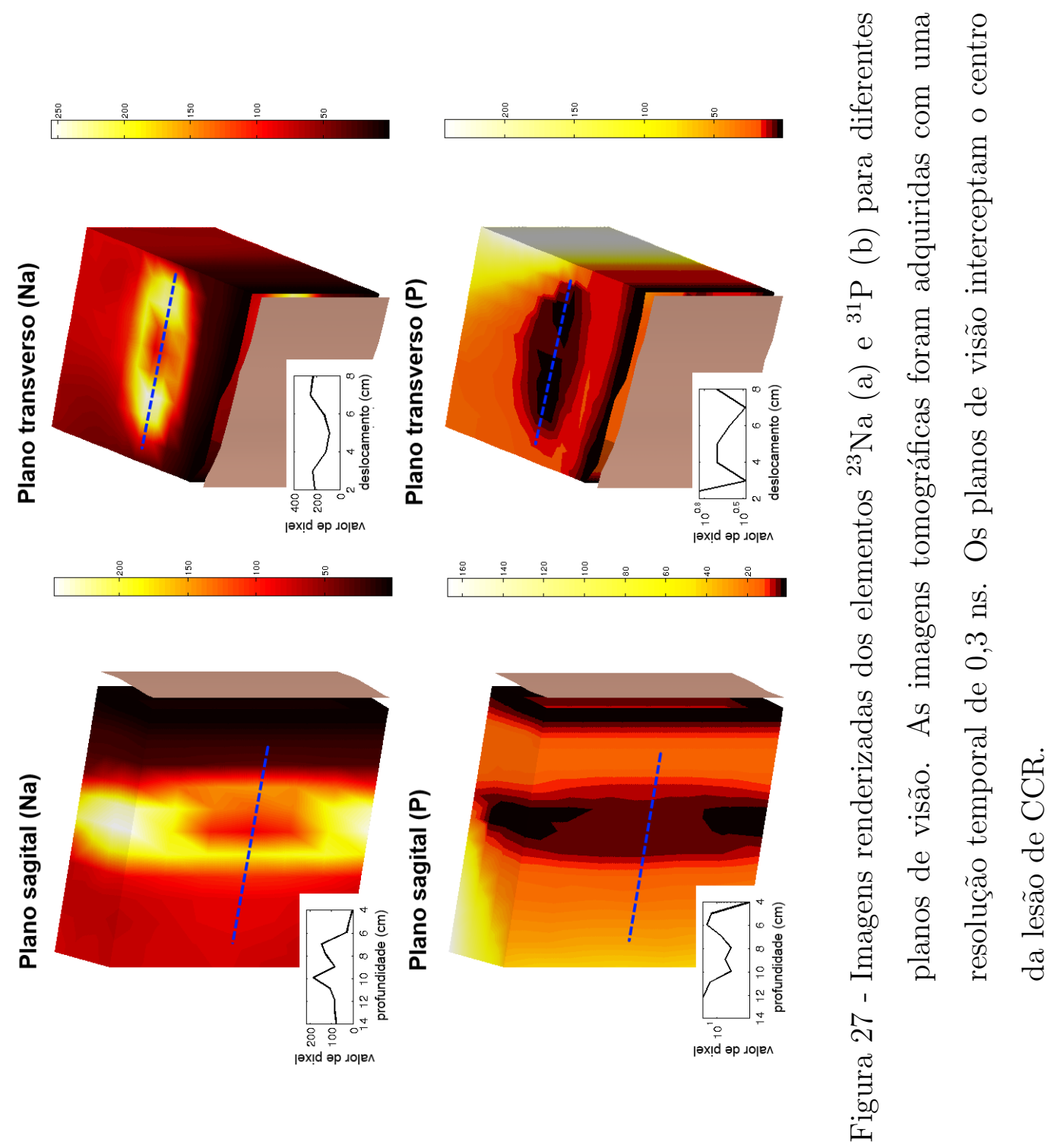


O teste estatístico conduzido na seção anterior também foi realizado neste estudo e os achados obtidos a partir dos resultados avaliados foram similares. O sistema tomográfico foi capaz de diferenciar os tecidos renais (tecido renal saudável e CCR) de acordo com a tendência de concentração do elementos selecionados. Entretanto, a quantificação dos isótopos ${ }^{23} \mathrm{Na}$ e ${ }^{31} \mathrm{P}$ não foi realizada de forma acurada devido ao limite de detecção.

\subsubsection{Dosimetria}

Esta seção apresenta o cálculo da dose efetiva associada aos resultados apresentados de acordo com a (I) aquisição das imagens tomográficas pelo sistema tomográfico de primeira geração (Seção 4.2.1) e com a (II) tomografia de emissão associada ao tempo de voo do nêutron (Seção 4.2.1.1).

Por influenciar diretamente na dose absorvida devido ao protocolo de irradiação, a principal característica entre as técnicas de aquisição apresentadas se resume no número de projeção do feixe de nêutrons utilizados em cada abordagem. Devido a necessidade de se projetar e detectar o espectro ao redor do meio a ser reconstruído, foram empregadas 6000 projeções do feixe de nêutrons pelo sistema tomográfico de primeira geração, enquanto que a modalidade que adota o tempo de voo do nêutron para a localização em profundidade do sítio de emissão empregou 70 projeções para irradiar apenas a seção do tronco onde está localizada o rim contendo a lesão de CCR.

Utilizando a metodologia descrita na Seção 3.4, a dose efetiva para as abordagens I e II foi calculada respectivamente como $3,85 \mathrm{mSv}$ e $42 \mu \mathrm{Sv}$ assumindo uma intensidade de fonte de $10^{7}$ nêutrons por projeção do feixe. Para efeito de comparação, a dose efetiva típica de um CT convencional para a aquisição de uma imagem abdominal é $\sim 10$ - 20 mSv (RSNA, 2014). A incerteza estatística associada aos cálculos apresentados é de $0,2 \%$ e os valores de dose são associados para cada protocolo de irradiação totalizado pelo número de projeções empregado. 


\subsubsection{Reconstrução de órgãos irradiados: imagens funcionais $\mathrm{e}$ anatômicas}

A técnica NSECT tem como principal característica a avaliação da composição dos tecidos irradiados pela espectroscopia ou reconstrução tomográfica. Entretanto, assim como mencionado na Seção 3.5.2.1, a anatomia do órgão irradiado é reconstruída apenas quando existe algum elemento encontrado predominantemente no órgão.

O mesmo conceito empregado, com base na combinação dos elementos S, C e N, para a reconstrução da anatomia renal foi utilizado para a reconstrução anatômica de outros órgãos, permitindo que o mesmo conjunto de dados forneça simultaneamente a informação fisiológica e anatômica dos órgãos irradiados. A Figura 28b mostra a reconstrução dos rins, coluna, baço, vesícula biliar e fígado irradiados pelo protocolo de aquisição adotado pelo sistema tomográfico de primeira geração descrito na Seção 4.2.1. Para efeito de comparação, a geometria dos órgãos modelados é apresentada na Figura 28a. A coluna, fígado e vesícula biliar não foram completamente reconstruídos na imagem devido ao volume do tronco irradiado.
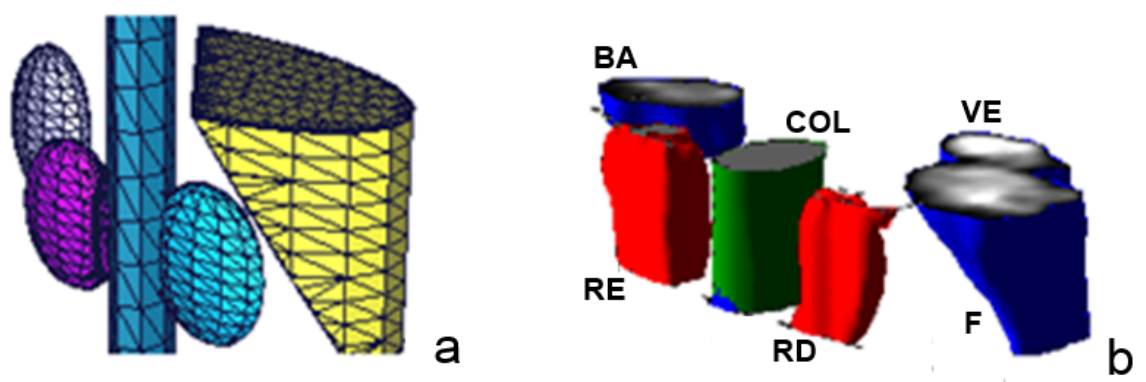

Figura 28 - Geometria dos órgãos modelados (a). Reconstrução anatômica a partir de imagens da NSECT (b): rim esquerdo (RE), rim direito (RD), coluna (COL), baço (BA), vesícula biliar (VE) e fígado (F).

A coluna foi reconstruída a partir de um limiar aplicado aos valores de pixel nas imagens do isótopo ${ }^{32} \mathrm{~S}$. Devido à densidade do tecido ósseo, o sinal 
produzido pela emissão deste isótopo é suficiente para a reconstrução da coluna sem a combinação com outros elementos. Nota-se que a reconstrução do tecido ósseo poderia ter sido realizada utilizando os fótons produzidos pelo elemento $\mathrm{Ca}$, abundante neste meio. Entretanto, o mesmo não foi avaliado neste estudo.

O baço, vesícula biliar e fígado foram reconstruídos a partir de uma combinação de reconstruções tomográficas de forma semelhante ao procedimento descrito para a reconstrução da anatomia renal. As imagens adquiridas para o isótopo ${ }^{12} \mathrm{C}$ (Figura 22a) (A) foram normalizadas na escala 0-1 e depois multiplicadas, elemento a elemento, pela suas respectivas inversões de valores de pixel (Figura 22d), resultando em um novo conjunto de imagens. Posteriormente, o conjunto de imagens obtidas a partir da combinação dos isótopos ${ }^{32} \mathrm{~S},{ }^{12} \mathrm{C}$ e ${ }^{14} \mathrm{~N}$, exemplificado na Figura 23a (B), foram também normalizadas na escala 0-1 e subtraídas das imagens para o isótopo ${ }^{12} \mathrm{C}$, i.e. (A-B).

Uma leitura atenta deste procedimento aponta que as imagens provenientes do isótopo ${ }^{12} \mathrm{C}$ foram utilizadas duas vezes. Entretanto, as informações obtidas a partir de A e B são complementares. Enquanto que as imagens em A segmentam as regiões compreendidas pelo rins, baço, vesicular biliar e fígado, as imagens em B segmentam apenas os rins entre o tecido mole. A operação linear A-B resulta na segmentação dos órgãos irradiados entre o tecido mole e a supressão dos rins. Um limiar para os valores de pixel também foi aplicado para se obter a melhor representação visual dos órgãos em meio ao ruído de reconstrução. Os rins também são apresentados na Figura 28b cuja metodologia para reconstrução já foi apresentada previamente.

A metologia empregada é descrita com base em uma combinação única entre os elementos presentes no objeto simulador. Como demonstrado, devido aos fundamentos da técnica NSECT, as composições dos órgãos irradiados são combinadas de tal forma que a anatomia pode ser associada com a informação fisiológica de uma patologia de interesse a partir do mesmo conjunto de dados fornecido pelo espectro de emissão. Logo, esta metodologia pode ser reproduzida em outras aplicações 
com base em diferentes protocolos de irradiação e combinações de elementos.

\subsubsection{Otimização da reconstrução tomográfica na NSECT}

A Seção 3.5.3 apresenta uma metodologia originalmente desenvolvida para a otimização dos sinogramas utilizados na NSECT, onde a aquisição tomográfica é simulada analiticamente pela Transformada de Radon (TR) empregando imagens de referência que representam a composição do meio a ser reconstruído. De acordo com o método proposto, a configuração de amostragem do sinograma é determinada com base na qualidade desejada da imagem reconstruída através da similaridade entre a reconstrução tomográfica e a imagem de referência, por sua vez avaliada pela Informação Mútua Normalizada (IMN).

Para validar o método proposto, o objeto simulador que originou as imagens de referência foi simulado com o código MCNP5 juntamente com um sistema tomográfico para reproduzir as configurações de amostragem avaliadas pela TR. As imagens tomográficas reconstruídas foram então avaliadas pela IMN com relação as imagens de referência criadas.

Como mencionado previamente, os valores de pixel nas imagens de referência são associados com a distribuição da concentração dos elementos selecionados entre os órgãos irradiados. Para avaliar o desempenho da metodologia desenvolvida para a representação do meio irradiado através das imagens de referência, quatro elementos foram selecionados neste estudo para diferentes aplicações, sendo eles: C, $\mathrm{Na}, \mathrm{Mg}$ e Fe.

O elemento $\mathrm{C}$ é um dos principais constituintes do tecido humano e foi empregado neste estudo para avaliar a capacidade da metodologia proposta em reconhecer, com base na imagem de referência para este elemento, a similaridade entre as geometrias (órgãos) reconstruídas nas imagens tomográficas sem considerar a influência do limiar de detecção do sistema tomográfico, por sua vez dependente da concentração do elemento imageado. Os valores calculados da IMN entre as imagens reconstruídas pela TR e pelas simulações com o código MCNP5 são apresentadas 
respectivamente nas Figuras 29 e 30. Os valores calculados da IMN para os isótopos selecionados foram normalizados na escala 0-1 e as reconstrução tomográficas apresentadas foram reconstruídas a partir da amostragem de sinograma associada ao maior valor de IMN.

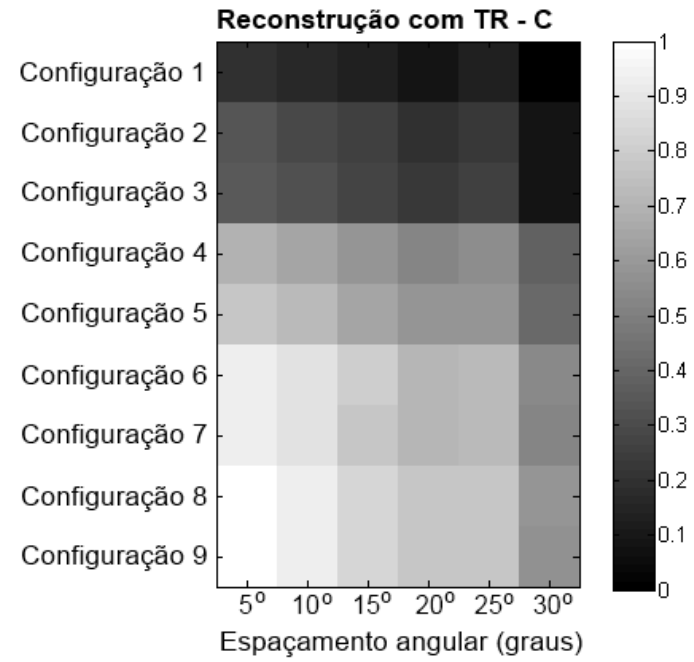

a

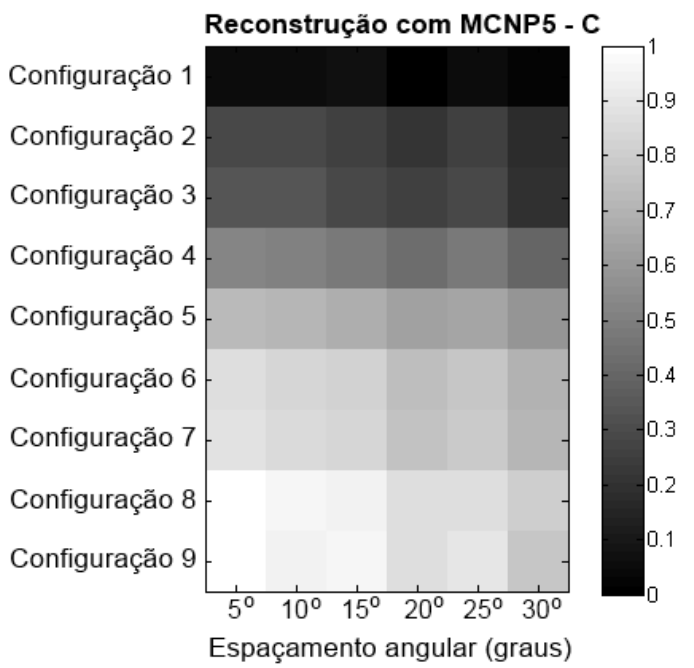

b

Figura 29 - Valores da IMN calculados entre as imagens reconstruídas para carbono de acordo com os sinogramas amostrados com TR (a) e MCNP5 (b).

As imagens reconstruídas pelos dois métodos (MCNP5 e TR) para o elemento $\mathrm{C}$ demonstram a habilidade da metodologia desenvolvida em avaliar a similaridade entre as imagens em função predominantemente das geometrias dos órgãos, tanto pela imagem de referência quanto pelo objeto simulador. Esta afirmação é feita com base no padrão encontrado entre os valores da IMN calculados (Figura 29). Como esperado, quanto maior a taxa de amostragem, maior o valor da IMN calculado e consequentemente maior a similaridade entre as imagens.

De acordo com a concentração dos elementos simulados (Tabela 8), o elemento C está presente numa concentração (fração em massa) variando entre 11,1 \% e 25,6 \% nos órgãos modelados. Devido a esta concentração, os órgãos modelados e suas interfaces estão claramente identificados nas imagens reconstruídas com a maior taxa de amostragem, apresentadas na Figura 30. 


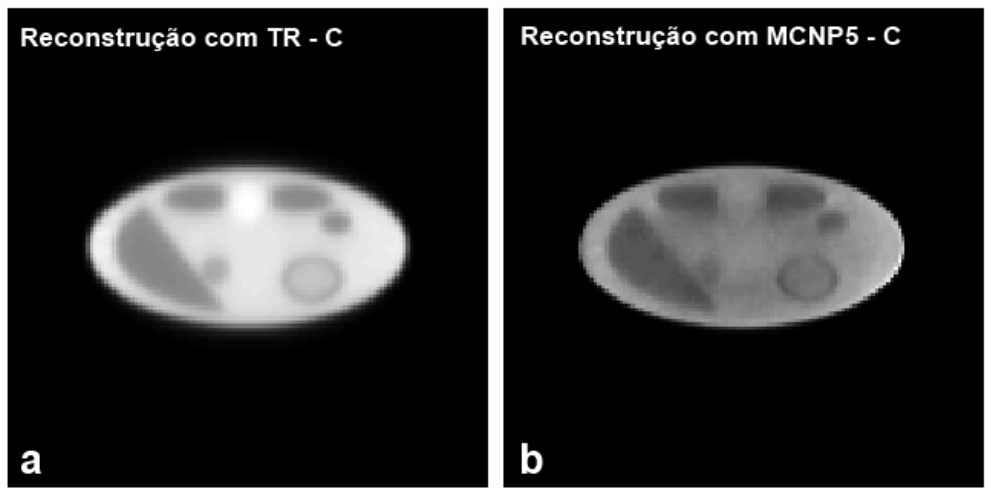

Figura 30 - Imagem tomográfica reconstruída para carbono de acordo com os sinogramas adquiridos com a TR (a) e simulações com o código MCNP5 (b) para a maior taxa de amostragem $(\mathrm{IMN}=1)$.

Os elementos $\mathrm{Na}$ e $\mathrm{Mg}$ foram selecionados neste estudo para avaliar o desempenho da metodologia desenvolvida quando elementos presentes em baixa concentração são reconstruídos. O elemento Na está presente nos órgãos reconstruídos numa concentração variando entre $0,1 \%$ e 0,2 \%. Apesar de sua baixa concentração, devido a densidade do tecido ósseo, a coluna pode ser facilmente identificada na reconstrução tomográfica apresentada na Figura 32b. Entretanto, não há uma distinção clara entre os órgãos (rins e fígado) reconstruídos com as simulações realizadas com o código MCNP5, sendo os mesmos visíveis apenas nas reconstruções adquiridas com a TR (Figura 32a).

Mesmo com a falha na identificação visual de todos os órgãos modelados, o mesmo padrão encontrado no cálculo da IMN entre os métodos de amostragem (Figura 31) foi obtido devido à reconstrução simultânea do contorno do tronco simulado e da coluna, cuja similaridade entre as imagens reconstruídas ainda é proporcional à configuração de amostragem do sinograma 


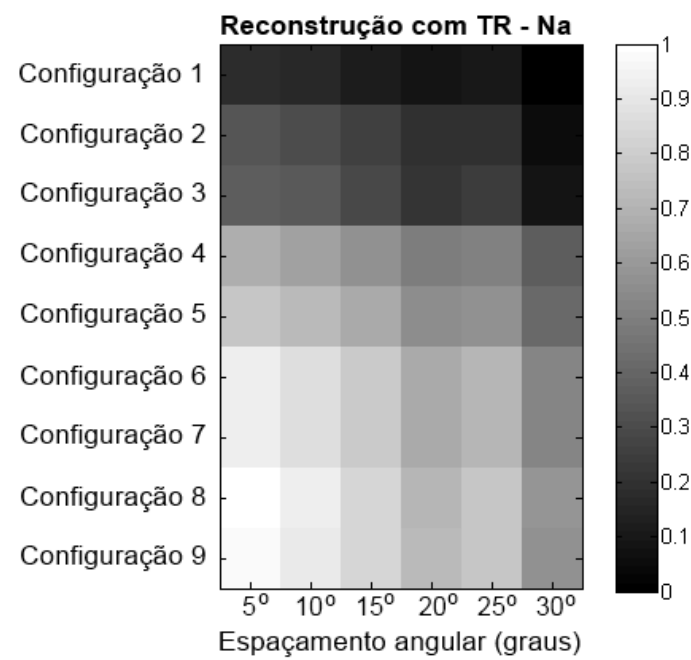

a

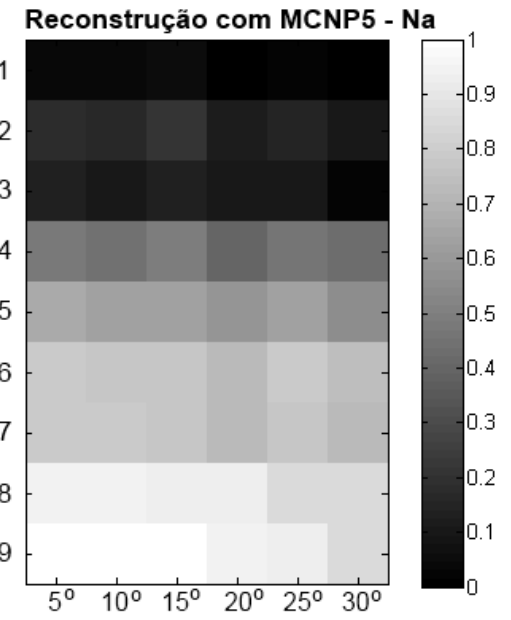

Espaçamento angular (graus)

b

Figura 31 - Valores da IMN calculados entre as imagens reconstruídas para sódio de acordo com os sinogramas amostrados com TR (a) e MCNP5 (b).

O elemento magnésio é encontrado, de acordo com a composição apresentada na Tabela 8, apenas na coluna com uma concentração de 0,2 \%. Entretanto, a intensidade de emissão de fótons por este elemento presente na coluna modelada não é suficiente para distinguir acuradamente o tecido modelado do ruído inerente à reconstrução tomográfica. Devido a densidade do tecido ósseo, fótons espalhados são registrados em posições não relacionadas com as projeções que irradiam diretamente a coluna, produzindo artefatos nos sinogramas adquiridos com as simulações com o código MCNP5. Tal ocorrência justifica a incompatibilidade entre os padrões encontrados no cálculo dos valores da IMN para os métodos de amostragem, observados na Figura 33. 

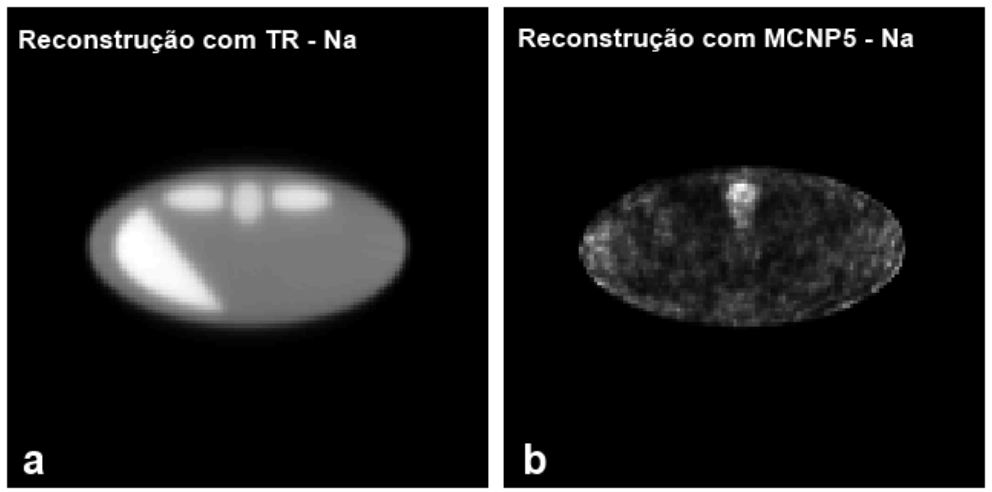

Figura 32 - Imagem tomográfica reconstruída para sódio de acordo com os sinogramas adquiridos com a TR (a) e simulações com o código MCNP5 (b) para a maior taxa de amostragem $(\mathrm{IMN}=1)$.

O artefato produzido pelo espalhamento de fótons no tecido ósseo se torna evidente quando as imagens tomográficas adquiridas pelos métodos de amostragem são comparadas na Figura 34. Nota-se claramente um efeito de sombreamento ao redor da coluna (Figura 34b), única estrutura fielmente reconstruída de acordo com a imagem de referência (Figura 34a). Como o cálculo da IMN avalia a similaridade entre as imagens, o artefato interfere na relação observada entre a taxa de amostragem e a qualidade de reconstrução. 

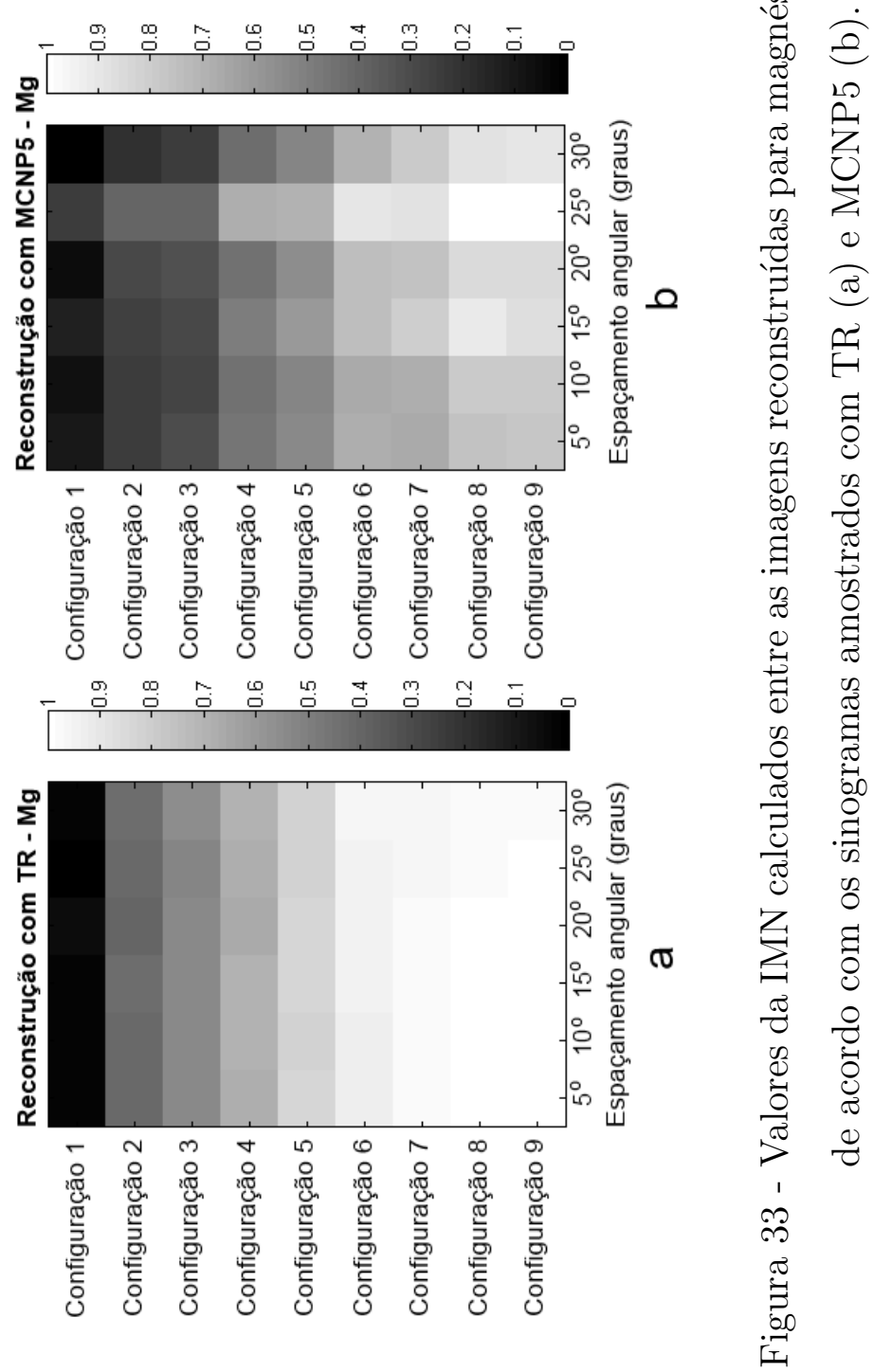


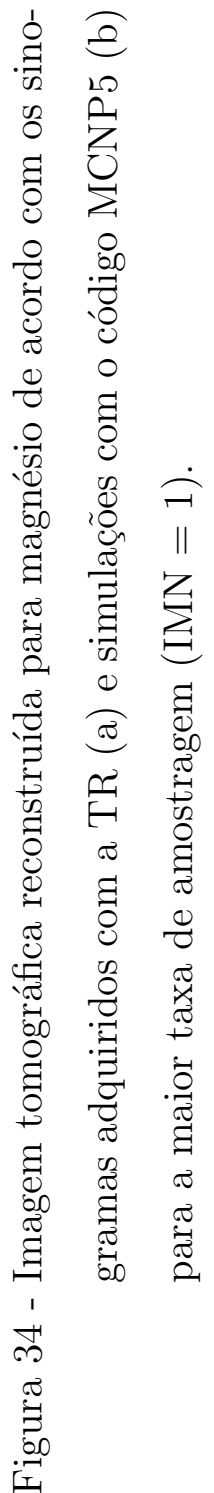


O elemento Fe foi selecionado para simular lesões de hemocromatose hepática com um concentração de ferro variando entre $0,2 \%$ e 2,0 \%, sendo estas concentrações clinicamente relevantes no diagnóstico desta patologia. Mesmo considerando as menores concentrações modeladas, as imagens obtidas a partir dos métodos de amostragem avaliados neste estudo estão em concordância com a imagem de referência empregada de acordo com o padrão observado para o cálculo da IMN (Figura 35).

O padrão circular das lesões modeladas é identificado por ambos os métodos de amostragem, como observado na Figura 36b pelas setas que indicam as localizações das lesões, mostradas também na imagem de referência (Figura 36a). Logo, as principais características das reconstruções obtidas com as simulações com o código MCNP5 são reproduzidas pela TR considerando a forma, composição e localização das lesões preservadas nos sinogramas.

As imagens provenientes do elemento $\mathrm{C}$ figuram neste estudo como uma prova do conceito teórico envolvido na metodologia proposta. Enquanto que o limiar de detecção do sistema tomográfico pode inviabilizar a reconstrução e identificação acurada dos órgãos, como demonstrado por meio das imagens dos elemento Mg e Na reconstruídas a partir dos sinogramas amostrados com o código MCNP5, as simulações das lesões da hemocromatose pela TR compreendem um resultado importante, uma vez que o diagnóstico desta patologia pela técnica NSECT já vem sendo estudado e desenvolvido (Agasthya et al., 2012). 


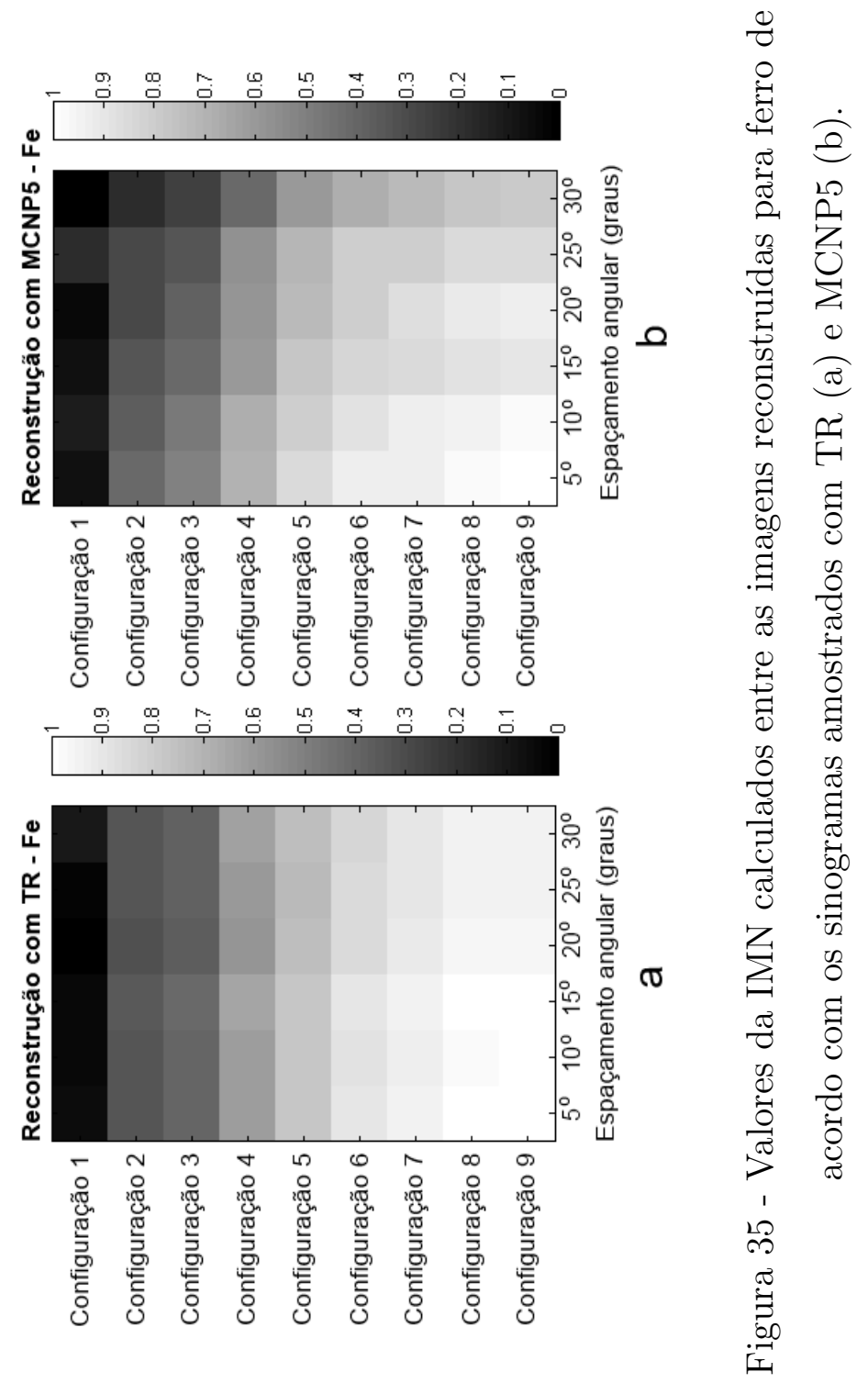




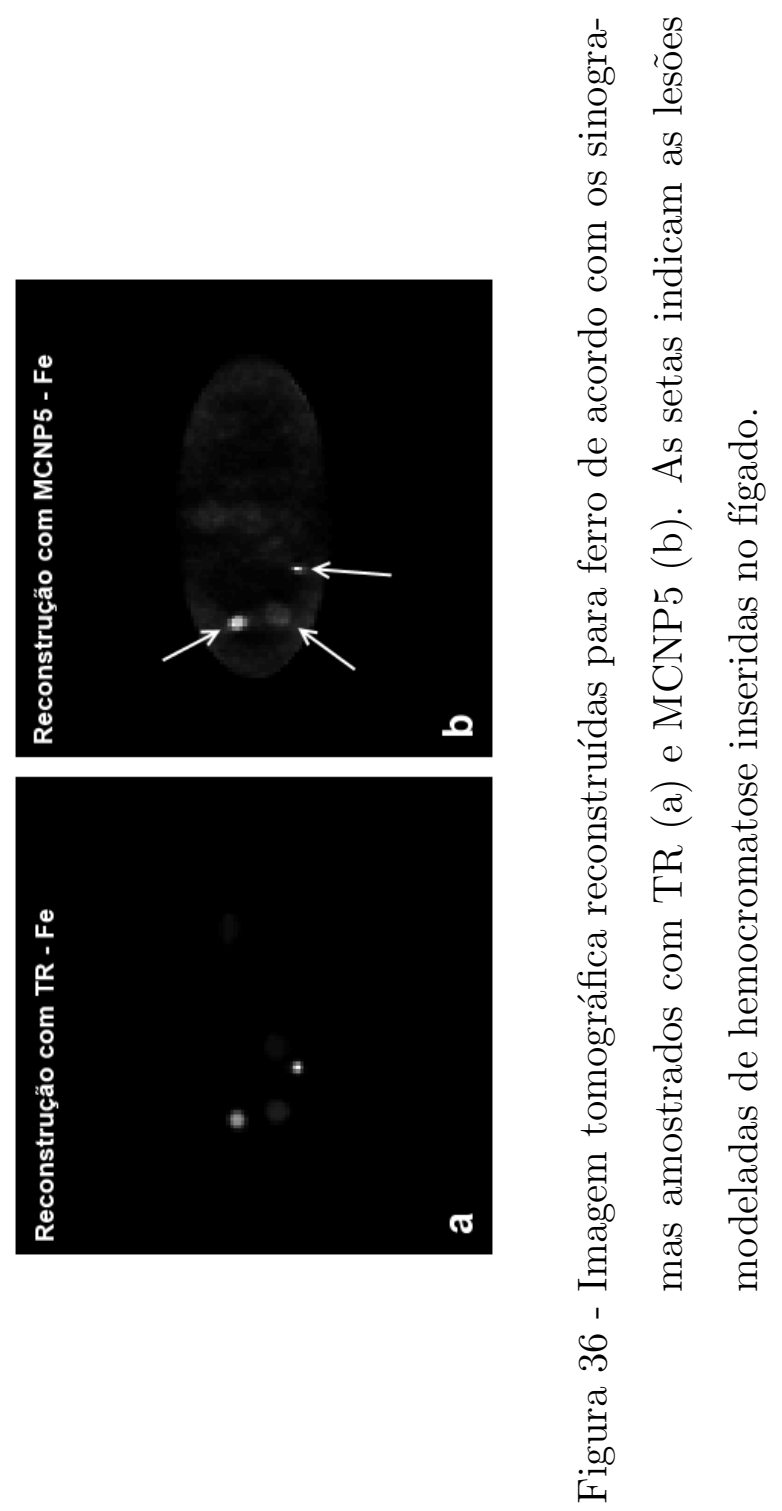




\subsubsection{Otimização da amostragem do sinograma em função do limiar de dose efetiva}

Como apresentado através da avaliação dos valores da IMN, a qualidade de reconstrução nas imagens tomográficas é dependente da configuração de amostragem do sinograma. Outra dependência também existente é relacionada com a dose absorvida pelo meio irradiado por meio do número de projeções do feixe empregado na aquisição dos espectros de emissão.

Logo, a metodologia proposta para a otimização da amostragem do sinograma na NSECT permite duas abordagens distintas para a tomada de decisão. Uma vez que os sinogramas obtidos com a TR são capazes de simular o sinograma real dos elementos de interesse, de acordo com o limiar de detecção do sistema tomográfico, a primeira abordagem consiste em alterar a configuração de amostragem com base na finalidade da imagem desejada, ou recursos disponíveis tais como a espessura de feixe. Neste caso, se o foco do estudo requer uma imagem de alta qualidade (visualização de detalhes em pequenas estruturas anatômicas), a taxa de amostragem é elevada a fim de se obter a maior similaridade possível.

A segunda abordagem consiste na escolha da configuração de amostragem associada com o maior valor de IMN, porém, em função de uma valor limiar de dose efetiva. Dessa forma, a semelhança entre a imagem reconstruída e a imagem ideal (imagem de referência) é assegurada pelo método desenvolvido sem que a dose efetiva exceda os valores permissíveis.

A análise proposta para relacionar a dose efetiva com a configuração de amostragem requer o cálculo dosimétrico dos protocolos de irradiação empregados neste estudo. Utilizando a metodologia descrita na Seção 3.4, a dose efetiva foi calculada considerando uma intensidade de fonte de $10^{7}$ nêutrons por projeção do feixe. Os valores obtidos são apresentados na Figura 37a. Para a melhor compreensão dos dados apresentados, os valores calculados são apresentados seguindo a mesma disposição empregada para os valores de IMN de acordo com os protocolos 
de irradiação. Nota-se claramente a dependência da dose efetiva com o número de projeções do feixe empregado.

Quando o limiar de dose efetiva é imposto, o método desenvolvido aponta a configuração de amostragem capaz de prover a imagem tomográfica que compartilha a maior similaridade com a imagem de referência. Para exemplificar este conceito, o limiar de $5 \mathrm{mSv}$ foi aplicado na Figura 37a, obtendo-se a Configuração 8 e espaçamento angular $15^{\circ}$ para a amostragem do sinograma. Esta configuração foi então aplicada simultaneamente nos sinogramas amostrados com a TR e com o código MCNP5 para o elemento C. As imagens resultantes são apresentadas respectivamente na Figura 37(b,c).

Observa-se que, utilizando a mesma configuração de amostragem, as imagens adquiridas para o elemento $\mathrm{C}$ compartilham as principais características do meio simulado, incluindo a forma dos órgãos e suas interfaces e, inclusive, os artefatos nas reconstruções devido a subamostragem dos sinogramas; como exemplificado nas áreas ampliadas das reconstruções pelas setas apontadas. 


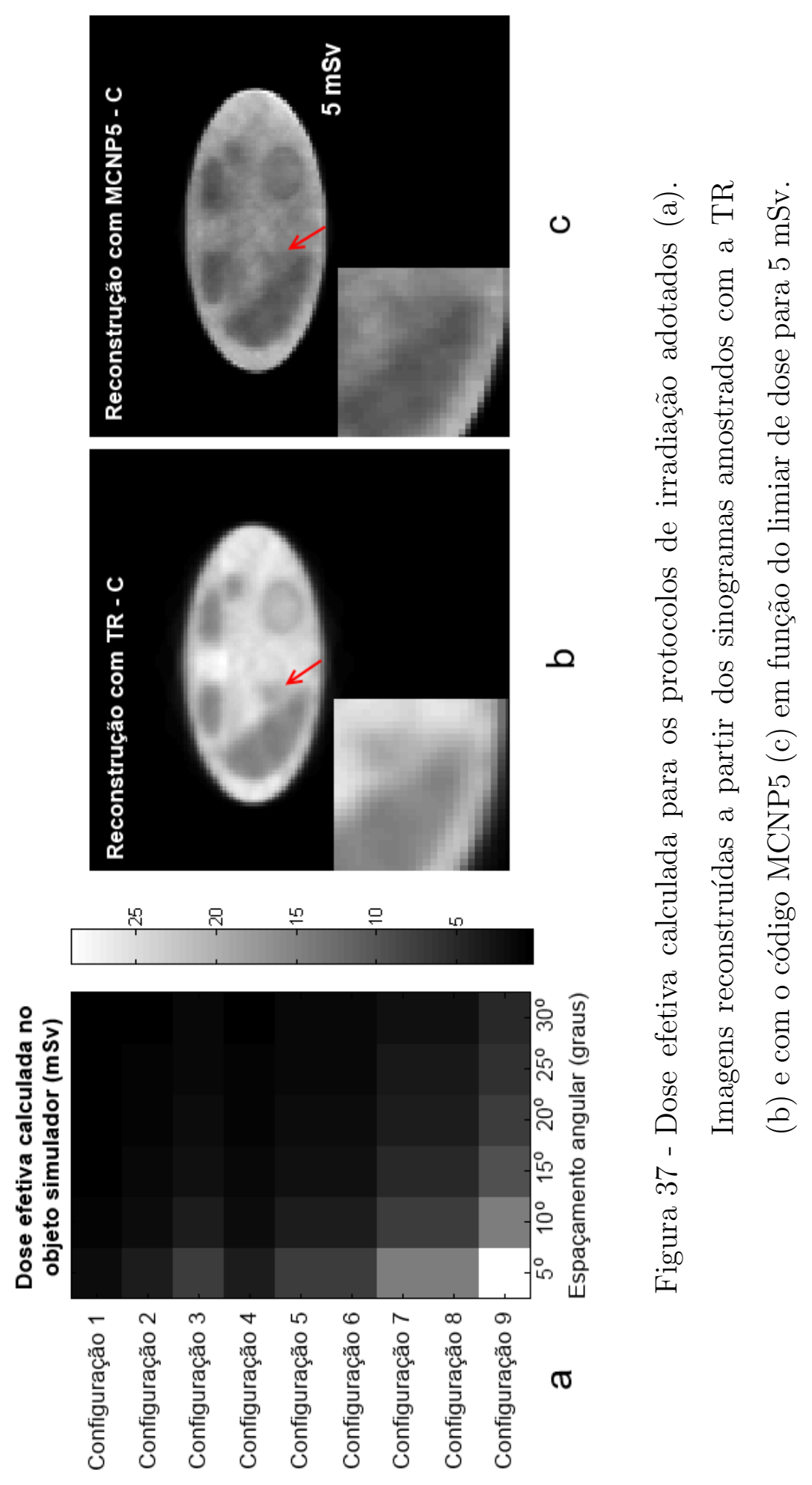




\subsubsection{Implementação do método: avaliação dosimétrica e as imagens de referência}

O emprego do método desenvolvido requer a aquisição de imagens de referências que simulam a distribuição da concentração dos elementos de interesse entre os tecidos de acordo com os valores de pixel. Ainda, como apresentado previamente, a avaliação dosimétrica associada aos protocolos de irradiação podem ser usados para restringir a dose efetiva e ainda garantir a qualidade de reconstrução. Estes dois requisitos devem ser, a priori, atendidos para que otimização da amostragem do sinograma possa ser explorada e empregada em qualquer meio irradiado de interesse.

A avaliação dosimétrica pode ser realizada empregando simulações com o método Monte Carlo aplicadas em um meio espalhador padrão onde os protocolos de irradiação são reproduzidos. Dessa forma, pode-se obter um banco de dados dosimétrico de acordo com a energia e a configuração de amostragem do feixe de nêutrons empregado.

Por se tratar de um método aplicado na aquisição de imagens médicas, o procedimento proposto para a otimização do sinograma deve ser conduzido de forma personalizada para cada meio a ser reconstruído, inclusive no mesmo indivíduo. Uma alternativa para satisfazer esta condição consiste em empregar imagens de CT da região anatômica de interesse na aquisição das imagens de referência.

De acordo com Schneider et al. (2000), os números de Hounsfield das imagens de CT podem ser empregados para se obter uma estimativa da composição e densidade dos tecidos irradiados. Com base nesta pesquisa, Massicano et al. (2011) desenvolveram o software ICCT (Image Conveter for Computer Tomography) para estimar a composição dos principais tecidos do corpo humano utilizando funções de interpolação entre o número de Hounsfield com a densidade e peso elementar teórico dos elementos nos tecidos. Desta forma, as imagens de referência podem ser obtidas a partir das imagens de CT para os elementos identificados pelo ICCT, 
preservando assim a informação anatômica dos órgãos reconstruídos e a distribuição da concentração dos elementos imageados. 


\section{CONCLUSÕES}

De acordo com os objetivos propostos, esta tese apresenta duas novas aplicações de diagnóstico para técnica NSECT considerando suas abordagens espectroscópica e tomográfica. Além das aplicações propostas, uma metodologia original foi desenvolvida para otimizar a amostragem do sinograma, permitindo que a qualidade de reconstrução, por sua vez dependente do protocolo de irradiação, seja avaliada por meio da similaridade entre as imagens reconstruídas e as imagens de referência de acordo com o elemento avaliado.

A detecção de microcalcificações mamárias por meio da análise do espectro de emissão para as energias que identificam o elemento Ca apontam que a técnica NSECT é capaz de identificar lesões isoladas a partir de $3 \mathrm{~mm}$ de diâmetro assim como um agrupamento de microcalcificações. Considerando que naturalmente são detectadas múltiplas lesões com diferentes diâmetros (e formas), a informação provida pelo espectro de emissão auxilia na detecção e possível diagnóstico devido ao limiar observado. Ainda nesta aplicação, a dose absorvida calculada mostra que a implementação da técnica é dependente da intensidade da fonte de nêutrons considerando respectivamente o limite de dose e o tempo de exposição. Outro resultado também associado à dosimetria na espectroscopia é que o feixe colimado deposita a energia no meio irradiado predominantemente ao longo de sua projeção. Dessa forma, órgãos distantes do caminho de projeção do feixe podem receber uma dose cerca de 150 vezes menor do que aqueles estão sendo irradiados diretamente.

A técnica NSECT também foi aplicada para o diagnóstico de Carcinoma de Célula Renal (CCR). Ainda em sua abordagem espectroscópica, a composição de tecidos renais humanos foi avaliada utilizando os espectros de emissão, 
onde foi identificado a diferença dos tecidos através dos picos de emissão referentes aos elementos Ca e P. Outros elementos também foram identificados cuja a concentração, proporcional à altura de pulso, também se apresentou diferente entre os tecidos. Com os resultados obtidos, constatou-se a viabilidade de se utilizar a reação $(n, n ')$ em identificar e diferenciar a concentração de elementos no meio irradiado, sendo este o cerne da técnica NSECT.

O diagnóstico de CCR também foi explorado por meio da abordagem tomográfica da técnica NSECT. Dois métodos de aquisição foram empregados considerando o mesmo objeto simulador e composição de CCR. O primeiro consiste em um sistema tomográfico inspirado nos modelos de primeira geração e o segundo compreende um avanço tecnológico para NSECT onde o tempo de detecção dos fótons é associado com o tempo de voo do nêutron, permitindo assim com que os sítios de emissão de fótons sejam localizados em profundidade ao longo da projeção do feixe.

As imagens adquiridas por ambos os métodos compartilham as mesmas características. O sistema tomográfico foi capaz de diferenciar os tecidos renais de acordo com a tendência de concentração do elementos Na, P e K. Entretanto, a quantificação não foi realizada de forma acurada devido ao limite de detecção, ainda não avaliado para esta aplicação de diagnóstico. Mesmo apresentando resultados similares, a tomografia de emissão associada ao tempo de voo do nêutron figura como um novo método de aquisição para a NSECT, cuja a dose efetiva é reduzida devido ao número de projeções do feixe envolvido na aquisição tomográfica. Entretanto, sua aplicação pode ser limitada de acordo com a energia dos isótopos de interesse devido à resolução energética dos detectores.

Por último, o método proposto para a otimização dos sinogramas empregados na NSECT apresentou potencial para aplicação devido aos resultados obtidos na avaliação da qualidade de reconstrução e dose efetiva em função da taxa de amostragem. Entretanto, futuras pesquisas devem ser conduzidas para estimar o limiar de detecção, uma vez que as imagens dos elementos presentes em baixa concentração não foram reproduzidas acuradamente durante o procedimento de va- 
lidação.

Em suma, os resultados obtidos e as conclusões apresentadas comprovam o potencial de diagnóstico pela NSECT. Em contraste com outras técnicas de diagnóstico, como a biópsia e tomografia computadorizada, a identificação e diferenciação entre tecidos pode ser realizada in vivo ao mesmo tempo que o mapeamento da distribuição isotópica dos isótopos de interesse é obtido. Desta forma, possíveis falhas na detecção de lesões por outras modalidades de imageamento são descartadas, uma vez que a informação sobre a fisiologia e anatomia do meio irradiado é adquirida pela mesma técnica e no mesmo conjunto de dados.

\subsection{Perspectivas de novas pesquisas}

A técnica NSECT foi apresentada à comunidade acadêmica em 2006 e desde então vem sendo desenvolvida, tanto para novas aplicações no diagnóstico clínico, quanto em avanços tecnológicos relacionados ao tempo de exposição e redução de dose efetiva. Entretanto, considerando a implementação da NSECT, a configuração e otimização do sistema tomográfico ainda requer novas pesquisas, através de simulações computacionais e experimentos, tais como as relacionadas com o efeito da blindagem e posicionamento do sistema de detecção no sinal detectado.

Em complemento ao estudo desenvolvido explorando a detecção e diagnóstico de CCR, a variabilidade da composição tecidual renal depende das condições ambientais em que o indivíduo está exposto, bem como de seus hábitos alimentares. Como consequência destas características, os estudos disponíveis na literatura apresentam composições elementares para a mesma patologia onde diferentes elementos são elegidos como indicadores do estado patológico. Com base nos resultados apresentados nesta tese e o potencial do diagnóstico pela NSECT, um estudo controlado deve ser conduzido utilizando cobaias, onde fatores como ambiente e alimentação não interfiram na composição dos tecidos renais. Desta forma, a composição tecidual pode ser quantificada sem a influência de fatores externos. Dessa forma, a simulação do diagnóstico de CCR pela NSECT, ainda que em fase precur- 
sora, deve identificar e eleger os isótopos relacionados apenas com o desenvolvimento da patologia.

Outra linha de pesquisa que deve ser seguida no futuro é o estudo de biomarcadores que possam ser empregados na NSECT para alterar localmente a concentração de elementos de interesse. Como observado nos resultados apresentados, os objetivos propostos foram atingidos com sucesso. Entretanto, assim como em qualquer outra técnica capaz de quantificar elementos ou compostos biológicos, o limiar de detecção exerce um papel fundamental na aplicação da NSECT. Caso a concentração de elementos de interesse seja elevada localmente nos órgãos ou tecidos alvo, o limiar de detecção pode ser elevado, tornando possível uma combinação de padrões de concentração dos elementos entre os órgãos irradiados. 


\title{
Anexo A
}

\author{
unesp UNVERSIADE ESTADUAL PAULISTA \\ Câmpus de Botucatu
}

TERMO DE CONSENTIMENTO LIVRE E ESCLARECIDO

\begin{abstract}
$\mathrm{Eu} \longrightarrow$ dou autorização ao corpo clínico do Hospital das Clínicas de realizar as investigações que se julgarem necessárias ao diagnóstico da sua doença ou como qualquer tratamento médico ou cirúrgico. Autorizo também a utilização de parte da lesão renal para pesquisa cientifica que será realizada no Serviço de Urologia.

Todas as informações sobre o procedimento serão fornecidas e o participante terá liberdade em qualquer etapa do estudo em desligar-se. Será mantido o sigilo de identidade e os dados estarão disponíveis somente aos pesquisadores e às entidades envolvidas.
\end{abstract} concordo voluntariamente em participar dos procedimentos de avaliação, os quais fui devidamente esclarecido.

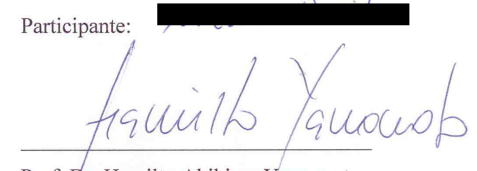

Prof. Dr. Hamilto Akihissa Yamamoto

Data: 06/07/2010. Faculdade de Medicina de Botucatu - Departamento de Urologia
Distrito de Rubiäo Júnior, s/n CEP 18618-970 Botucatu São Paulo Brasi TSTrt 55143811000 s

* O nome do paciente foi omitido para preservar sua privacidade. 


\section{REFERÊNCIAS BIBLIOGRÁFICAS}

ACR. Mammography Quality Control Manual, Committee on Quality Assurance in Mammography - American College of Radiology (ACR), 1999.

AGASTHYA, G. Low-dose imaging of liver diseases through neutron stimulated emission computed tomography: Simulations in GEANT4, 2013. Tese (Doutorado) - Duke University.

AGASTHYA, G.; KAPADIA, A. Locating stored iron in the liver through attenuation measurement in NSECT. In: , 2009. Nuclear Science Symposium Conference Record (NSS/MIC), 2009 IEEE; resumos. , 2009. 2419-2422.

AGASTHYA, G. A.; HARRAWOOD, B. C.; SHAH, J. P.; KAPADIA, A. J. Sensitivity analysis for liver iron measurement through neutron stimulated emission computed tomography: a Monte Carlo study in GEANT4. Physics in Medicine and Biology, v.57, n.1, p.113, 2012.

ALTEKIN, E.; COKER, C.; SISMAN, A. The relationship between trace elements and cardiac markers in acute coronary syndromes. J. Trace Elem. Med. Biol., v.18, p.235-242, 2005.

BENDER, J. E.; KAPADIA, A. J.; SHARMA, A. C.; TOURASSI, G. D.; HARRAWOOD, B. P.; FLOYD, C. E. Breast cancer detection using neutron stimulated emission computed tomography: prominent elements and dose requirements. Med Phys, v.34, n.10, p.3866-71, 2007. 
CAHILL, N. Normalized Measures of Mutual Information with General Definitions of Entropy for Multimodal Image Registration. Biomedical Image Registration, v.6204, p.258-268, 2010.

CAlvO, F.; SANTOS, D.; RODRIGUES, C.; KRUG, F.; MARUMO, J.; SCHOR, N.; BELLINI, M. Variation in the Distribution of Trace Elements in Renal Cell Carcinoma. Biological Trace Element Research, v.130, n.2, p.107-113, 2009.

CHEWPRADITKUL, W.; MOSZYNSKI, M. Scintillation Properties of $\operatorname{Lu}_{3} \mathrm{Al}_{5} \mathrm{O}_{12}$, $\mathrm{Lu}_{2} \mathrm{SiO}_{5}$ and $\mathrm{LaBr}_{3}$ Crystals Activated with Cerium. In: , 2011. ; resumos. International Conference on Physics Science and Technology, 2011. 218-226.

CHMIELNICKA, J.; NASIADEK, M. The trace elements in response to lithium intoxication in renal failure. Ecotoxicology and Environmental Safety, v.55, n.2, p.178-183, 2003.

COHEN, H. T.; MCGOVERN, F. J. Renal-Cell Carcinoma. New England Journal of Medicine, v.353, n.23, p.2477-2490, 2005.

CRISTY, M.; ECKERMAN, F. Specific Absorbed Fractions of Energy at Various Ages from Internal Photon Sources. I. Methods. Oak Ridge National Laboratory - Report ORNL/TM-8381/VI, 1987.

DEMPSTER, A.; LAIRD, N.; RUBIN, D. Maximum Likelihood from Incomplete Data via the EM Algorithm. Journal of the Royal Statistical Society, Series B, v.39, n.1, p.1-38, 1977.

DINELEY, J. Neutrons identify kidney cancer, $2013 . \quad$ URL: http://medicalphysicsweb.org/cws/article/research/54703.

FLOYD, C.; SHARMA, S.; BENDER, J.; KAPADIA, A.; XIA, J.; HARRAWOOD, B.; TOURASSI, G.; LO, J.; KISER, M.; CROWELL, A.; PEDRONI, R.; MACRI, R.; TAJIMA, S.; HOWELL, C. Neutron stimulated emission computed tomography: 
Background corrections. Nuclear Instruments and Methods in Physics Research Section B: Beam Interactions with Materials and Atoms, v.254, n.2, p.329 - 336, 2007.

FLOYD, C. E.; BENDER, J. E.; SHARMA, A. C.; KAPADIA, A.; XIA, J.; HARRAWOOD, B.; TOURASSI, G. D.; LO, J. Y.; CROWELL, A.; HOWELL, C. Introduction to neutron stimulated emission computed tomography. Phys Med Biol, v.51, n.14, p.3375-90, 2006.

GLODO, J.; MOSES, W.; HIGGINS, W.; VAN LOEF, E. V. D.; WONG, P.; DERENZO, S.; WEBER, M.; SHAH, K. Effects of Ce concentration on scintillation properties of LaBr3:Ce. Nuclear Science, IEEE Transactions on, v.52, n.5, p.1805-1808, 2005.

GUO, P.; ADAMOVICS, J.; OLDHAM, M. A practical three-dimensional dosimetry system for radiation therapy. Medical Physics, v.33, n.10, 2006.

HAKANSSON, P. An Introduction to the Time-of-Flight Technique. Braz.J.Phys., v.29, p.422-427, 1999 .

HALLGRIMSSON, P.; KARESEN, R.; ARTUN, K.; SKJENNALD, A. Non-palpable breast lesions. Diagnostic criteria and preoperative localization. Acta Radiol, v.29, p.285-2888, 1988.

HEINRICH, M.; JENKINSON, M.; BHUSHAN, M.; MATIN, T.; GLEESON, F.; BRADY, S.; SCHNABEL, J. MIND: Modality independent neighbourhood descriptor for multi-modal deformable registration. Medical Image Analysis, v.16, p.1423-1435, 2012.

ICRP103. The 2007 Recommendations of the International Commission on Radiological Protection - Report 103. International Commission on Radiological Protection, 2007. 
ICRP110. Adult Reference Computational Phantoms: Annals of the ICPR

- Report 110. International Commission on Radiological Protection, 2009.

ICRU. Photon, Electron, Proton and Neutron Interaction Data for Body Tissues - Report 46. International Commission on Radiation Units and Measurements, 1992.

INCA. Instituto Nacional do Câncer, Estimativa 2014 - Incidência de Câncer no Brasil, 2014. URL: http://www.inca.gov.br.

JOSEPH, P. M.; SPITAL, R. D.; STOCKHAM, C. D. The effects of sampling on $\{\mathrm{CT}\}$ images. Computerized Tomography, v.4, n.3, p.189 - 206, 1980.

KAK, A. C.; SLANEY, M. Principles of Computerized Tomographic Imaging. Society for Industrial and Applied Mathematics, 2001.

KALAMBET, Y.; KOZMIN, Y.; MIKHAILOVA, K.; NAGAEV, I.; TIKHONOV, P. Reconstruction of chromatographic peaks using the exponentially modified Gaussian function. Journal of Chemometrics, v.25, n.7, p.352-356, 2011.

KAPADIA, A. Accuracy and Patient Dose in Neutron Stimulated Emission Computed Tomography for Diagnosis of Liver Iron Overload: Simulations in GEANT4, 2007. Tese (Doutorado) - Duke University.

KAPADIA, A.; CROWEll, A.; FAllin, B.; HOWEll, C.; AGASTHYA, G.; LAKSHMANAN, M.; NEWTON, J.; JUANG, T.; OLDHAM, M. SU-E-T-108: 3D Measurement of Neutron Dose from a Novel Neutron Imaging Technique. Medical Physics, v.39, n.6, 2012.

KAPADIA, A.; FLOYD, C. J.; BENDER, J.; HOWELL, C.; CROWELL, A.; KISER, M. Non-invasive quantification of iron isup ¿56i/sup ¿Fe in beef liver using neutron stimulated emission computed tomography. In: , 2005. Nuclear Science Symposium Conference Record, 2005 IEEE; resumos. , 2005. 2232-2234. 
KAPADIA, A.; SHAH, J.; AGASTHYA, G. Quantitative elemental imaging with neutrons for breast cancer diagnosis: A GEANT4 study. In: , 2010. Nuclear Science Symposium Conference Record (NSS/MIC), 2010 IEEE; resumos., 2010. 3065-3068.

KAPADIA, A.; SHARMA, A.; TOURASSI, G.; BENDER, J.; CROWELL, A.; KISER, M.; HOWELL, C.; FLOYD, C. J. Neutron Stimulated Emission Computed Tomography (NSECT) for Early Detection of Breast Cancer. In: , 2006a. Nuclear Science Symposium Conference Record, 2006. IEEE; resumos. , 2006a. 39283931.

KAPADIA, A.; SHARMA, A.; TOURASSI, G.; BENDER, J.; CROWELL, A.; KISER, M.; HOWELL, C.; FLOYD, C. J. Non-Invasive Estimation of Potassium $(39 \mathrm{~K})$ in Bovine Liver Using Neutron Stimulated Emission Computed Tomography (NSECT). In: , 2006b. Nuclear Science Symposium Conference Record, 2006. IEEE; resumos. , 2006b. 2076-2078.

KAPADIA, A. J.; TOURASSI, G. D.; SHARMA, A. C.; CROWELL, A. S.; KISER, M. R.; HOWELL, C. R. Experimental detection of iron overload in liver through neutron stimulated emission spectroscopy. Phys Med Biol, v.53, n.10, p.2633-49, 2008 .

KHADER, M.; HAMZA, A. B. An information-theoretic method for multimodality medical image registration. Expert Systems with Applications, v.39, p.5548$5556,2012$.

KIM, J.; CHO, J.; MOON, K.; LEE, H.; KIM, S. Segmental enhancement inversion at biphasic multidetector CT: characteristic finding of small renal oncocytoma. Radiology, v.252, p.441-448, 2009.

KIM, J.; KIM, J.; KIM, N.; K CHO. RADIOLOGY, 246, .-. CT histogram analysis: differentiation of angiomyolipoma without visible fat from renal cell carcinoma at CT imaging. Radiology, v.246, p.472-479, 2008. 
KING, L. Absorption problems in radioactivity. Philosophical Magazine Series 6, v.23, n.134, p.242-250, 1912.

KUHN, A.; SURTI, S.; SHAH, K.; KARP, J. Investigation of LaBr3 detector timing resolution. In: , 2005. Nuclear Science Symposium Conference Record, 2005 IEEE; resumos. , 2005. 5 pp.-.

LISKIEN, H.; PAULSEN, A. Neutron production cross sections. Nuclear Data Tables, v.11, p.568-619, 1973.

MASSICANO, F.; POSSANI, R.; CINTRA, F.; MASSICANO, A.; YORIYAZ, H. Influence of elemental weight of human tissues estimated by ICCT software in absorbed dose calculation. Rev. Bras. Fis. Med., v.5, p.127-132, 2011.

MATLAB. MATLAB version 8.0 - R2012b. Natick, Massachusetts, The MathWorks Inc, 2012.

MCLACHLAN, G.; KRISHNAN, T. The EM algorithm and Extensions. United States of America: Wiley-Interscience and Sons, 2007.

MCNITT-GRAY, M. F. AAPM/RSNA Physics Tutorial for Residents: Topics in CT: Radiation Dose in CT1. Radiographics, v.22, n.6, p.1541-1553, 2002.

MCNP5. MCNP - A General N-Particle Transport Code, Version 5, Volume I: Overview and Theory LA-UR-03-1987. Los Alamos National Laboratory, 2003.

MILlET, I.; DOYON, F.; HOA, D.; S, R. T.; MERIGEAUD, S.; SERRE, I.; TAOUREL, P. Characterization of small solid renal lesions: can benign and malignant tumors be differentiated with CT? AJR Am J Roentgenol, v.197, p.887-896, 2011.

MOON, W.; KOH, F. I. Y.; NOH, D.; PARK, I. US of mammographically detected clustered microcalcifications. Radiology, v.217, p.849-854, 2000. 
MORGAN, M.; COOKE, M.; ; MCCARTHY, M. Microcalcifications associated with breast cancer: an epiphenomenon or biologically significant feature of selected tumors? J Mammary Gland Biol Neoplasia, v.10, p.181-187, 2005.

NUDAT2.6. National Nuclear Data Center, Brookhaven National Laboratory, 2014. URL: http://www.nndc.bnl.gov/nudat2/.

OLDHAM, M. 3D dosimetry by optical-CT scanning. J Phys Conf Ser, v.56, p.58-71, 2006.

PLUIM, J.; MAINTZ, J.; VIERGEVER, M. Mutual-information-based registration of medical images: a survey. Expert Systems with Applications, v.22, p.9861004, 2003.

RIZK, L.; SKY-PECK, H. Comparison between concentrations of trace elements in normal and neoplastic human breast tissue. Cancer Res., v.44, p.5390-5394, 1984.

RSNA. Patient Safety: Radiation Dose in X-Ray and CT Exams, American College of Radiology (ACR) and the Radiological Society of North America (RSNA), 2014.

SALOMOM, A.; BEITRAGE, Z. Pathologie der mamacarcinome. Arch Klin Chir, v.101, p.572-668, 1913.

SBU. Sociedade Brasileira de Urologia, Estudo Nacional sobre o Câncer Renal, 2014. URL: http://www.sbu.org.br/.

SCHNEIDER, W.; BORTFELD, T.; SCHLEGEL, W. Correlation between CT number and tissue parameters needed for Monte Carlo simulations of clinical dose distributions. Phys Med Biol, v.45, p.459-478, 2000.

SCHWARZ, G. Estimating the Dimension of a Model. The Annals of Statistics, v.6, n.2, p.461-464, 1978.

SHANNON, C. A mathematical theory of communication. Bell system technical journal, v.27, 1948. 
SOMPEL, D.; BRADY, M. Regularising limited view tomography using anatomical reference images and information theoretic similarity metrics. Med Image Anal, v.16, p.278-300, 2012.

STEDMAN, J.; SPYROU, N. Major and trace element concentration differences between the right and left hemispheres of the "normal' human brain. Nutrition, v.11, n.5, p.542-545, 1995.

STUDHOLME, C.; HILL, D.; HAWKES, D. An overlap invariant entropy measure of 3D medical image alignment. Pattern Recognition, v.32, p.71-86, 1999.

STUTTLE, M.; GALES, M. Combining A Gaussian Mixture Model Front End With Mfcc Parameters. In: , 2002. In Proceedings ICSLP; resumos. , 2002. 1565-1568.

TABAR, L.; CHEN, H.; DUFFY, S.; YEN, M.; CHIANG, C.; DEAN, P.; SMITH, R. A novel method for prediction of long-term outcome of women with T1a, T1b, and 10-14 mm invasive breast cancers: a prospective study. Rev. Bras. Fis. Med., v.355, p.429-433, 2000.

VERMA, S.; MITCHELL, D.; YANG, R.; ROTH, C.; O’KANE, P.; VERMA, M.; PARKER, L. Exophytic renal masses: angular interface with renal parenchyma for distinguishing benign from malignant lesions at MR imaging. Radiology, v.255, p.501-507, 2010 .

VIANA, R.; YORIYAZ, H. NSECT applied to the assessment of calcium deposition due to the presence of microcalcifications associated with breast cancer. Rev. Bras. Fis. Med., v.5, p.41-46, 2011.

VIANA, R. S.; AGASTHYA, G. A.; YORIYAZ, H.; KAPADIA, A. J. 3D element imaging using NSECT for the detection of renal cancer: a simulation study in MCNP. Phys Med Biol, v.58, n.17, p.5867-83, 2013.

VIOLA, P.; WELLS, W. Alignment by maximisation of mutual information. In: , 1995. ; resumos. Proc. 5th Int. Conf. on Computer Vision, 1995. 15-23. 
VUNCKX, K.; ATRE, A.; BAETE, K.; REILHAC, A.; DEROOSE, C.; LAERE, K. V.; NUYTS, J. Evaluation of three MRI-based anatomical priors for quantitative PET brain imaging. IEEE Trans Med Imaging, v.31, p.599-612, 2012.

ZHANG, S.; WANG, Y. An approach to positron emission tomography based on penalized cross-entropy minimization. Signal Process, v.81, p.1069-1074, 2001. 


\section{APÊNDICES}

\section{Apêndice A}

\section{Estimador de Máxima Verossimilhança}

Considere $f(x ; \Theta)$ como sendo a função de densidade de probabilidade (fdp) de uma variável aleatória avaliada no ponto $x$, em que $\Theta$ é um parâmetro ou um vetor de parâmetros da fdp.

Seja $X_{1}, X_{2}, \ldots, X_{n}$ uma amostra aleatória de tamanho $n$ da variável aleatória $X$ e $x_{1}, x_{2}, \ldots, x_{n}$ os valores amostrais. A função de verossimilhança $L$ é dependente da própria amostra e do parâmetro $\Theta$, sendo definida como:

$$
L\left(\Theta ; x_{1}, \ldots, x_{n}\right)=f\left(x_{1} ; \Theta\right) f\left(x_{2} ; \Theta\right) \ldots f\left(x_{n} ; \Theta\right)=\prod_{i=1}^{n} f\left(x_{i} ; \Theta\right) .
$$

A estimativa de máxima verossimilhança de $\Theta$, denotada por $\hat{\Theta}$, é o valor de $\Theta$ que torna máxima a função $L\left(\Theta ; x_{1}, \ldots, x_{n}\right)$. Este valor pode ser obtido maximizando-se o logaritmo de $L\left(\Theta ; x_{1}, \ldots, x_{n}\right)$ já que a função log é monótona, de tal modo que $\log L\left(\Theta ; x_{1}, \ldots, x_{n}\right)$ alcançará seu valor máximo para o mesmo $\Theta$ que o fará com $L\left(\Theta ; x_{1}, \ldots, x_{n}\right)$. Por isso, sob condições gerais, admitindo-se que $\Theta$ seja um 
número real e que $L\left(\Theta ; x_{1}, \ldots, x_{n}\right)$ seja uma função derivável em $\Theta$, a estimativa de $\hat{\Theta}$ é obtida através da resolução de:

$$
\frac{\partial}{\partial \Theta} \log L\left(\Theta ; x_{1}, \ldots, x_{n}\right)=0
$$

que é conhecida como equação de verossimilhança.

Caso a estimativa seja feita para múltiplos parâmetros, a equação 14 deve ser utilizada considerando as derivadas parciais sob cada parâmetro. Portanto, as soluções das equações serão obtidas individualmente, de forma que para $\Theta=(\alpha, \beta)$ temos:

$$
\begin{aligned}
& \frac{\partial}{\partial \alpha} \log L\left(\alpha, \beta ; x_{1}, \ldots, x_{n}\right)=0 \\
& \frac{\partial}{\partial \beta} \log L\left(\alpha, \beta ; x_{1}, \ldots, x_{n}\right)=0
\end{aligned}
$$

\section{Apêndice B}

\section{Conceitos básicos do Algoritmo EM}

O algoritmo EM (Expectation Maximization) é visto como uma abordagem amplamente empregada na estimação de máxima verossimilhança quando as observações são interpretadas como dados incompletos. Neste contexto, devido à natureza da grandeza de interesse ou ao método de amostragem, o vetor de dados observados y é considerado como incompleto, sendo uma função observável do então denominado vetor de dados completos $x$. Em linhas gerais, o termo dados incompletos se aplica em situações onde nem todos os dados disponíveis são observados, sendo denominados dados não observados $z$. Deste modo, $x=(y, z)$. 
Seja $Y$ uma variável aleatória correspondente ao vetor de dados observados y com uma fdp descrita por $g(y, \Psi)$, onde $\Psi$ é o vetor de parâmetros desconhecidos com espaço paramétrico $\omega$. Considere agora $g_{c}(x, \Psi)$ como a fdp da variável aleatória $X$ correspondente ao vetor de dados completos $x$. O logaritmo da função de verossimilhança dos dados completos, dependente de $\Psi$, se $x$ fosse completamente observável é dado por $\log L_{c}(\Psi)=\log g_{c}(x, \Psi)$. Entretanto, uma vez que $x$ não é completamente observável, devido a relação entre os dados completos e incompletos, o logaritmo da função de verossimilhança é calculado em termos do vetor de dados incompletos $y$ através da esperança condicional de $x$ dado $y$ e atualizado iterativamente.

Cada iteração do algoritmo EM envolve duas etapas: a etapa do cálculo da esperança de $\log L_{c}(\Psi)$ (E-step) e a etapa de maximização da esperança (M-step). O algoritmo EM é iniciado com $\Psi^{(0)}$ como valor inicial para $\Psi$. Em seguida, as duas etapas são executadas recursivamente atualizando a estimativa de $\Psi$ na iteração seguinte.

1. E-step

Utilizando $\Psi^{(0)}$ como a estimativa inicial para o algoritmo, a primeira etapa requer o cálculo da seguinte expressão:

$$
Q\left(\Psi, \Psi^{(0)}\right)=E_{\Psi^{(0)}}\left\{\log L_{c}(\Psi) \mid y\right\}
$$

\section{M-step}

A segunda etapa é então adotada para maximizar o valor da equação 17 com respeito a $\Psi$ sob o espaço paramétrico $\omega$. Este procedimento é realizado analogamente à expressão 14, porém o mesmo é conduzido de forma iterativa, tal que:

$$
Q\left(\Psi^{(1)}, \Psi^{(0)}\right) \geq Q\left(\Psi, \Psi^{(0)}\right)
$$


Ao final desta etapa, a convergência do algoritmo é testada pela diferença entre as estimativas obtidas em iterações consecutivas, tal que $\xi=\Psi^{(k+1)}-\Psi^{(k)}$ é um valor pré-definido.

A prova de convergência do algoritmo EM e outras informações podem ser encontradas em Dempster et al. (1977).

\section{Apêndice C}

\section{Modelo de Mistura Gaussiana}

Sejam $x=\left(x_{1}, x_{2}, \ldots, x_{n}\right)$ uma amostra de com $n$ observações independentes de uma mistura de $J$ distribuições normais univariadas e $z=\left(z_{1}, z_{2}, \ldots, z_{n}\right)$ as variáveis de indicação que determinam qual componente da mistura gerou a observação. A densidade de probabilidade marginal da variável aleatória $X$ é expressa como:

$$
p(x ; \Theta)=\sum_{j=1}^{J} \pi_{j} f\left(x \mid \Theta_{j}\right) .
$$

$\pi$ denota o vetor de proporções desconhecidas entre as gaussianas da mistura que geraram a observação, tal que $\sum_{j=1}^{J} \pi_{j}=1$ e $f\left(x \mid \Theta_{j}\right)$ é a função de densidade de probabilidade normal com os parâmetros desconhecidos dados por $\Theta_{j}=\left(\mu_{j}, \sigma_{j}^{2}\right)$.

Logo, utilizando a definição apresentada na equação 13, a função de verossimilhança baseada nos dados observados é dada por:

$$
L(\Theta ; y)=\prod_{i=1}^{n} \sum_{j=1}^{J} I\left(z_{i}=j\right) \pi_{j} f\left(x_{i} \mid \mu_{j}, \sigma_{j}^{2}\right),
$$

em que $I\left(z_{i}=j\right)=1$ se $z_{i}=j$ e zero caso contrário e $\Theta=\left(\Theta_{1}, \Theta_{2}, \ldots, \Theta_{J}\right)$. 
Assumindo que $x_{i} \sim N\left(\mu_{j}, \sigma_{j}^{2}\right)$, a expressão 20 pode ser então reescrita para simplificar as operações como:

$$
L(\Theta ; y)=\exp \left\{\sum_{i=1}^{n} \sum_{j=1}^{J} I\left(z_{i}=j\right)\left[\ln \left(\pi_{j}\right)-\frac{1}{2}\left(\ln \sigma_{j}^{2}-\frac{\left(x_{i}-\mu_{j}\right)^{2}}{\sigma_{j}^{2}}-\ln 2 \pi\right)\right]\right\} .
$$

Uma vez calculada a função de verossimilhança 21, as etapas do algoritmo EM, empregado na estimação do vetor $\Theta$, podem ser descritas como segue:

1. E-step

Dada a estimativa atual dos parâmetros em $\Theta^{k}$, em que $k$ corresponde ao número de iterações do algoritmo, a distribuição condicional de $Z_{i}$, pelo Teorema de Bayes, é a proporção penalizada da densidade normal, dada por:

$$
T_{j, i}^{k}=P\left(Z_{i}=j \mid X_{i}=x_{i} ; \Theta^{k}\right)=\frac{\pi_{j}^{k} f_{j}\left(x_{i} \mid \Theta^{k}\right)}{\sum_{j=1}^{J} \pi_{j}^{k} f_{j}\left(x_{i} \mid \Theta^{k}\right)} .
$$

Desta forma, a expressão resultante no E-step é:

$Q\left(\Theta \mid \Theta^{k}\right)=E[\log (L(\Theta ; y))]=\sum_{i=1}^{n} \sum_{j=1}^{J} T_{j, i}^{k}\left[\log \pi_{j}-\frac{1}{2}\left(\log \sigma_{j}^{2}-\frac{\left(x_{i}-\mu_{j}\right)^{2}}{\sigma_{j}^{2}}-\log 2 \pi\right)\right]$.

\section{M-step}

Considerando $k$ interações, na etapa de maximização é necessário a obtenção do argumento que maximiza $Q\left(\Theta \mid \Theta^{k}\right)$, ou seja:

$$
\left(\pi_{j}^{(k+1)}, \sigma_{j}^{2(k+1)}, \mu_{j}^{(k+1)}\right)=\operatorname{argmax}_{\Theta}\left\{Q\left(\Theta \mid \Theta^{k}\right)\right\}
$$

Sendo assim, a maximização de $Q\left(\Theta \mid \Theta^{k}\right)$ pode ser realizada pelo procedimento descrito na equação 14, resultando em:

$$
\pi_{j}^{(k+1)}=\frac{1}{n} \sum_{i=1}^{n} T_{j, i}^{(k)}
$$




$$
\begin{gathered}
\mu_{j}^{(k+1)}=\frac{\sum_{i=1}^{n} x_{i} T_{j, i}^{(k)}}{\sum_{i=1}^{n} T_{j, i}^{(k)}}, \\
\sigma_{j}^{2(k+1)}=\frac{\sum_{i=1}^{n} T_{j, i}^{(k)}\left(x_{i}-\mu_{j}^{(k+1)}\right)^{2}}{\sum_{i=1}^{n} T_{j, i}^{(k)}} .
\end{gathered}
$$

\section{Apêndice D}

\section{Entropia e Informação Mútua Normalizada}

De acordo com a Teoria de Informação, inicialmente proposto por Shannon (1948), a quantidade de informação trocada em um sistema de comunicação é dependente da variabilidade da mensagem. Uma das medidas mais comuns encontradas na literatura para quantificar a variabilidade da informação contida no sistema é baseada na formulação da equação de Boltzmann para o cálculo da entropia. Nesta formulação a variabilidade da informação é proporcional a quantidade de informação disponível no sistema de comunicação.

Seja a mensagem expressa pelo vetor $t$ composto por $k$ elementos $e_{1}, e_{2}, \ldots, e_{k}$ com probabilidades de ocorrência $q_{1}, q_{2}, q_{3}, \ldots, q_{k}$ dado pelo histograma de $t$. Neste caso, a entropia $H$ é calculada por:

$$
H=-\sum_{i=1}^{k} q_{i} \log q_{i} .
$$

Por considerar a mensagem e sua probabilidade de ocorrência, o cálculo da entropia $H$ pode exprimir a incerteza com que a mensagem é transmitida. Em linhas gerais, a dispersão da probabilidade de ocorrência $q$ na equação 28 pode ser compreendida como um indicador da incerteza contida na mensagem. A Figura 38 
exemplifica este conceito apresentando três conjuntos de números aleatórios normalmente distribuídos com médias iguais e variâncias diferentes.

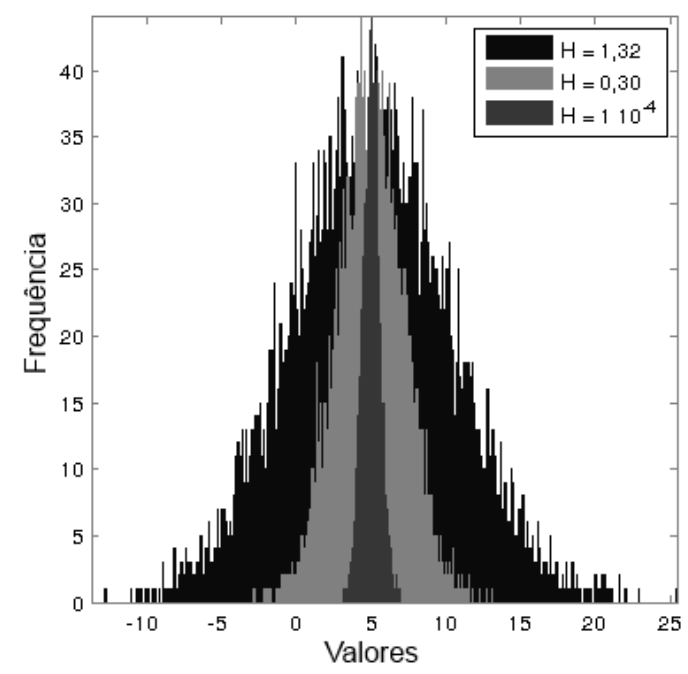

Figura 38 - Entropia $H$ em função da variabilidade da informação.

Como os três conjuntos de dados foram gerados com a mesma média $(\mu=5)$, a dispersão dos dados em torno do valor central expressa a variabilidade observada, tal que quanto maior a dispersão, maior a entropia $H$. Logo, a menor entropia é associada a menor incerteza, o que coincide com a distribuição gerada com a menor variância.

O cálculo da entropia obtido pela equação 28 pode ser estendido para imagens digitais onde cada valor de pixel pode ser interpretado como uma fração da informação contida na imagem. Quando as probabilidade de ocorrência dos valores de pixel são calculadas através do histograma da imagem, nota-se facilmente que existem alguns valores que são frequentes e outros raros (baixa probabilidade de ocorrência). Assumindo a existência de uma distribuição de probabilidade associada à ocorrência dos valores de pixel, pode-se então estimar a probabilidade para que um dado valor apareça na imagem e a própria incerteza da estimativa. Desta forma, temse então dois cenários plausíveis a serem considerados: (a) caso existam diferentes probabilidades de ocorrência para os valores de pixel, a incerteza sobre a informação 
contida na imagem é elevada pois diferentes valores de pixel poderiam ocorrer na imagem, mesmo com probabilidade iguais e (b) caso existam valores de pixel com elevada probabilidade de ocorrência, a incerteza associada à estimativa do valor de pixel mais provável na imagem é reduzida, uma vez que a certeza sobre a informação transmitida é maior.

O conceito de entropia possui várias aplicações em imagens médicas devido à sua interpretação da incerteza sobre os dados avaliados. Dentre as aplicações mais conhecidas, a reconstrução tomográfica (Sompel \& Brady, 2012; Vunckx et al., 2012; Zhang \& Wang, 2001) e o registro de imagens médicas (Cahill, 2010; Heinrich et al., 2012; Khader \& Hamza, 2012) recebem destaque, sendo o registro de imagens médicas a aplicação utilizada nesta pesquisa.

O registro contempla a fusão de imagens de tal forma que regiões similares se sobreponham. Para a aplicação clínica, o registro pode ser empregado para a fusão de imagens médicas de mesma modalidade ou de modalidades diferentes, como por exemplo a fusão de imagens de tomografia computadorizada de raios-x (Computed Tomography - CT) e imagens de PET (Positron Emission Tomography); encontradas na prática clínica como images de PET/CT.

Dado duas imagens $A$ e $B$ utilizadas no registro com respectivamente $\mathrm{Na}$ e $\mathrm{Nb}$ pixels, o objetivo da fusão é alinhar as regiões comuns entre as imagens. Quando as imagens são sobrepostas e alinhadas por meio de transformações algébricas, os pixels em ambas as imagens são mapeados para se avaliar a incerteza sobre o alinhamento. Desta forma, a entropia das imagens sobrepostas é analisada de tal forma que a imagem formada pela fusão seja semelhante simultaneamente as imagens originais. Em decorrência da interpretação (b) mencionada anteriormente, o registro busca combinar as duas imagens de tal forma que a incerteza sobre os valores de pixel na imagem obtida seja a mínima possível com relação as imagens originais. Logo, da mesma forma que a entropia pode ser calculada para uma única imagem, a dispersão dos valores dos pixels entre duas imagens sobrepostas durante o registro pode ser avaliada através do histograma conjunto das probabilidades de 
ocorrência $q_{a, b}$, conhecido também como distribuição de probabilidade conjunta, obtido pelo cálculo da probabilidade de ocorrência com que um par de valores de pixels ocorre simultaneamente nas imagens $A$ e $B$. A Figura 39 exemplifica o cálculo $q_{a, b}$.

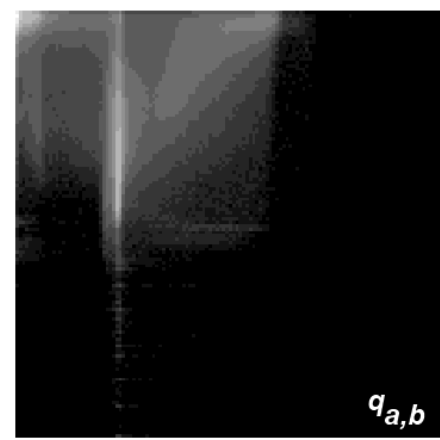

(a)

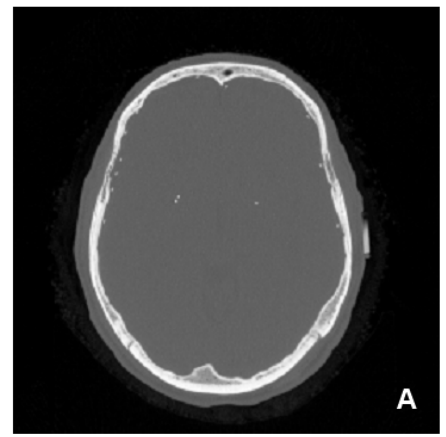

(b)

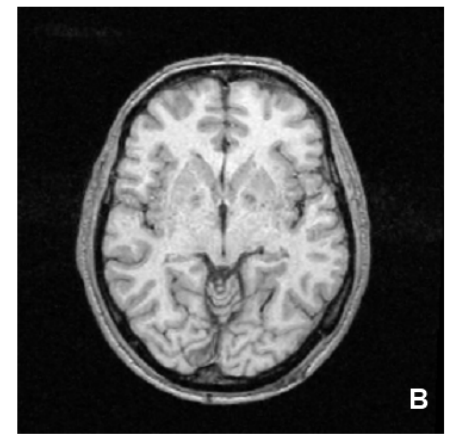

(c)

Figura 39 - Imagem do histograma conjunto $q_{a, b}$ (a) calculado a partir das imagens $A$ (b) e $B(\mathrm{c})$. O histograma conjunto é obtido a partir da frequência de ocorrência dos pares de valores de pixel entre as imagens, tal que $a \in A$ e $b \in B$ (Pluim et al., 2003).

Analogamente à equação 28 , a entropia conjunta $H(A, B)$ calculada para o registro de duas imagens é dada por:

$$
H(A, B)=-\sum_{a=1}^{N a} \sum_{b=1}^{N b} q_{a, b} \log q_{a, b},
$$

de acordo com o histograma conjunto que relaciona a dispersão dos valores de pixel na sobreposição das imagens para $a \in A$ e $b \in B$.

A partir da interpretação da incerteza sobre os valores de pixel no registro dado pela entropia conjunta $H(A, B)$, quando as imagens estão sobrepostas de tal maneira que as regiões semelhantes estão alinhadas, a incerteza sobre os valores de pixel na imagem obtida na fusão é mínima pois as probabilidade de ocorrência dos pixels é maximizada. Entretanto, a contribuição individual das imagens $A$ e $B$ na incerteza no registro não é considerado. Com o objetivo de superar tal limitação, o cálculo da Informação Mútua $I(A, B)$ contempla simultaneamente a avaliação individual da incerteza das imagens utilizadas no registro e a incerteza associada à 
sobreposição (Viola \& Wells, 1995). Dado as entropias $H(A)$ e $H(B)$ calculadas a partir da equação 28 e $H(A, B)$, a Informação Mútua $I(A, B)$ é calculada como segue:

$$
I(A, B)=H(A)+H(B)-H(A, B) .
$$

Como mencionado anteriormente, o objetivo do registro é realizar a fusão de imagens de tal maneira que a imagem obtida com a fusão seja simultaneamente semelhante às imagens originais, considerando as fronteiras e os próprios valores de pixel. Entretanto, de acordo com os resultados apresentados por Studholme et al. (1999), as regiões de fundo presente nas imagens utilizadas na fusão podem alterar o cálculo de $I(A, B)$ ocasionando falha de registro dependendo da orientação de sobreposição. Isto pode ocorrer devido a semelhança entre os valores de pixel, mesmo nas regiões de fundo. Logo, foi proposto um método de cálculo que é considerado invariante à mudança na orientação das regiões sobrepostas durante o registro, conhecido na literatura como Informação Mútua Normalizada $Y(A, B)$; calculado como segue de acordo com as definições anteriores.

$$
Y(A, B)=\frac{H(A)+H(B)}{H(A, B)} .
$$

Quando as imagens $A$ e $B$ estão devidamente sobrepostas, a variabilidade dos valores de pixel no registro é minimizado, maximizando assim o valor calculado para $Y(A, B)$. As entropias $H(A)$ e $H(B)$ são maximizadas apenas na região de sobreposição, enquanto que a incerteza associada à sobreposição é minimizada, caracterizada por $H(A, B)$. 


\section{PUBLICAÇÕES}

\subsection{Artigos publicados em periódicos}

1. VIANA, R. S. S. ; AGASTHYA, G. ; YORIYAZ, H. ; KAPADIA, A. 3D element imaging using NSECT for the detection of renal cancer: A simulation study in MCNP. Physics in Medicine and Biology, v. 58, p. 5867-5883, 2013.

2. VIANA, R. S. S. ; YORIYAZ, H. NSECT applied to the assessment of calcium deposition due to the presence of microcalcifications associated with breast cancer. Revista Brasileira de Física Médica, v. 4, p. 41-46, 2011.

\subsection{Resumos publicados em anais de congressos}

1. VIANA, R. S. S. ; LAKSHMANAN, M; AGASTHYA, G; YORIYAZ, H. ; KAPADIA, A. Detection of renal cell carcinoma using neutron time of flight spectroscopy. In: International Nuclear Atlantic Conference - INAC 2013 Recife, 2013.

2. VIANA, R. S. S. ; YORIYAZ, H. ; KAPADIA, A. 3D molecular imaging of elements through neutron stimulated emission computed tomography. In: SNMMI 2013 Annual Meeting, 2013, Vancouver. Journal of Nuclear Medicine, 2013. v. 54.

3. VIANA, R. S. S. ; SANTOS, A. ; YORIYAZ, H. Conditional probability distribution associated to the E-M image reconstruction algorithm for neutron 
stimulated emission tomography. In: International Conference on Mathematics and Computational Methods Applied to Nuclear Science and Engineering, 2011.

4. FONSECA, P. ; MATOS, R. ; FLAUZINO, E. ; VIANA, R. ; MIRANDA, J. Algoritmos de reconstrução iterativos em tomografia por BAC. In: VII Congresso de Física Aplicada à Medicina, 2011.

5. CINTRA, F. B. ; VIANA, R. S. S. ; YORIYAZ, H. ; SANTOS, A. Espectroscopia gama estimulada por nêutrons rápidos de uma fonte de Am-Be na estimativa da concentração de metais usando MCNP5. In: VI Congresso de Física Aplicada à Medicina, 2010.

6. VIANA, R. S. S. ; YORIYAZ, H. ; SANTOS, A. Simulação da detecção de intoxicação renal por mercúrio utilizando espectrometria gama estimulada por nêutrons rápidos. In: VI Congresso de Física Aplicada à Medicina, 2010, Botucatu. VI Congresso de Física Aplicada à Medicina, 2010.

7. VIANA, R. S. S. ; YORIYAZ, H. ; SANTOS, A. Simulação da espectrometria gama estimulada por nêutron rápidos aplicada na detecção da alteração da concentração de cálcio em tecidos mamários. In: VI Congresso de Física Aplicada à Medicina, 2010. 